University of Rhode Island

DigitalCommons@URI

Open Access Dissertations

2000

\title{
To Parcel or Not to Parcel: The Effects of Item Parceling in Confirmatory Factor Analysis
}

Brett A. Plummer

University of Rhode Island

Follow this and additional works at: https://digitalcommons.uri.edu/oa_diss

\section{Recommended Citation}

Plummer, Brett A., "To Parcel or Not to Parcel: The Effects of Item Parceling in Confirmatory Factor Analysis" (2000). Open Access Dissertations. Paper 917.

https://digitalcommons.uri.edu/oa_diss/917

This Dissertation is brought to you for free and open access by DigitalCommons@URI. It has been accepted for inclusion in Open Access Dissertations by an authorized administrator of DigitalCommons@URI. For more information, please contact digitalcommons-group@uri.edu. 
TO PARCEL OR NOT TO PARCEL:

THE EFFECTS OF ITEM PARCELING

IN CONFIRMATORY FACTOR ANALYSIS

BY

BRETT A. PLUMMER

A DISSERTATION SUBMITTED IN PARTIAL FULFILLMENT OF THE REQUIREMENTS FOR THE DEGREE OF DOCTOR OF PHILOSOPHY

IN

PSYCHOLOGY

THE UNIVERSITY OF RHODE ISLAND 


\section{Abstract}

When testing confirmatory factor analysis (CFA) models, the researcher may either utilize individual items as the manifest variables for the model, or use item parcels or composites, i.e., the sum or average of a set of individual items. Utilizing parcels instead of items may affect the chance of obtaining a proper solution, the fit of the model, and model parameter estimates. Unfortunately there is little previous research to guide the decision to choose between a parcel-level analysis and an item-level analysis. This investigation examined the current status of parceling in the literature and the impacts of parceling through three data simulation studies. In Study 1, three psychology journals were reviewed to determine the status of parceling in applied research. Parceling was utilized extensively, typically without justification or with a test of parcel unidimensionality. In Study 2, item-level solutions were compared with two-item parcel-level solutions across four general model structures, four levels of sample size, two levels of saturation and three levels of kurtosis. Percent of proper converging solutions was greater in item-level models, but only when the number of indicators per factor $(\mathrm{p} / \mathrm{f}$ ) was reduced to two in the parcel-level analyses. Mean item saturation and four measure of goodness of fit (GFI, CFI, NNFI and RMSEA) were improved in the parcel-level solutions. Study 3 extended the results found in Study 2 to four- and eight-item parcel models. Percent of proper converging solutions was decreased when $\mathrm{p} / \mathrm{f}$ was decreased to two. Mean indicator saturation and goodness of fit indices improved as the number of items per parcel increased. Study 4 examined eleven mis-specified parcel model 
structures, most of which included non-unidimensional parcels. In general, the mis-specified parcel models fit just as well or better than the correctly specified item-level models. This demonstrates both the advantages of and some very serious problems with using parcels. Utilizing parcels can result in violations of intra-parcel unidimensionality, hidden correlated errors, fit index bias and incorrect model confirmation. It is recommended that measurement models should be evaluated only at the item level and parcels should be employed only after extensive preliminary testing. 


\section{ACKNOWLEDGEMENT}

I would like to thank everyone that has helped me complete this project. First, I would like to thank my committee members, Drs. Wayne Velicer, Joseph Rossi, Colleen Redding, and Robert Dufresne for their support and advice. Margaret Ackley, Kathryn Meier, Sara Johnson, Greg Norman, Elaine Taylor, and Dr. Lisa Harlow have always been there to offer motivational support. My parents, Wayne and Irene Plummer, have always fully supported the difficult decisions that I've had to make in life and in graduate school. They are the two people who deserve the most recognition for all of my achievements thus far. 


\section{TABLE OF CONTENTS}

ABSTRACT

ACKNOWLEDGEMENT iv

TABLE OF CONTENTS $\quad$ V

LIST OF TABLES vii

LIST OF FIGURES $\quad$ ix

CHAPTER 1: Advantages, Disadvantages and Assumptions of Item Parceling

What is a Parcel? $\quad 2$

$\begin{array}{ll}\text { Advantages of Item Parceling } & 8\end{array}$

$\begin{array}{ll}\text { Assumptions of Item Parceling } & 14\end{array}$

$\begin{array}{ll}\text { Disadvantages of Item Parceling } & 17\end{array}$

$\begin{array}{ll}\text { Alternatives to Item Parceling } & 18\end{array}$

$\begin{array}{ll}\text { Simulation Studies and Item Parceling } & 19\end{array}$

$\begin{array}{ll}\text { Hypotheses } & 23\end{array}$

CHAPTER 2: A Review of the Utilization of Item Parceling In The Literature

$\begin{array}{ll}\text { (Study 1) } & 25\end{array}$

$\begin{array}{ll}\text { METHOD } & 26\end{array}$

$\begin{array}{ll}\text { RESULTS } & 27\end{array}$

$\begin{array}{ll}\text { DISCUSSION } & 30\end{array}$

CHAPTER 3: Evaluating the Effects of Item Parceling When the Parceling Assumption is Not Violated (Study 2) 32 
METHOD

RESULTS

DISCUSSION

CHAPTER 4: Evaluating the Effects of Different Forms of Parceling (Study 3)

METHOD

RESULTS

DISCUSSION

CHAPTER 5: Evaluating the Effects of Item Parceling When the Parceling

Assumption is Violated (Study 4) $\quad 68$

METHOD \& RESULTS $\quad 68$

$\begin{array}{ll}\text { OVERALL RESULTS } & 101\end{array}$

$\begin{array}{ll}\text { DISCUSSION } & 107\end{array}$

CHAPTER 6: Conclusions and Recommendations for Using Parcels 109

$\begin{array}{ll}\text { Study Limitations } & 112\end{array}$

$\begin{array}{ll}\text { Future Directions } & 112\end{array}$

$\begin{array}{ll}\text { BIBLIOGRAPHY } & 114\end{array}$ 


\section{LIST OF TABLES}

Table 1. Frequencies of Item-Level and Parcel-Level CFA Models in Three Journals

Table 2. Percent of Properly Converging Solutions Across Conditions - Study 2

Table 3. Mean Goodness of Fit Indices Across Conditions - Study 2

Table 4. Percent of Item and Parcel Solutions Meeting Standard Fit Criteria Across Conditions - Study 2

Table 5. Mean Indicator Saturation Across Conditions - Study 2

Table 6. Percent of Properly Converging Solutions Across Conditions - Study 3

Table 7. Mean Fit Indices for Model Structure \#1 - Study 3

Table 8. Mean Fit Indices for Model Structure \#2 - Study 3

Table 9. Mean Fit Indices for Model Structure \#3 - Study 3

Table 10. Mean Fit Indices for Model Structure \#4 - Study 3

Table 11. Percent of Item and Parcel Solutions Meeting Standard Fit Criteria Study 3

Table 12. Mean Item Saturations Across Conditions - Study 3

Table 13. Model \#1 Comparisons - Study 4

Table 14. Model \#2 Comparisons - Study 4

Table 15. Model \#3 Comparisons - Study 4

Table 16. Model \#4 Comparisons - Study 4

Table 17. Model \#5 Comparisons - Study 4

Table 18. Model \#6 Comparisons - Study 4 
Table 19. Model \#7 Comparisons - Study 4

Table 20. Model \#8 Comparisons - Study 4

Table 21. Model \#9 Comparisons - Study 4

Table 22. Model \#10 Comparisons - Study 4

Table 23. Model \#11 Comparisons - Study 4 


\section{LIST OF FIGURES}

Figure 1. Example of model reduction from 35 indicators to 15 indicators.

Figure 2. Item and parcel model comparisons for measurement model.

Figure 3. Item and parcel model comparisons for hierarchical measurement model.

Figure 4. Item \& parcel model comparisons for prediction model.

Figure 5. Example of EQS data simulation routine.

Figure 6. Percent of Proper Converging Solutions - Study 2

Figure 7. Visual representation of the true and mis-specified model \#1 of study \#4.

Figure 8. Visual representation of the true and mis-specified model $\# 2$ of study \#4.

Figure 9. Visual representation of the true and mis-specified model $\# 3$ of study \#4.

Figure 10. Visual representation of the true and mis-specified model $\# 4$ of study \#4.

Figure 11. Visual representation of the true and mis-specified model \#5 of study \#4.

Figure 12. Visual representation of the true and mis-specified model $\# 6$ of study \#4.

Figure 13. Visual representation of the true and mis-specified model \#7 of study \#4. 
Figure 14. Visual representation of the true and mis-specified model \#8 of study \#4.

Figure 15. Visual representation of the true and mis-specified model \#9 of study \#4.

Figure 16. Visual representation of the true and mis-specified model \#10 of study $\# 4$.

Figure 17. Visual representation of the true and mis-specified model \#11 of study \#4 


\section{CHAPTER 1}

\section{ADVANTAGES, DISADVANTAGES AND ASSUMPTIONS}

\section{OF ITEM PARCELING}

The use of a general construct or factor represents a core concept for behavioral science theories. The construct serves to organize a set of observed variables. Confirmatory factor analysis (CFA) provides a means of empirically evaluating the relation between a set of observed variables and the unobserved factor. When testing CFA models, the researcher may either utilize individual items as the manifest indicators of the model, or instead use parcels or composites, i.e., the sum or average of a set of observed variables. Utilizing parcels instead of items may affect the chance of obtaining a proper solution, fit indices, and model parameter estimates. Unfortunately there is little previous research to show the effects of choosing a parcel-level analysis instead of an item-level analysis.

Researchers generally utilize item parceling without knowing the assumptions and implications. To the naïve researcher, it may seem that models utilizing item parcels are preferable to item-level models. The common justification for parceling is the improvement in the likelihood of model convergence. But the convergence of the item-level model is rarely tested or is not reported in journals. Others may parcel simply because parceled models generally have better fit indices than item-level models. But on it's own, a better-fitting model is not a legitimate justification for parceling. Additionally, the assumptions for parceling are often not tested. In general, 
many researchers use parceling when it is not appropriate. This may be partly due to a lack of research showing when it is and is not appropriate.

It is not well understood what happens in model fitting as a result of parceling. Through data simulation, this investigation examines how much fit indices improve over item-level models. It will also investigate how parceling affects the chance of converging upon a proper solution across several model types. Alternatively, it is important to determine what happens when items are parceled incorrectly, or when the unidimensionality assumption is violated. This will be examined in eleven different measurement models.

\section{What is a parcel?}

The first explicit use of parcels was by Cattell (1956a, 1956b). Parcel utilization has been reported in many studies since, especially in the areas of personality (Marsh \& Gouvernet, 1989), ability (Widaman, Gibbs, \& Geary, 1987) and in measurement development (Velicer, Laforge, Levesque, \& Fava, 1994; Velicer, Huckel, \& Hansen, 1989). Parcels were used in the development of some of the most common psychological measures, such as the MMPI and the WAIS. Parcels are sometimes referred to as testlets, composites, sums or FHIDs (Comrey, 1988).

A parcel is simply the sum or mean of several items assessing the same construct. Multiple parcels are developed from the items constituting a scale, but no item should be assigned to more than one parcel. A first-order factor defined by these 
parcels of items as indicators may then be used to represent the latent construct of interest.

One example of the use of item parcels is in the Velicer et al. (1994) paper in which the structure of a 35-item Smoking Policy Inventory was tested for model fit. The 35 -item inventory consisted of 5 scales, each having 7 items. For each scale, the seven items were reduced to only three indicators. Reducing the number of indicators from seven to three involved summing two unique pairs of items and one triplet of items. As a result, the matrix to be analyzed in the confirmatory analysis was reduced from a $35 \times 35$ matrix to a $15 \times 15$ matrix. A graphical demonstration of this model reduction is displayed in Figure 1. Figures 2-4 display other parcel model reductions, including a hierarchical factor model (Figure 3) and a prediction model (Figure 4).

When parcels are created from items, the covariance matrix changes in both size and structure. The size of the matrix is smaller because of the reduction in the number of parameters. The structure is changed because the indicators, now parcels instead of items, have changed, resulting in different variance and covariance estimates. Because of the changing size and structure of the matrix, many model estimates will subsequently be different. Estimates that will differ include all fit indices, factor loadings, errors and uniquenesses. Utilizing item parcels rather than the items themselves generally results in higher factor loadings and better fit indices (Gribbons \& Hocevar, 1994). However, this may not be true under all conditions. 
Figure 1. Example of Model Reduction From 35 Indicators to 15 Indicators

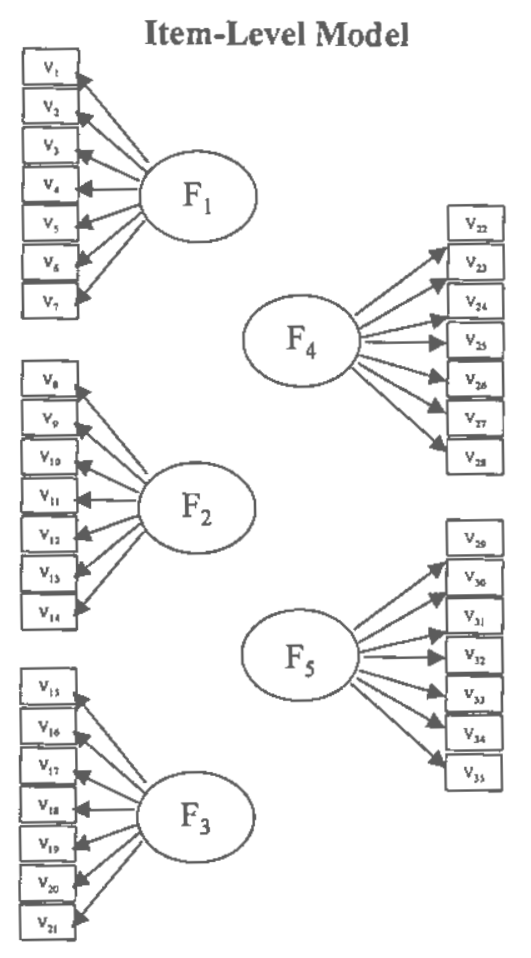

\author{
Parceled Model
}

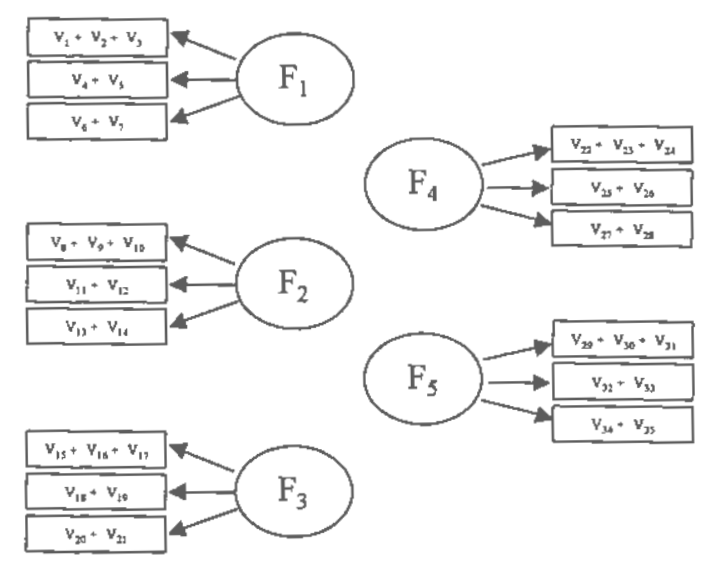


Figure 2. Item and Parcel Model Comparisons for Measurement Model

Item-Level Model

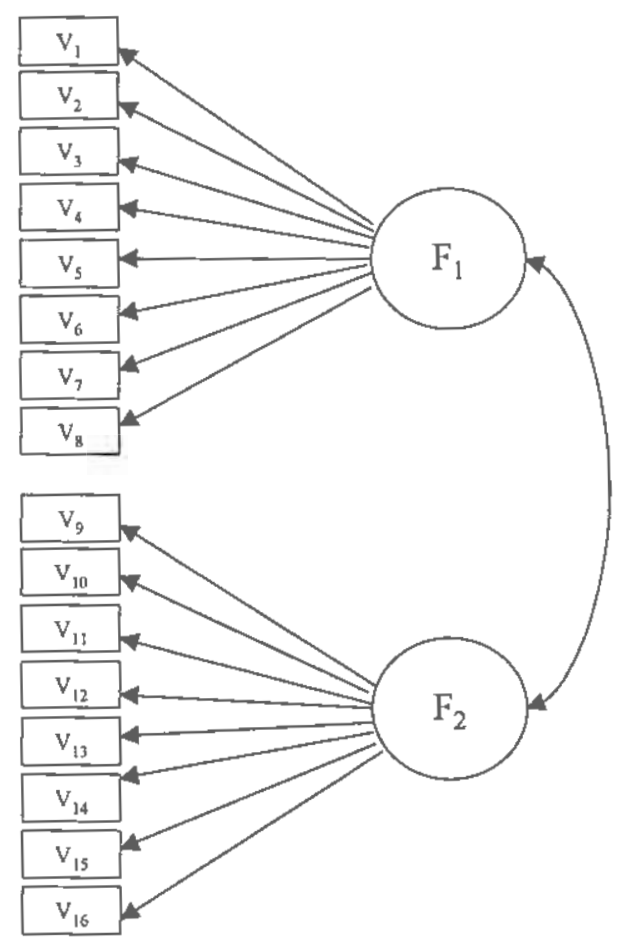

Parceled Model

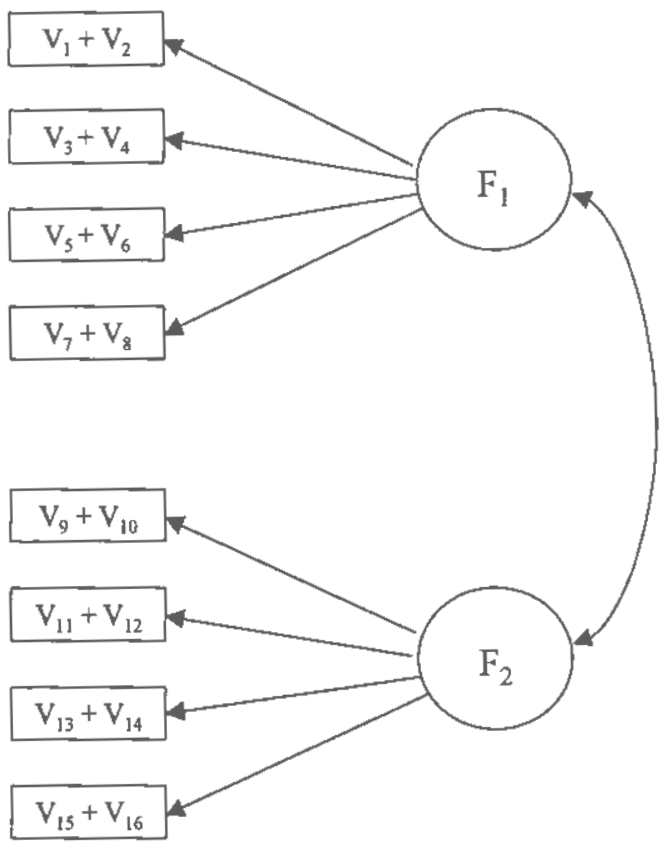


Figure 3. Item \& Parcel Model Comparisons for Hierarchical Measurement Model

Item-Level Model

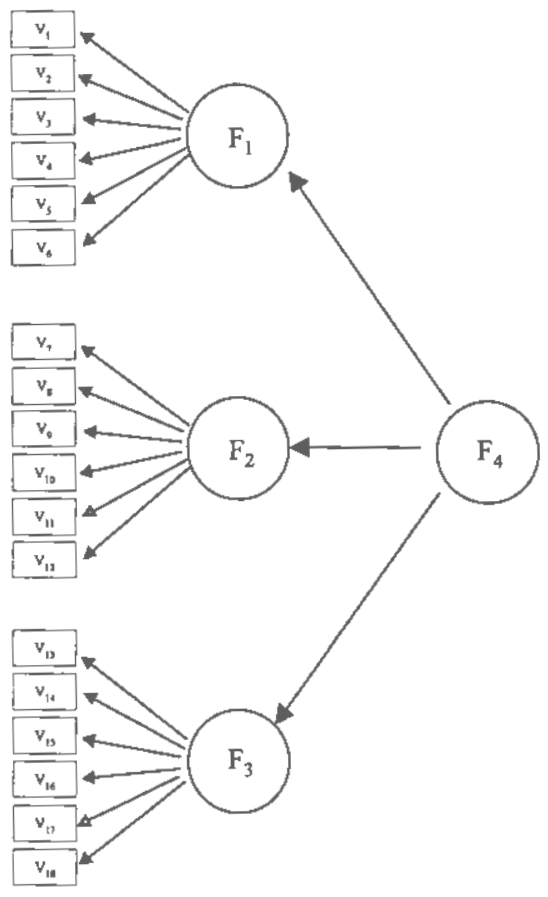

Rarceled-Level Madel

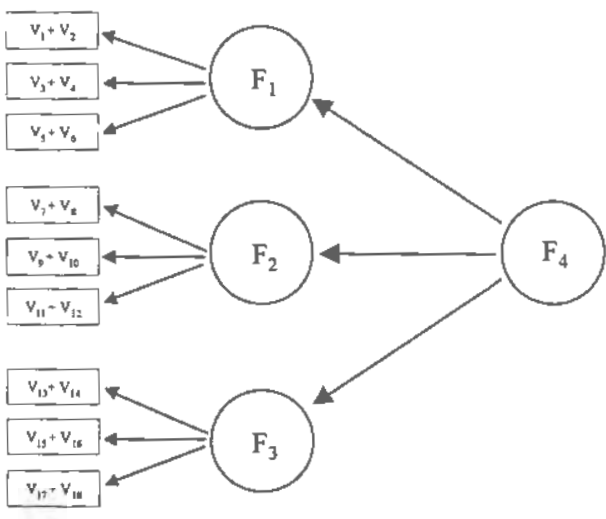


Figure 4. Item and Parcel Model Comparisons for Prediction Model
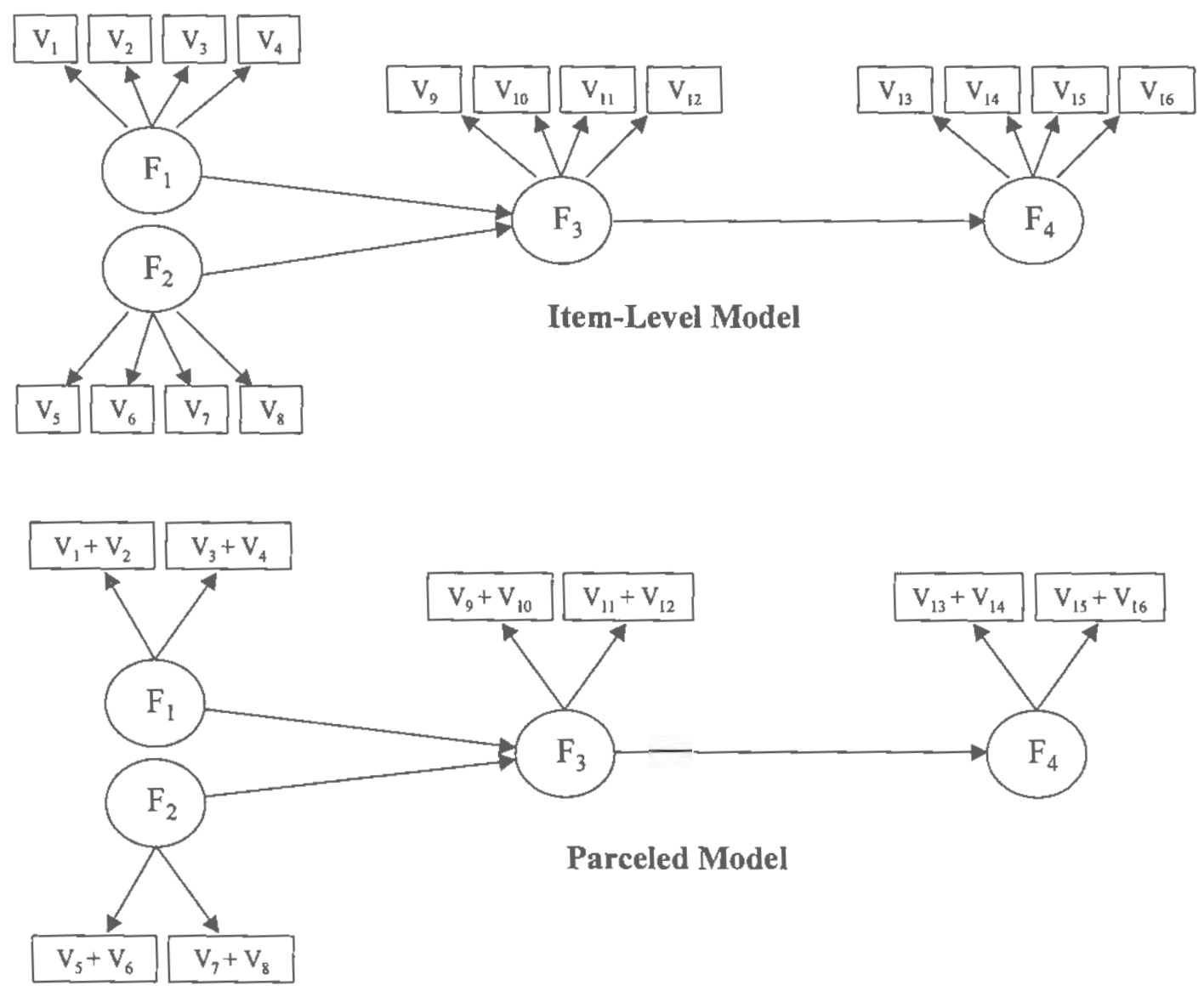


\section{Advantages of Item Parceling}

An overview of the advantages of item parceling will show the conditions in which parcels might be preferred over items. However, advantages of item parceling may not be the reasons that researchers use parcels. They are also not reasons that justify the use of parcels. It should be noted that using parcels may be advantageous in conditions discussed here, but this has not been demonstrated either mathematically or through simulation studies. Parceling may be used to (1) improve the normality of the indicators, (2) stabilize conditions of multicollinearity, (3) reduce the number of parameters to be estimated, (4) improve the internal consistency of the parameters, (5) improve the chances of proper convergence, (6) improve the fit indices, and (7) allow for better tests of model parameters.

Improve Normality. Screening for normality is an important early step that should be followed in almost every multivariate analysis. Although normality of the variables is not always required for analysis, maximum likelihood (ML) and generalized least squares (GLS) solutions should theoretically have more stable solutions and will have better chances of proper convergence if the variables are normally distributed. ML and GLS are estimation methods that assume both univariate and multivariate normality (Browne, 1974; Joreskog, 1969). When items are added together, the summed score will generally have better distributional properties than the items examined separately (West, Finch, \& Curran, 1995). This could be particularly advantageous if one wishes to use qualitative or dichotomous variables in a 
confirmatory modeling framework. Summing items that are qualitative can create a quantitative variable that is normally distributed.

In general, both skewness and kurtosis will be reduced, resulting in item distributions that are more normal. Skewness has to do with the symmetry of a distribution while kurtosis has to do with the peakedness of a distribution. A nonnormal distribution is either too peaked (with too few cases in the tails) or too flat (with too many cases in the tails). Kurtosis values above zero indicate a distribution that is too peaked (too many values close to the mean). Negative kurtosis values indicate a distribution that has too many values far from the mean. A variable can have significant skewness, kurtosis, or both. The distribution of parcels will be affected by the number of items aggregated (the more the better), the item distributions (the more normal the better) and their inter-correlations (the lower the better). If individual items are already normally distributed, there is some question as to whether parceling is needed. Gregorich (personal communication, 1997) has stated that when items already have good measures of normality, parceling will not significantly affect parameter estimates. However, this has yet to be shown either mathematically or through a simulation approach in any publication. Normality will be one of the key conditions in this study.

Stabilize Conditions of Multicollinearity. Although it has not been empirically tested, parceling may be an effective way of dealing with multicollinearity problems by combining highly correlated items. These problems occur within a correlation matrix when variables are too highly correlated. With multicollinearity, the variables are very 
highly correlated (.90 and above); with singularity, the variables are perfectly correlated and one of the variables is a combination of one or more of the other variables. With factor analysis models, it is desirable to have variables that are correlated, indicating that they are measuring the same construct. However, bivariate correlations above .90 can cause statistical problems. The problem is that singularity prohibits and multicolinearity renders unstable matrix inversion. Matrix inversion is the logical equivalent of division; calculations requiring division cannot be performed on singular matrices because they produce determinants equal to zero, i.e., the matrix equivalent of dividing by zero. It is also a problem when the determinant is not exactly zero, but is zero to several decimal places. Division by a near-zero determinant produces very large and unstable numbers in the inverted matrix. The sizes of the numbers in the inverted matrix can fluctuate wildly with only minor changes. The portions of a multivariate solution which flow from an inverted matrix that is unstable are also likely to be unstable. In PCA, multicollinearity is not a problem because there is no need to invert a matrix. For most forms of FA and for estimation of factor scores in any form of FA, singularity or extreme multicolliearity is a problem. The squared multiple correlation (SMC) is a measure of multicollinearity and singularity in a variable. If the SMC is high (near 1.0), the variable is highly related to others in the set, indicating multicollinearity. If the SMC is 1.0 , the variable is perfectly related to others in the set and there is singularity. Multicollinearity and singularity will not be addressed in this study. 
Reduce Number of Parameters. Another advantage of parcels is that fewer parameters will need to be estimated in a measurement model. There are two major implications of this. The first is that complex models may have a greater likelihood of converging if there are fewer parameters to estimate. This is tested in the current investigation. The second is that model estimates may be more stable in small samples.

Improve Internal Consistency. Another advantage of parceling is the perceived improvement in internal consistency, usually measured by Crobach's Alpha (1951). Individual items may have low-medium intercorrelations resulting in a low alpha. Averaging or summing items to form parcels will likely increase intercorrelations and the resulting reliabilities. This is a result of the parceled items having reduced standard errors relative to the individual items. Although the same items would be assessed in order to construct the scale, the Cronbach's Alpha computed with the parceled items might be better than the item-level Cronbach's Alpha. However, this may not be the case, especially when the number of indicators is few (less than 6). All other things being equal, adding additional items to a scale will increase Cronbach's Alpha.

Improve Chances of Proper Convergence. It is generally believed that utilizing parcels will decrease the chance of nonconvergence in a model. Although this belief is widely acknowledged, it has not been well tested. Only a single recent paper has reported that parceling did not improve proper convergence rates (Marsh et al., 1998), which is contrary to popular thought. This was a simulation study in which parceling was not a focus of the paper, and therefore only very limited conditions were examined. The only direct comparisons between item-level and parcel-level models involved 
exactly 12 variables. All item-level models converged to fuily proper solutions, while parceled models made up of 2 six-item parcels had lower rates of convergence. Models with 3 four-item parcels, 4 three-item parcels, and 6 two-item parcels all had 100.0\% rate of proper convergence when sample size was at least 100 . The authors' rationale for the lower rate of proper convergence in the six-item parcel models was that the number of indicators per factor was extremely small (only two). They call for this interesting finding to be examined across more diverse situations with different numbers of variables and factors. From their results, Marsh et al. conclude that reducing the number of estimated parameters, which is a direct result of parceling, will lead to higher rates of improper solutions.

Improvement of Fit Indices. Many researchers see the biggest advantage of parceling as the overall improvement in fit indices of most models. Fit indices are usualiy the most important result of a confirmatory analysis. Because of the increase in the N-to-parameter ratio (NTPR), it is generally believed that most parceled models will have better fit, although this has not been tested. However, the improvement in fit of the parceled model is then attributed to the improved distribution and reliability of the parceled items. It is more likely that the improvement in fit is a result of a bias of a fit index with model type and size.

It is important to note that an improvement in fit indices when using parcels would reflect a problem inherent with the existing fit indices. Fit indices generally rely most heavily on the chi-square value, and less heavily on the number of estimated parameters or model complexity. For this reason, less complex models will generally 
appear to fit the data better than more complex models, even when average loadings, correlations, and error terms are equal. In more technical terms, the goodness of fit of highly parameterized complex models tends to be greater than for simpler models because of the loss of degrees of freedom of the complex models (Akaike, 1987; James et al., 1982; Jöreskog \& Sorbom, 1981, 1984; Mulaik, 1990; Steiger \& Lind, 1980; Hu $\&$ Bentler, 1995). Demonstrating that using parcels improves fit indices would further illustrate the need for fit indices that take model complexity into account. From an alternative viewpoint, the problem does not lie in the calculation of the fit indices, but in our interpretation of them. A goodness-of-fit index of . 90 for a model with only 6 indicators does not mean the same as a goodness-of-fit of .90 for a model with 60 indicators. Yet no matter how complex a model is, researchers generally use .90 as a benchmark for a good-fitting model. From this viewpoint, better guidelines are needed to establish norms for what should be considered good-fitting and poor-fitting models. Recent work by Hu and Bentler (1998a) has moved toward this.

Allow for Better Test of Model Parameters. In some instances, the focus of model testing is not the overall fit but instead on particular parameter estimates. This is especially true with more advanced structural equation modeling techniques such as invariance tests or growth curve modeling. In growth curve modeling, for example, the parameters of primary interest are usually the change in level and slope estimates. When parameter estimates are the only focus, using the best available measures for each construct may be more appropriate. 
These advantages are typically used to defend parcels. However, satisfying these issues is neither necessary nor sufficient to justify parceling. These are advantages of parcels and are reasons parceling may be useful, but they do not provide empirical evidence that parcels are defensible.

\section{Assumptions of Item Parceling}

Employing parcels in any structural model should be preceded by a check of assumptions. These include: 1) indicators should follow univariate and multivariate normality, and 2) items used to form parcels should be unidimensional.

Univariate and Multivariate Normality. Whether indicators are single items or composites of items, they should be both univariate and multivariate normal. Minor to moderate violations of this assumption will not greatly sacrifice the solution.

Unidimensionality. Creating item parcels and using them as manifest variables in a measurement model is based upon the assumption that intra-factor parceled items are unidimensional, and that the inter-factor parceled items are orthogonal conditional on the factor model (i.e., no correlated uniquenesses). Unidimensionality refers to the existence of a single trait or construct underlying a set of measures (McDonald, 1981). It is a critical and basic assumption of measurement theory that a set of items forming a composite score measure just one thing. A mathematical definition of unidimensionality is given by McDonald (1981). The unidimensionality assumption has been coined the "parceling assumption".

Unidimensionality is slightly different than internal consistency, as measured by Cronbach's Alpha (1951). This can be seen by examining the equation for Coefficient 
Alpha. In the equation, internal consistency can be increased simply by increasing the number of items or by increasing the average off-diagonal correlation. However, increasing these two does not affect unidimensionality, as it does internal consistency.

In a single-factor factor analysis, if the item-level model does not fit the data well, then the assumption required for defending parceling is simultaneously not supported empirically. Testing such a model using parcels as indicators would be ignoring the empirical evidence that the required assumption is not defensible. It is probably true that some investigators never test item-level factor models because of limited success with them in the past.

Testing the unidimensionality of a parcel has been termed the "parcel construction model" by Gregorich (personal communication, 1997). The parcel construction model, according to Gregorich, is rarely questioned. It has been shown (Gregorich, S., personal communication, 1997) that an incorrect parcel construction model can result in a highly misspecified model that fits the (parceled) data well. Fit indices may be subsequently improved and the model may still be rendered a wellfitting model. In cases such as this, researchers often do not realize that their parcel construction was unjustified, and therefore, their model was flawed.

To test for unidimensionality, Gerbing and Anderson (1988) incorporate confirmatory factor analysis in their updated paradigm for scale development. Their important paper illustrates unidimensionality in terms of items forming constructs, but their ideas apply just as well to instances in which items form parcels. They believe that confirmatory factor analysis provides a stricter test of unidimensionality than 
testing through more traditional methods such as coefficient alpha, item-total correlations, and exploratory factor analysis. Their paper shows that different conclusions about unidimensionality can be drawn, depending on the method used. They also explain conceptually and mathematically why other techniques do not test unidimensionality. The backbone of their test is that different items intended to form a construct should have parallel relationships with other measures in the set of items.

Kishton and Widaman (1994) have offered two methods for determining whether items can be defensibly parceled for use in confirmatory analyses: 1) pass a minimum standard of reliability; and 2) provide indications of unidimensionality. Their first standard could be met simply by meeting a certain reliability level measured by Cronbach's Alpha. They suggest creating subscales of the items to be parceled, and assessing the reliabilities of each. Their second standard would require performing an "exploratory" factor analysis and examining the eigenvalues via the Scree test (Cattell, 1966) to determine the number of underlying factors present. If the eigenvalues suggest a single factor, the items can be considered unidimensional. Although their methods seem to have some merit, a brief search of the literature did not reveal a single study using their procedures.

One could test the item-level measurement model, and after finding acceptable fit, resort to parceling. But the advantage of this approach is not clear. The item-level analysis provides a stronger test of the hypothesis than the parcel-level analysis. Therefore, if an item-level model fits the data well, there may be no reason to use parcels. 


\section{Disadvantages of Item Parceling}

Above and beyond violating the assumptions of parceling, there are also disadvantages of using parcels as indicators rather than items. The cons of parceling include: 1) statistical power is sacrificed, 2) the possibility of hidden correlated errors, and 3) added work to ensure that basic assumptions are met.

Statistical Power is Sacrificed. Forming parcels will decrease the number of freely estimated parameters, or degrees of freedom (df), in a structural model. When df is reduced, the power to reject the hypothesized model is also reduced. Hence, there are cases when item parceling might result in statistical power being too low. However, checking power for a factor analysis or structural equation modeling is rarely done. Ironically, reduction in power may be desirable to some researchers who do not want to reject their measurement models. Using the same number of measured variables while reducing $\mathrm{df}$ creates a weaker test of model fit.

Hidden Correlated Errors. Using item parcels could also be dangerous because correlated error terms could become hidden when items are added together. Items that are combined to form parcels should fall on the same factor and will therefore be highly correlated. Correlated error terms suggests the presence of an additional unmeasured factor, therefore breaking the assumption of unidimensionality.

Added Work Involved When Parceling. When forming parcels, careful attention should be given to the method in which the items are averaged or summed. Those who argue against parceling often take issue with the arbitrary use of parcels. Published studies using testing CFA models often use different numbers of items per 
parcel even within each model, usually without justification. There is also the arbitrary nature of deciding which items are to be combined. Different item combinations may form parcels that produce indicators with different means, variances, and distributions. There are more empirically justifiable ways of determining which items should be combined than choosing items randomly that fall on the same factor. The formation of parcels may also be guided by theory, as outlined by Comrey $(1973,1988)$.

\section{Alternatives to Item Parceling}

Normalcy is critical for the chi-square test, which is the basis of the most commonly used fit indices. Because of this, having normal data is desirable for those who are doing model testing. In cases where variables are non-normal, many researchers choose to use parcels. If the justification for parceling is that the formation of parcels will make the indicators more normal, there are other alternatives that could be considered. Some of these include: 1) item transformations, 2) employing the Asymptotically Distribution Free Estimator (ADF), 3) employing the scaled $\chi^{2}$ statistic.

Item Transformations. Transformations of the original items will increase item normality in most cases. This is especially true with items that have extreme values of skewness or kurtosis. The most common transformations include the log or square root transformations. If items are measured on continuous scales, transformations should work very well. Transforming the data will not affect the number of parameters to be estimated in the model fitting phase, as the number of variables will not be changed, only their distributions. 
Asymptotically Distribution Free Estimator. Non-normality can also be handled during the analysis phase. One remedy for poorly distributed items is to use the Asymptotically Distribution Free Estimator (ADF) (Browne, 1984). The goal of this estimation technique is to yield unbiased estimates of the $\chi^{2}$ test, parameter, and standard error estimates. The ADF estimator is sometimes referred to as the arbitrary generalized least squares (AGLS) estimator. In contrast, $\mathrm{ML}$ and GLS estimators are normal theory-based and will provide biased estimates under conditions of nonnormality. However, because of the complexity of this method, large sample sizes ( $>$ 5000) are necessary to produce stable estimates (Curran, West, \& Finch, 1994). Hence, this method is usually not a practical alternative.

The Scaled $\chi^{2}$ Statistic. The scaled $\chi^{2}$ statistic (Satorra, 1989; Satorra \& Bentler, 1994) is another way to adjust for non-normality. The normal theory $\chi^{2}$ that is computed with ML or GLS can be divided by a constant $k$, which adjusts for nonnormality and gives a less biased approximation of the $\chi^{2}$ statistic. This same approach can be used to adjust standard errors that have been biased as a result of non-normality. Again, simulation studies have shown that large sample sizes are required for stable estimates (Finch, Curran, \& West, 1994). As with the ADF estimator, the large sample size requirement does not make this method a practical alternative in most cases.

\section{Simulation Studies and Item Parceling}

Kishton \& Widaman (1994) proclaimed that there were too few guidelines for using parcels. Marsh et al. (1998) called for more Monte Carlo studies of parceling. A review of the literature on simulation studies examining parcels turned up only the 
Marsh et al. (1998) paper. Certainly this is an area that needs attention. The problem is that, compared with simulations of factor analysis and PCA, there is great difficulty in performing simulation studies to test the effects of parceling.

The difficulty in conducting simulation studies of parceling has to do with the available SEM programs. The most commonly used SEM programs such as LISREL, EQS, and AMOS can simulate hundreds or thousands of data sets based on specified model parameters and data characteristics. However, if the goal is to compare itemlevel and parcel-level solutions, there is no straightforward method available within each program to carry out this task. First, the item-level data must be simulated. Then, this data must be combined to form parcels. Next, the SEM program can analyze each of these parcel-level data sets individually. The SEM programs currently available cannot fit multiple data structures with a single syntax file. In effect, each parcel model test must be given individual attention. This process is long and tedious, especially with multiple model structures and conditions. This would partially explain why there are no comprehensive studies examining the effects of parceling. Future versions of the SEM programs could make this process much simpler.

A few guidelines can help investigators who wish to compare parceled models. First, analyses should be conducted in the covariance metric. This is important because the expected variance of a parcel score, depending on the number of items in the parcel, is less than the variability of the item scores. This complicates comparisons between item and parcel solutions. It is possible to compare 2-item solutions with 2-parcel solutions, and 3-item solutions with 3-parcel solutions, etc. These types of 
comparisons are of limited value because they confound effects of the number of indicators (whether items or parcels), the number of items, and the saturation (loadings) of each indicator. It is more relevant to compare the results of item-level models with parcel-level models utilizing the same items. This simulates applied research, where there are a fixed number of items per factor and the decision has to be made to analyze either items or parcels (or combinations of each).

Marsh et al. (1998) Study. The results of the recent Marsh et al. (1998) study are very important to the present investigation. Item parceling was not the focus of the paper, but several of their findings are related to parceling and led to some of the questions being addressed in the present investigation. This work could be seen as an extension of the Marsh study, although the primary goals are different. The overall goal of this study is examining the effects of item parceling under a greater variety of conditions. Marsh et al. evaluated the proposal that "more is better" both in terms of number of sample size and number of indicators per factor. In testing this proposal, they also tested parceled models.

They found that, as with individual items, the greater the number of parcels, the greater the likelihood of a proper solution. Their study found this to be true particularly with 3- and 4-indicator solutions. However, their study was limited to only 12 item models. All 12-item solutions resulted in fully proper solutions under all conditions of N.

In addition, the study showed that when the number of parcels is small and $\mathrm{N}$ is small to moderate, parcel solutions are more likely than item solutions to result in 
improper solutions. Under the conditions of their study, the rate of improper solutions was considered a disadvantage of using parcels. However, their study conditions were limited to very simple models with very few indicators. With 12 items, there were at most 6 indicators with the parceled solutions. Marsh et al. suggest that with more complex models, better relationships between item and parcel solutions would be more evident.

Additionally, Marsh et al. found that the saturations of the parceled solutions were higher than the item-level solutions. This was not a surprising finding. The authors report that comparing item and parcel solutions' mean factor loadings and standard deviation of factor loadings was complicated by the change in metric. The consistent finding across levels of item and parcel solutions was that greater $\mathrm{p} / \mathrm{f}$ led to smaller standard deviations (suggesting greater measurement precision).

The goodness of fit, measured with Chi-Square/df, of the parcel solutions were poorer as the number of parcels increased. This reflected a systematic bias in the ChiSquare statistic. Other goodness of fit indices such as RMSEA might have been more appropriate.

The present investigation will attempt to replicate some of the findings of the Marsh et al. study. But because of the limited conditions with which item parceling was tested in the Marsh study, the present investigation should be viewed as an extension of that study.

The overall investigation of item parceling was divided into 4 separate studies. Study 1 reviews the use of item parceling in the literature. In Study 2 , the effects of 
item parceling on fit indices, item saturations, and percent of properly converging solutions was tested across a wide range of conditions within four general model structures. For Study 3 , the effect of forming parceis from two, four, and eight indicators each is tested across two model structures and four sample sizes. Study 4 examines eleven different mis-specified model structures, most containing nonunidimensional parcels.

\section{Hypotheses}

Ten hypotheses were tested in this investigation. Studies 1-4 will provide the information relevant to these hypotheses. The hypotheses are:

1) Within recent published articles in three psychology journals in which item parceling was used, the majority of studies did not state their justification for parceling or whether the necessary assumptions were taken into consideration. (Addressed in Study 1)

2) Under less than ideal conditions (low sample size and/or non-normality and/or low saturation), parceling will improve rates of proper convergence, compared to the item-level analyses. (Study 2)

3) Parcel-level solutions will have better goodness-of-fit indices than item-level solutions. (Study 2)

4) Parcel-level solutions will have greater mean loadings than item-level solutions. (Study 2) 
5) Models in which the number of items per parcel is greater will have a higher rate of convergence to proper solutions compared to parceled models with a lower number of items per parcel. (Study 3)

6) Models in which the number of items per parcel is greater will have higher mean fit indices compared to parceled models with a lower number of items per parcel. (Study 3)

7) Models in which the number of items per parcel is greater will have higher mean loadings compared to parceled models with a lower number of items per parcel.

8) When the parceling assumption is violated, the rate of convergence to proper solutions will not differ between the correctly specified item-level models and the misspecified parceled models. (Study 4)

9) When the parceling assumption is violated, goodness of fit will not significantly differ between item-level solutions and mis-specified parcel-level solutions. (Study 4)

10) When the parceling assumption is violated, mean item loadings will not be significantly different between item-level solutions and parcel-level solutions. (Study 4) 


\section{CHAPTER 2}

\section{A Review of The Utilization of Item Parceling In The Literature (Study 1)}

There were three purposes of Study 1: 1) to determine how often item parcels were utilized in published articles which utilize confirmatory factor analysis, 2) to find what the most common justifications were for parceling, and 3) to determine how often the parceling assumption was given attention. Answering these questions would be an important step toward developing guidelines for when parceling may or may not be appropriate.

The issues surrounding parceling have been given attention in scattered areas of book chapters, rare journal articles, and occasionally some attention on the structural equation modeling network e-mail list (SEMNET). The attention given to parceling may be inadequate if the number of published articles using parcels instead of items is great. If in many applications the use of parcels is questionnable, the topic may be deserving of more attention than it has received. This would be even more true if parcels are being used under questionnable circumstances in highly respected journals. This finding would also bring into question the extent of knowledge about parcels within the general research community.

Why researchers choose to parcel is an important question that would indicate where parceling is being used without proper justification. Examining published research may not reveal the reasons why researchers use parcels. It is likely that at least some researchers use parcels for no other reason that to obtain better fit indices. However, it is improbable that this would be reported within a published journal article. 
Another justification that researchers may offer for parceling is to reduce the number of indicators in the fitted model. Presumably, this would help convergence and improve the stability of estimates, although recent research has not shown this to be true (Marsh et al., 1998).

The parceling assumption of unidimensionality is an issue that many applied researchers may not be familiar with. It is expected that in many cases the use of item parcels will not be precluded with a test of intra-parcel item unidimensionality. This would be an alarming finding, especially if the intra-parcel items do not have a history of scale development establishing their unidimensionality. However, a test of unidimensionality may not necessarily be reported depending on the quality and type of journal and previous measurement work with the items being examined.

\section{METHOD}

This study involved a non-traditional form of data collection. Data was gathered from three prominent psychology journals. Articles from the Journal of Consulting and Clinical Psychology (JCCP), the Journal of Personality and Social Psychology (JPSP), and Psychological Assessment (PA) during a four year period (1996-1999) were examined.

These journals were chosen for multiple reasons. Each of these journals regularly publishes articles utilizing sophisticated data analyses such as SEM, across a wide range of applied areas. JCCP and JPSP are generally considered high-quality journals with stringent standards for acceptance and a relatively large number of 
readers. Both journals were expected to contain a moderate number of articles that utilize confirmatory factor analysis. The third journal, PA, may not be as highly regarded but it was chosen because it is likely to contain a greater number of articles using CFA.

Commentaries, "Brief Report", and "Special Section" articles were not examined. Articles that used confirmatory factor analysis were flagged for further review. These articles were classified by whether the analyses utilized individual items or parcels as indicators in the model. If a model had a mix of items and parcels as indicators, it was classified as a parceled model. Of those articles that used parceling, the stated justification for parceling, if any, was recorded. Each article utilizing parcels was reviewed for any statement that suggested attention was given to the parceling assumption.

\section{RESULTS}

Within the Journal of Consulting and Clinical Psychology, 318 articles were reviewed. Of these, 23 (6.6\%) used CFA models. Within these 23 articles, $8(34.8 \%)$ used item-level CFA models and $17(73.9 \%)$ tested CFA models that included parcels. There were two articles that tested both types of models, although the item- and parcellevel models tested within these articles were not related to each other. None of the 17 articles that used parceling declared that the same-parcel items were tested for unidimensionality. In fairness to some authors, parcels were formed on the basis of unidimensionality established in previous studies. The number of items per parcel 
varied dramatically, from only 2 items per parcel up to 85 items per parcel. Within 4 of the 17 articles that used parcels, the authors stated that parcels were formed in order to reduce the number of indicators in the tested models. No other justification was given for the utilization of parcels instead of items. The frequencies of articles which included item- or parcel-level analyses can be found in Table 1.

The review of articles in the Journal of Personality and Social Psychology was very similar. In total, 317 articles were reviewed, of which 29 (9.1\%) examined CFA models. Of those, $10(34.5 \%)$ articles using item-level models and $19(65.5 \%)$ using parcels. One article tested unrelated item- and parcel-level models. None of the articles described any test of unidimensionality for the parcels that were formed. The number of items per parcel within these articles varied from 2 up to 68 items. Within 3 (15.8\%) of the 19 articles that used parcels, the authors stated that parcels were formed in order to reduce the number of indicators in the models. No other justification was given for the utilization of parcels instead of items.

The articles reviewed in Psychological Assessment were dissimilar to the articles in the other two journals. The total number of articles reviewed was 160 , of which $48(30.0 \%)$ examined CFA models. Of these, 34 (70.8\%) examined item-level CFA models and 14 (29.2\%) examined parcel-level CFA models, and 4 (11.8\%) examined both types. One article tested the same data using both item- and parcel-level analyses. All fit indices except RMSEA were greater in the parcel-level solution. The unidimensionality assumption was not tested in any article, although some authors explained previous work with scale development of the items that were being 
Table 1. Frequencies of Item-Level and Parcel-Level CFA Models in Three Journals

Journal of Consulting and Clinical Psychology

$$
\text { Articles Articles }
$$

Articles with Item- with Parcel-

\begin{tabular}{cccc} 
& & Level CFA & Level CFA \\
\hline 1999 & 77 & 1 & 3 \\
1998 & 79 & 3 & 4 \\
1997 & 88 & 3 & 4 \\
1996 & 74 & 1 & 6 \\
\hline Total & 318 & 8 & 17
\end{tabular}

Journal of Personality \& Social Psychology

\begin{tabular}{llll}
\hline 1999 & 82 & 3 & 5 \\
1998 & 74 & 3 & 4 \\
1997 & 81 & 2 & 4 \\
1996 & 80 & 2 & 6 \\
\hline Total & 317 & 10 & 19
\end{tabular}

Psychological Assessment

\begin{tabular}{cccc}
\hline 1999 & 40 & 7 & 4 \\
1998 & 46 & 10 & 3 \\
1997 & 35 & 9 & 4 \\
1996 & 39 & 8 & 3 \\
\hline Total & 160 & 34 & 14
\end{tabular}


combined. In only $2(14.3 \%)$ of the 14 articles that used parcels did the authors state that parcels were used in order to reduce the number of indicators. No other justification was given for the utilization of parcels instead of items.

\section{DISCUSSION}

In reviewing these three journals, 50 articles utilized parcels in at least one CFA model. This demonstrates that the utilization of parcels is fairly common and accepted in high-profile journals. The overall frequency of articles using parcels implies that journal editors and reviewers are probably not biased against publishing these articles. The high frequency of utilization of parcels also shows that this method is deserving of attention in the form of theoretical, simulation, and mathematical studies.

Most articles reviewed here did not report testing for unidimensionality, a critical assumption when forming parcels. It can only be speculated whether or not the authors tested unidimensionality at any point in time and chose to not report this in the articles. This is an important point that should not be ignored in articles with CFA model fitting. Because of its' importance, editors and reviewers should make this a necessary condition if parcels are used in confirmatory analyses.

In only a few articles did the authors state that parcels were used in order to reduce the number of items. Again, we can only speculate as to why the authors felt this was necessary. They might have believed that this would increase the chances of obtaining a proper solution. They might have thought that their chances of obtaining highly desirable fit indices would increase, knowing the systematic bias of fit indices 
reported in other studies. It is interesting that in the one article that tested CFA models first with items as indicators and then with parcels as indicators, the fit indices were greater in the parceled models, except for RMSEA. Whether this result would be duplicated across many types of model structures and conditions is one of the important questions addressed in Study 2. 


\section{CHAPTER 3}

\section{Evaluating the Effects of Item Parceling}

\section{When The Parceling Assumption Is Not Violated (Study 2)}

Marsh et al. (1998) examined one item-level model structure and compared the results to four types of parcel-level analyses. With the exception of this very limited examination, no other published simulation study has examined the effects of parceling across a broad range of model structures. An extensive simulation study would be an important addition to the literature and would help many researchers understand how solutions may or may not differ when parcels are used instead of items.

The purpose of Study 2 was to examine the consequences of item parceling when the parceling assumption is not being violated. The examination of parcel-level analyses when the parceling assumption does not hold is left for investigation in Study 4. Study 2 will only be concerned with 2-item parcels, with other types of parcels left for investigation in Study 3. In order to generalize the results, four general model structures will be examined across differential levels of sample size, item saturation and kurtosis.

With the lack of published articles, researchers are probably unaware of the effects of parceling. Using parcel-level instead of item-level analyses may affect fit indices, loadings, and the chances of obtaining a proper solution. The differences in these dependent variables between the item- and parcel-level solutions may be differential across specific conditions of the model structures, such as the magnitude of 
specified item loadings. Sample size and normality are other variables that may affect these outcomes. Examining the behavior of item and parcel solutions across different levels of these variables may show where parceling may be advantageous, disadvantageous, or possibly even dangerous.

\section{METHOD}

All models examined in Study 2 fall into a general class of models referred to as measurement models. All measurement models are a specific sub-class of the general structural equation model. No prediction is tested in the measurement models. In practice, the researcher has previous indications, usually from exploratory factor analysis procedures, that common variables measure known constructs. This is tested by only allowing the correlations between measured variables and the corresponding latent construct to be freely estimated, while all other variable-construct correlations are fixed at zero. The latent constructs can be estimated or fixed at zero, depending on the theory guiding the investigation.

The number of measurement models that could be simulated are endless. The models chosen for Study 2 were chosen so that the data could be analyzed in such a way that the hypotheses could be tested within the limitations of the EQS program. The models chosen also are good representations of models commonly found in applied studies.

Independent Variables 
In Study 2, three parameters will be varied across the different model structures: sample size, item saturation, and kurtosis. Along with the method of analysis (item vs. parcel), these can be viewed as the independent variables of Study 2 . The items per factor $(\mathrm{p} / \mathrm{f})$ ratio could also be considered an independent variable, although it is a result of the different model structures being examined. These variables and justifications for choosing their different levels are discussed below.

Independent Variable: Sample Size. Four conditions of sample size were tested in Study 2: 75, 150,300, and 600. A sample size of 100 is generally considered to be the smallest recommended sample size. However, for this study it was desirable to test the effects on the outcome variables for the lower limits of sample size. An N of 75 is often considered too low, but will still allow enough free parameters so that the model is identified. An N of 150 may still be problematic for larger models. 300 is usually considered sufficient for confirmatory modeling. For most simulation studies, asymptotic behavior of parameter estimates occurs when $\mathrm{N}$ is near 600 .

Boomsma (1982) found that almost all properties of solutions were improved with larger sample size. Boomsma recommended that $\mathrm{N}$ should be at least 100 , but N's of 200 or more would be desirable under some circumstances. This has been found in other simulation studies, many of which are summarized by Gerbing and Anderson (1993) in their article on Monte Carlo evaluations of goodness of fit.

Independent Variable: Normality. As outlined earlier, normality can affect parameter estimates, goodness-of-fit, and chances of proper convergence. The parceled solutions should improve the univariate normality of the variables, and consequently 
improve the stability of estimates, fit, and convergence. The skewness and kurtosis restrictions will be placed on the raw simulated data only. When this data is parceled, the skewness and kurtosis values will systematically improve in most cases.

Three levels of normality were tested in Study 2. In the first condition, each variable was specified to be univariate and multivariate normal, with both skewness and kurtosis approaching zero. In the second condition, kurtosis will equal approximately 10.0. This value approximates an extremely leptokurtic variable; i.e., one with an extreme peakedness. In the third condition, kurtosis will equal approximately -1.139. This value approximates a perfectly platykurtic variable; i.e., one with a completely 'flat' distribution. It would be of great benefit to have conditions under which skewness was extremely high or low. However, the current version of EQS does not allow for the specification of skewness greater than 1.0 or less than -1.0 . Skewness values of this magnitude are common and generally would not be considered as breaking normality. Therefore, specifying these values as conditions for skewness was not deemed useful.

Independent Variable: Specified Item Saturation. Two different levels of item saturation (factor loadings) were tested in Study $2, .40$ and .70 . Generally items with loadings below .40 are not considered good measures of a construct. Indicators with loadings of .70 are usually considered good. Guadagnoli \& Velicer (1988) showed that item saturation was an important factor that affected the ability to produce a stable solution. In fact, item saturation was more indicative of stability than sample size, 
which is contrary to popular belief. This finding has been consistently replicated (Velicer \& Fava, 1998; Marsh et al., 1998).

$\mathrm{p} / \mathrm{f}$ Ratio. Although $\mathrm{p} / \mathrm{f}$ ratio is a result of the model structures chosen, the effects of $\mathrm{p} / \mathrm{f}$ ratio are significant enough to warrant individual attention. For the models tested, the $\mathrm{p} / \mathrm{f}$ ratios when using the raw data were 4 and 16 . For the parceled data the $\mathrm{p} / \mathrm{f}$ ratios were halved to 2 and 8 . These were chosen because they represent two extremes of what is commonly found in confirmatory modeling. Two indicators is the fewest number of indicators for a latent factor, and most studies do not have more than 16 items per latent factor.

Boomsma (1982) found that solutions were better behaved for $\mathrm{p} / \mathrm{f}=4$ than for $\mathrm{p} / \mathrm{f}=2$ when saturations were large. In a Monte Carlo study of principal components analysis, Guadagnoli and Velicer (1988) found that estimates were more stable when $\mathrm{p} / \mathrm{f}$ was large. The same result was found by Velicer and Fava $(1987,1994)$. Their studies showed that increasing the $\mathrm{p} / \mathrm{f}$ ratio improved convergence rates and goodness of fit indices in principal components analysis, image component analysis, and maximum likelihood factor analysis. Others (Anderson and Gerbing, 1984; Boomsma, 1985; Ding, Velicer, and Harlow, 1995) also report that the likelihood of fully proper solutions increases with an increasing p/f ratio. Multiple studies (Ding et al., 1995; Boomsma, 1982) have shown that when $\mathrm{p} / \mathrm{f}$ ratios were larger, goodness of fit statistics that utilize the Chi-Square statistic are increasingly biased. 
Factor Correlations. Factor correlations are usually of interest in models such as these. Therefore, in Study 2 all factor correlations in the true models were specified at .30 , a moderate and likely factor correlation in a measurement model.

\section{Dependent Variables}

Several outcomes were measured for each simulation, which were summarized across replications and compared across conditions. Item saturations and goodness of fit indices were summarized with means and standard deviations across the conditions of Study 2. The percent of properly converging solutions was also measured.

Outcome Measure: Item Saturations. For the analysis of the generated raw data, the mean loading should be approximately equal to the loading size specified in the data simulation, either .40 or .70 . However, with the parceled data, the loadings may be systematically increased or decreased. With 100 replications within each condition, the indicator saturations for the two types of analyses (item vs. parcel) can be tested for significant mean differences using paired-sample t-tests.

\section{Outcome Measure: \% of Properly Converging Models. The rate of} convergence to proper solutions was compared for each condition. Nonconvergence is likely to be the result of the data or the specified model rather than the number of iterations or the starting values (Jöreskog \& Sorbom, 1988; Velicer \& Jackson, 1990). Even when there is convergence, the solution may not be proper. Improper solutions have standardized loadings and error terms that have an absolute values greater than 1.0. In this investigation, solutions were evaluated in one of two ways: 1) proper converging; 2) improper converging or nonconverging. The percent of proper 
converging solutions for item and parcel analyses can be compared for significant differences using a chi-square test.

Outcome Measure: Goodness of Fit Indices. As mentioned previously, the most commonly used fit indices are based on the chi-square value and are therefore biased toward models with smaller numbers of estimated parameters. It would still be an important observation if the parceled solutions had significantly better fit indices than the item-level solutions of the same data. For each study condition, the mean and standard deviation will be recorded for four of the most commonly used fit indices: GFI, CFI, NNFI and RMSEA. An excellent review of these fit indices are provided by Hu \& Bentler (1998a, 1998b). Paired-sample t-tests will be the test for significant mean differences between item and parcel-level solutions.

\section{Outcome Measure: \% of Models Meeting Standard Fit Criteria. Most} researchers believe that the common fit indices are considered acceptable at .90 or greater, or less than .05 for RMSEA. Meeting these criteria leads many researchers to conclude that their model is a good representation of the data. In Study 2, the percent of models meeting standard criteria for GFI, CFI, NNFI (.90), and RMSEA (.05) were examined by the method of analysis.

Procedure.

Four different measurement models were tested. The first model included two latent factors measured by 4 items per factor. The second model included four factors measured by 4 items per factor. The third model had two factors measured by 16 items per factor while the forth model had four factors measured by 16 items each. 
For each model, the same data was evaluated in two ways: 1) using the raw simulated data as indicators, and 2) the parceled data as indicators. In Study 2, all parcel models consisted of only 2 -item parcels. The conditions within each model were systematically varied, so reliable conclusions could be drawn while keeping the number of simulations minimized. The conditions that were varied in each model were sample size ( 4 conditions), kurtosis ( 3 conditions), and item saturation ( 2 conditions). The interactions of the varied conditions created 96 different models. For each model, there were 100 simulations.

Model Specifications. EQS (Bentler, 1995) was used both to simulate the data and to evaluate the models. EQS has built-in procedures in data simulation routines for creating non-normal data and was therefore chosen instead of LISREL (Jöreskog \& Sorbom, 1996). With LISREL, in order to generate data with a specified covariance structure with specified skewness and kurtosis, a combination of the matrix decomposition procedure (Vale \& Maurelli, 1983) and Fleishman's (1978) method is needed. An example of the EQS code required to simulate data for a 2-factor, 16-item measurement model is presented in Figure 5.

All models were estimated with the maximum likelihood estimation technique. Maximum likelihood is the most commonly employed estimation technique when evaluating structural models and has shown to be fairly robust with non-normal indicators. All factor variances were fixed at unity. Factor loadings, uniquenesses, and factor correlations were freely estimated. The maximum number of iterations for each model was set at 500 . The default starting values of EQS were used. The admissibility 
Figure 5. Example of EQS Data Simulation Routine.

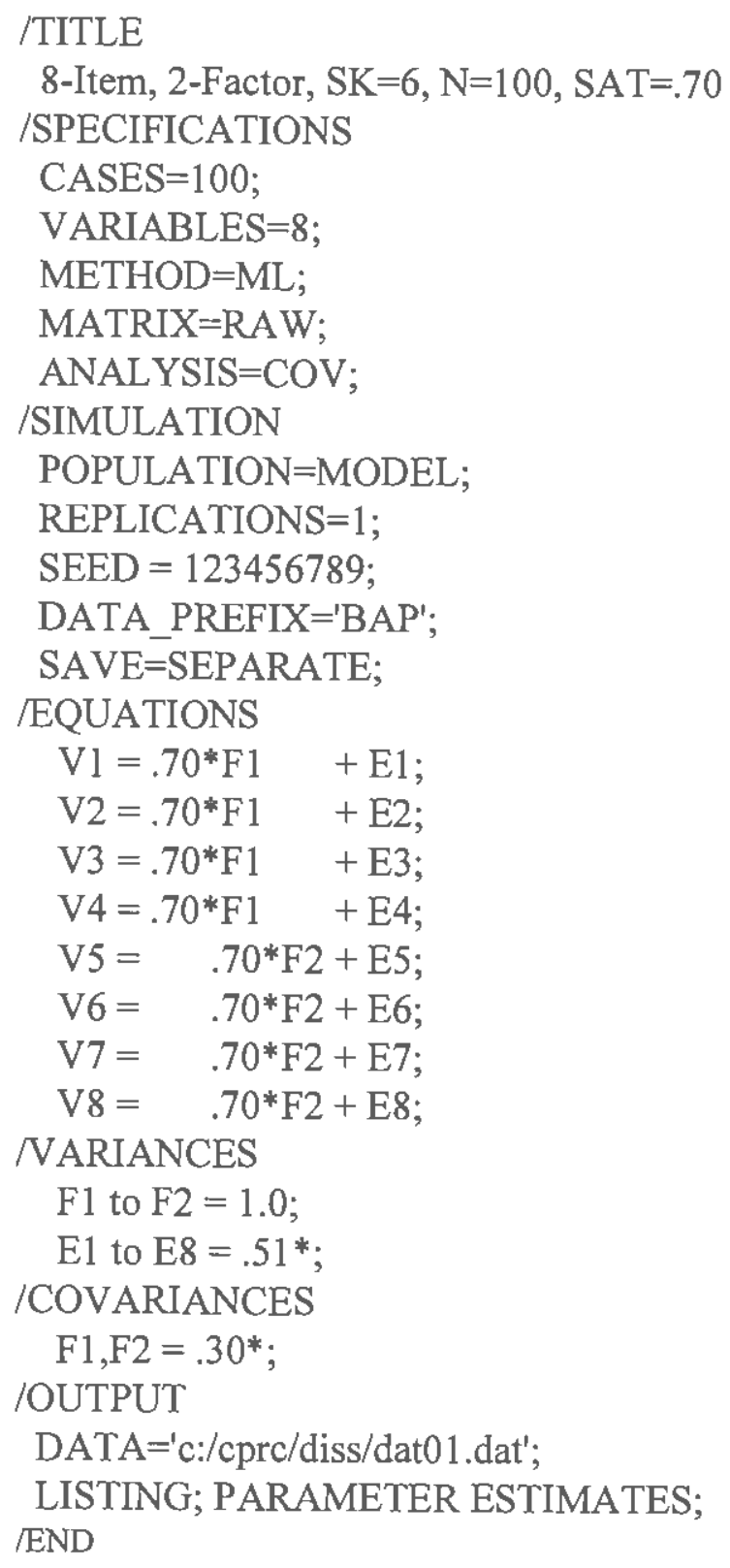


check was turned off. All item-level models tested were considered to be "true" models. This means that the same model that was used to generate the data was also used to estimate the fit of the generated data. For each parceled model, the parcel indicators were computed using the same data that was generated with the corresponding item-level model, using SPSS. The alternative approach was to simulate separate data to be tested in each condition. However, the approach used here allows a more direct comparison of the methods.

\section{RESULTS}

The results of Study 2 are divided into three sections which cover the hypotheses of the investigation. It was hypothesized that when parceling, the rates of proper converging models, goodness of fit indices, and item saturations would significantly increase. For each of these measures, the main effect of four independent variables (saturation, items per factor, sample size, kurtosis) are examined.

Convergence. One of the hypotheses for Study 2 was that parceling would improve rates of proper convergence under conditions of small $\mathrm{p} / \mathrm{f}$ ratio, low sample size, non-normality and/or low saturation.

This hypothesis was clearly not supported. In fact, the opposite was true, at least for conditions where the $\mathrm{p} / \mathrm{f}$ ratio in the item-level models was 4 ( 2 in the parcellevel models). When saturation $(s)=.40$, and the $p / f$ ratio was $8 / 2$ and $16 / 4$, the percent of models converging to proper solutions was significantly less in the parcel level 
analyses $(61.8 \%, 58.0 \%)$ compared to the item-level analyses $(88.7 \%, 77.3 \%)$. When $\mathrm{s}$ $=.70$ and the $\mathrm{p} / \mathrm{f}$ ratio was $8 / 2$ and $16 / 4$, the percent of models converging to proper solutions was also significantly less in the parcel-level analyses $(72.0 \%, 72.8 \%)$ than the item-level analyses $(100 \%, 100 \%)$. When the $\mathrm{p} / \mathrm{f}$ ratio was $16 / 2$ and $64 / 4$, all itemlevel and parcel-level models converged to proper solutions. Since the reduction in rates of proper convergence was only observed in the $\mathrm{p} / \mathrm{f}=8 / 2$ and $\mathrm{p} / \mathrm{f}=16 / 4$ model structures, it is reasonable to conclude that parceling will only hinder the chance of proper convergence when the $\mathrm{p} / \mathrm{f}$ ratio is very low. In the $\mathrm{p} / \mathrm{f}=8 / 2$ and $\mathrm{p} / \mathrm{f}=16 / 4$ models, parceling reduces the ratio to only 2 items per factor. The percent of properly converging models by $\mathrm{p} / \mathrm{f}$ ratio can be observed in Table 2 and graphically in Figure 6 .

Observing the rates of proper convergence across the four levels of sample size, it is clear that a sample size of at least 300 is required in order to negate the effect of reducing the $\mathrm{p} / \mathrm{f}$ ratio as a result of parceling. When $\mathrm{N}=75-150$, the percent of proper converging solutions was much less in the parcel-level analyses. However, the percent of proper converging solutions in the parcel-level analyses when $\mathrm{N}=300-600$ was only slightly less.

Kurtosis did not affect the rates of proper convergence. When $s=.40$, the percent of proper converging solutions was approximately $80.0 \%$ in the parcel solutions for each of the kurtosis conditions. When $\mathrm{s}=.70$, the percentage of proper converging solutions was approximately $86.0 \%$ in the parcel solutions for each condition.

Saturation had an effect on the percent of properly converging models, as demonstrated in Table 2. However the reduction in the percent of properly converging 
Table 2. Percent of Properly Converging Solutions Across Conditions - Study 2

$\%$ of Properly Converging Solutions

\begin{tabular}{|c|c|c|c|c|c|c|}
\hline \multirow[b]{2}{*}{ Condition } & \multicolumn{3}{|c|}{ Saturation $=.40$} & \multicolumn{3}{|c|}{ Saturation $=.70$} \\
\hline & $\begin{array}{c}\text { Item } \\
\text { Model }\end{array}$ & $\begin{array}{c}\text { Parceled } \\
\text { Model }\end{array}$ & $\mathrm{N}$ & $\begin{array}{c}\text { Item } \\
\text { Model }\end{array}$ & $\begin{array}{c}\text { Parceled } \\
\text { Model }\end{array}$ & $\mathrm{N}$ \\
\hline All Models & $91.5 \%$ & $80.0 \%$ & 4800 & $100 \%$ & $86.2 \%$ & 4800 \\
\hline$p / f=8 / 2$ & $88.7 \%$ & $61.8 \%$ & 1200 & $100 \%$ & $72.0 \%$ & 1200 \\
\hline$p / f=16 / 4$ & $77.3 \%$ & $58.0 \%$ & 1200 & $100 \%$ & $72.8 \%$ & 1200 \\
\hline $\mathrm{p} / \mathrm{f}=16 / 2$ & $100.0 \%$ & $100.0 \%$ & 1200 & $100 \%$ & $100 \%$ & 1200 \\
\hline$p / f=64 / 4$ & $100.0 \%$ & $100.0 \%$ & 1200 & $100 \%$ & $100 \%$ & 1200 \\
\hline $\mathrm{N}=75$ & $72.8 \%$ & $61.8 \%$ & 1200 & $100 \%$ & $68.6 \%$ & 1200 \\
\hline$N=150$ & $93.6 \%$ & $73.0 \%$ & 1200 & $100 \%$ & $82.1 \%$ & 1200 \\
\hline$N=300$ & $99.6 \%$ & $88.2 \%$ & 1200 & $100 \%$ & $94.8 \%$ & 1200 \\
\hline$N=600$ & $100 \%$ & $96.9 \%$ & 1200 & $100 \%$ & $99.3 \%$ & 1200 \\
\hline$K=-1.139$ & $90.9 \%$ & $81.0 \%$ & 1600 & $100 \%$ & $85.7 \%$ & 1600 \\
\hline$K=0.0$ & $92.2 \%$ & $80.1 \%$ & 1600 & $100 \%$ & $86.8 \%$ & 1600 \\
\hline$K=10.0$ & $91.4 \%$ & $78.8 \%$ & 1600 & $100 \%$ & $86.1 \%$ & 1600 \\
\hline
\end{tabular}

Note: $\mathrm{p} / \mathrm{f}=$ Items/Factors, $\mathrm{N}=$ Sample Size, $\mathrm{K}=$ Specified Kurtosis 
Figure 6. Percent of Proper Converging Solutions - Study 2

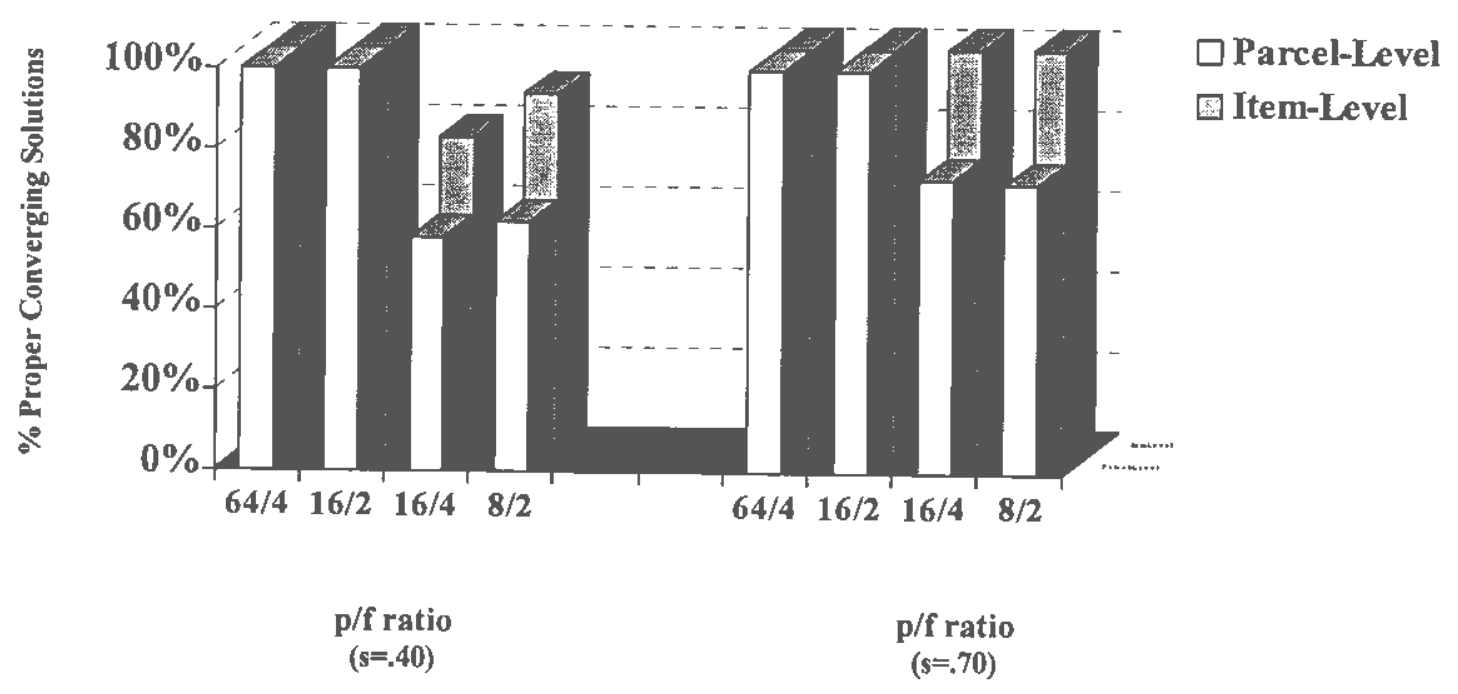


models with the parcel analysis was approximately the same for both $\mathrm{s}=.40$ and $\mathrm{s}=$ .70 . When $s=.40$, item-level models properly converged at a rate of $91.5 \%$ compared to $80.0 \%$ of parcel-level models. This difference is $11.5 \%$. When $\mathrm{s}=.70$, item-level models properly converged at a rate of $100 \%$ compared to $86.2 \%$ of parcel-level models. This difference was $13.8 \%$, or approximately the same as when $\mathrm{s}=.40$. Given the differences across other independent variables, saturation alone does not contribute to the reduction in percent of properly converging parcel models.

An additional analysis also showed that parceling will not improve the chances of obtaining a properly converging solutions. Overall, 408 item-level analyses did not converge to proper solutions. Of these models, only $67(16.4 \%)$ of the parcel-level analyses converged to a proper solution.

Goodness of Fit. Another hypothesis of Study 2 was that parceling will improve fit indices under conditions of small $\mathrm{p} / \mathrm{f}$ ratio, low sample size, non-normality and/or low saturation. The mean GFI, CFI, NNFI and RMSEA for item- and parcel-level solutions were compared for models in which both types of analyses converged to proper solutions.

Across all models in which $\mathrm{s}=.40$, the mean parcel-level GFI, CFI, and NNFI were greater than the corresponding item-level means. The mean RMSEA was less in the parcel-level solutions compared to the item-level solutions. The same was true for all models in which $\mathrm{s}=.70$. GFI, CFI, and NNFI were greater while RMSEA was less in the parcel-level solutions compared to the item-level solutions. Parceling afftected 
GFI, CFI, and NNFI about the same, while RMSEA did not seem to change as drastically from item- to parcel-level solutions. The mean GFI, CFI, NNFI, and RMSEA by each independent variable of Study 2 can be found in Table 3 .

For each $\mathrm{p} / \mathrm{f}$ condition, the mean of each fit index was greater (less for RMSEA) in the parcel-level solutions compared to the item-level solutions. This was true both when $s=.40$ and $s=.70$. The improvement in the fit indices was greatest with the more complex models $(\mathrm{p} / \mathrm{f}=16 / 2$ and $\mathrm{p} / \mathrm{f}=64 / 4)$. In the $\mathrm{p} / \mathrm{f}=8 / 2$ and $\mathrm{p} / \mathrm{f}=16 / 4$ models, the mean fit indices were already extremely high in the item-level analyses, leaving little room for improvement in the parcel-level analyses.

The mean of each fit index was greater (less for RMSEA) in the parcel-level solutions compared to the item-level solutions for each sample size condition. For the $\mathrm{N}=600$ models, there was little room for improvement in fit. However with small sample sizes, the improvement in fit for parcel-level models was great.

Across each level of kurtosis, the fit indices improved with the parcel-level analyses. For each of the four fit indices, the improvement in fit was not different by level of kurtosis.

Although the overall mean of each fit index was better in parcel-level models, saturation seemed to affect CFI and NNFI moreso than GFI and RMSEA. For GFI, the mean improvement was .063 when $\mathrm{s}=.40$ and .064 when $\mathrm{s}=.70$. For RMSEA, the improvement was .007 and .006. However for CFI the mean improvement was .107 when $\mathrm{s}=.40$ and .039 when $\mathrm{s}=.70$. The mean improvement in NNFI was .106 when $\mathrm{s}$ $=.40$ and .039 when $s=.70$. 
Table 3. Mean Goodness of Fit Indices Across Conditions Across Conditions - Study 2

\begin{tabular}{|c|c|c|c|c|c|c|c|c|}
\hline \multirow[b]{3}{*}{ Condition } & \multicolumn{8}{|c|}{ Saturation $=.40$} \\
\hline & \multicolumn{2}{|c|}{ GFI } & \multicolumn{2}{|c|}{ CFI } & \multicolumn{2}{|c|}{ NNFI } & \multicolumn{2}{|c|}{ RMSEA } \\
\hline & $\begin{array}{l}\text { Item } \\
\text { Model }\end{array}$ & $\begin{array}{l}\text { Parcel } \\
\text { Model }\end{array}$ & $\begin{array}{c}\text { Item } \\
\text { Model }\end{array}$ & $\begin{array}{l}\text { Parcel } \\
\text { Model }\end{array}$ & $\begin{array}{c}\text { Item } \\
\text { Model }\end{array}$ & $\begin{array}{l}\text { Parcel } \\
\text { Model }\end{array}$ & $\begin{array}{c}\text { Item } \\
\text { Model }\end{array}$ & $\begin{array}{l}\text { Parcel } \\
\text { Model }\end{array}$ \\
\hline All Models & .863 & .926 & .858 & .965 & .848 & .954 & .025 & .018 \\
\hline $\mathrm{p} / \mathrm{f}=8 / 2$ & .981 & .999 & .972 & .994 & .960 & .966 & .012 & .013 \\
\hline $\mathrm{p} / \mathrm{f}=16 / 4$ & .960 & .989 & .882 & .967 & .874 & .962 & .026 & .021 \\
\hline $\mathrm{p} / \mathrm{f}=16 / 2$ & .854 & .916 & .965 & .989 & .957 & .979 & .011 & .009 \\
\hline $\mathrm{p} / \mathrm{f}=64 / 4$ & .748 & .856 & .707 & .932 & .696 & .926 & .039 & .022 \\
\hline $\mathrm{N}=75$ & .674 & .814 & .536 & .876 & .512 & .856 & .066 & .042 \\
\hline $\mathrm{N}=150$ & .827 & .913 & .841 & .975 & .829 & .964 & .026 & .016 \\
\hline $\mathrm{N}=300$ & .914 & $.96 \mathrm{I}$ & .950 & .989 & .946 & .980 & .014 & .011 \\
\hline $\mathrm{N}=600$ & .957 & .970 & .981 & .989 & .977 & .983 & .008 & .010 \\
\hline $\mathrm{K}=-1.139$ & .863 & .929 & .862 & .970 & .852 & .960 & .024 & .016 \\
\hline $\mathrm{K}=0.0$ & .864 & .929 & .857 & .965 & .847 & .956 & .025 & .017 \\
\hline $\mathrm{K}=10,0$ & .862 & .918 & .855 & .958 & .846 & .947 & .025 & .020 \\
\hline
\end{tabular}

\begin{tabular}{|c|c|c|c|c|c|c|c|c|}
\hline \multirow[b]{3}{*}{ Condition } & \multicolumn{8}{|c|}{ Saturation $=.70$} \\
\hline & \multicolumn{2}{|c|}{ GFI } & \multicolumn{2}{|c|}{ CFI } & \multicolumn{2}{|c|}{ NNFI } & \multicolumn{2}{|c|}{ RMSEA } \\
\hline & $\begin{array}{c}\text { Item } \\
\text { Model }\end{array}$ & $\begin{array}{l}\text { Parcel } \\
\text { Model }\end{array}$ & $\begin{array}{c}\text { Item } \\
\text { Model }\end{array}$ & $\begin{array}{l}\text { Parcel } \\
\text { Model }\end{array}$ & $\begin{array}{c}\text { Item } \\
\text { Model }\end{array}$ & $\begin{array}{l}\text { Parcel } \\
\text { Model }\end{array}$ & $\begin{array}{c}\text { Item } \\
\text { Model }\end{array}$ & $\begin{array}{l}\text { Parcel } \\
\text { Model }\end{array}$ \\
\hline All Models & .864 & .928 & .950 & .989 & .947 & .986 & .029 & .023 \\
\hline $\mathrm{p} / \mathrm{f}=8 / 2$ & .976 & .998 & .993 & .999 & .989 & .992 & .019 & .017 \\
\hline $\mathrm{p} / \mathrm{f}=16 / 4$ & .948 & .985 & .961 & .989 & .958 & .987 & .032 & .028 \\
\hline $\mathrm{p} / \mathrm{f}=16 / 2$ & .845 & .911 & .991 & .997 & .989 & .994 & .015 & .014 \\
\hline $\mathrm{p} / \mathrm{f}=64 / 4$ & .740 & .851 & .878 & .977 & .874 & .956 & .043 & .028 \\
\hline $\mathrm{N}=75$ & .699 & .833 & .828 & .967 & .818 & .961 & .066 & .044 \\
\hline $\mathrm{N}=150$ & .833 & .918 & .957 & .990 & .954 & .987 & $.03 \mathrm{I}$ & .024 \\
\hline $\mathrm{N}=300$ & .913 & .961 & .986 & .996 & .984 & .994 & .018 & .016 \\
\hline$N=600$ & .955 & .969 & .994 & .997 & .993 & .996 & .012 & .013 \\
\hline $\mathrm{K}=-1.139$ & .853 & .925 & .959 & .992 & .956 & .990 & .024 & .018 \\
\hline $\mathrm{K}=0.0$ & .871 & .934 & .937 & .986 & .932 & .982 & .036 & .027 \\
\hline $\mathrm{K}=10.0$ & .867 & .923 & .954 & .990 & .951 & .987 & .027 & .023 \\
\hline
\end{tabular}

Note: $\mathrm{p} / \mathrm{f}=\mathrm{Item} /$ Factors, $\mathrm{N}=$ Sample Size, $\mathrm{K}=$ Specified Kurtosis

All Fit Indices not in italics are significant at $p<.001$ 
In addition to examining the means of the four fit indices within each condition, the percent of models meeting the standard acceptable fit criteria was examined for the item- and parcel-level analyses. The same patterns were found as with the mean fit indices. Parcel-level analyses much more likely to meet standard fit criteria, especially when the $\mathrm{p} / \mathrm{f}$ ratio was large and/or $\mathrm{N}$ was small. In some conditions, the percent of solutions meeting the criteria doubled from the item-level analyses to the parcel-level analyses. The percent of solutions meeting standard fit indices is displayed in Table 4 .

Saturation. A third hypothesis of Study 2 was that parceling would improve fit indices under conditions of small $\mathrm{p} / \mathrm{f}$ ratio, low sample size, non-normality and/or low saturation. This hypothesis was confirmed, as the mean item saturation in parcel-level solutions was greater than in the item-level solutions with each condition. For each $\mathrm{p} / \mathrm{f}$, sample size, and kurtosis condition, the parcel-level analyses produced approximately the same increase in mean saturation. In $\mathrm{s}=.40$ models, the mean saturation increased from .397 in item-level solutions to .525 in parcel-level solutions. In $\mathrm{s}=.70$ models, the mean saturation increased from .698 in item-level solutions to .810 in parcel-level solutions. The mean item-level saturations approximated what was specified in the data simulation (.40 and .70$)$, supporting the internal validity of the analyses.

For simulations in which both item-level and parcel-level solutions converged to proper solutions, 7907 out of 7908 (99.99\%) models had a higher mean parcel-level saturation compared to the mean item-level saturation. The mean indicator saturation by each independent variable of Study 2 can be found in Table 5 . 
Table 4. Percent of Item and Parcel Solutions Meeting Standard Fit Criteria Across Conditions - Study 2

\begin{tabular}{|c|c|c|c|c|c|c|c|c|c|}
\hline \multirow[b]{3}{*}{ Condition } & \multicolumn{7}{|c|}{ Saturation $=.40$} & \multirow{2}{*}{\multicolumn{2}{|c|}{ RMSEA $<.05$}} \\
\hline & & \multicolumn{2}{|c|}{$\mathrm{GFI}>.90$} & \multicolumn{2}{|c|}{$\mathrm{CFI}>.90$} & \multicolumn{2}{|c|}{$\mathrm{NNFI}>.90$} & & \\
\hline & $\mathrm{N}$ & $\begin{array}{c}\text { Item } \\
\text { Model }\end{array}$ & $\begin{array}{l}\text { Parcel } \\
\text { Model }\end{array}$ & $\begin{array}{c}\text { Item } \\
\text { Model }\end{array}$ & $\begin{array}{l}\text { Parcel } \\
\text { Model }\end{array}$ & $\begin{array}{c}\text { Item } \\
\text { Model }\end{array}$ & $\begin{array}{l}\text { Parcel } \\
\text { Model }\end{array}$ & $\begin{array}{c}\text { Item } \\
\text { Model }\end{array}$ & $\begin{array}{l}\text { Parcel } \\
\text { Model }\end{array}$ \\
\hline All Models & 3777 & 59.6 & 73.1 & 65.2 & 88.0 & 62.8 & 84.1 & 85.4 & 88.0 \\
\hline $\mathrm{p} / \mathrm{f}=8 / 2$ & 712 & 100.0 & 100.0 & 91.7 & 99.0 & 86.8 & 89.7 & 95.5 & 89.7 \\
\hline $\mathrm{p} / \mathrm{f}=16 / 4$ & 665 & 96.1 & 100.0 & 89.2 & 98.5 & 85.1 & 93.1 & 99.4 & 96.8 \\
\hline $\mathrm{p} / \mathrm{f}=16 / 2$ & 1200 & 49.8 & 65.9 & 62.7 & 89.3 & 61.3 & 86.3 & 82.2 & 88.0 \\
\hline $\mathrm{p} / \mathrm{f}=64 / 4$ & 1200 & 24.8 & 49.4 & 38.6 & 74.4 & 37.7 & 73,4 & 75.0 & 81.9 \\
\hline$N=75$ & 700 & 10.7 & 14.3 & 12.0 & 45.3 & 11.9 & 41.7 & 24.9 & 53.1 \\
\hline$N=150$ & 858 & 30.0 & 64.0 & 41.1 & 95.2 & 38.0 & 89.9 & 97.6 & 94.9 \\
\hline$N=300$ & 1056 & 71.3 & 99.3 & 82.2 & 100.0 & 78.0 & 95.9 & 99.7 & 97.2 \\
\hline$N=600$ & 1163 & 99.8 & 91.4 & 99.4 & 97.6 & 97.9 & 94.5 & 100.0 & 95.4 \\
\hline $\mathrm{K}=-1.139$ & 1273 & 59.9 & 75.7 & 63.3 & 88.8 & 61.0 & 85.5 & 85.8 & 89.1 \\
\hline $\mathrm{K}=0.0$ & 1262 & 59.6 & 76.1 & 67.0 & 90.0 & 64.3 & 86.0 & 85.2 & 89.1 \\
\hline $\mathrm{K}=10.0$ & 1242 & 58.9 & 67.4 & 65.2 & 85.3 & 63.0 & 80.6 & 85.3 & 85.6 \\
\hline
\end{tabular}

\begin{tabular}{|c|c|c|c|c|c|c|c|c|c|}
\hline \multirow[b]{3}{*}{ Condition } & \multirow[b]{3}{*}{$\mathrm{N}$} & \multicolumn{6}{|c|}{ Saturation $=.70$} & & \\
\hline & & \multicolumn{2}{|c|}{$\mathrm{GFI}>.90$} & \multicolumn{2}{|c|}{$\mathrm{CFI}>.90$} & \multicolumn{2}{|c|}{$\mathrm{NNFI}>.90$} & \multicolumn{2}{|c|}{ RMSEA $<.05$} \\
\hline & & $\begin{array}{c}\text { Item } \\
\text { Model }\end{array}$ & $\begin{array}{l}\text { Parcel } \\
\text { Model }\end{array}$ & $\begin{array}{c}\text { Item } \\
\text { Model }\end{array}$ & $\begin{array}{l}\text { Parcel } \\
\text { Model }\end{array}$ & $\begin{array}{c}\text { Item } \\
\text { Model }\end{array}$ & $\begin{array}{l}\text { Parcel } \\
\text { Model }\end{array}$ & $\begin{array}{c}\text { Item } \\
\text { Model }\end{array}$ & $\begin{array}{l}\text { Parcel } \\
\text { Model }\end{array}$ \\
\hline All Models & 4137 & 56.5 & 73.6 & 86.5 & 99.6 & 85.6 & 98.8 & 82.2 & 84.0 \\
\hline $\mathrm{p} / \mathrm{f}=8 / 2$ & 864 & 99.3 & 100.0 & 99.2 & 100.0 & 98.6 & 98.3 & 89.9 & 85.3 \\
\hline $\mathrm{p} / \mathrm{f}=16 / 4$ & 873 & 89.5 & 100.0 & 99.7 & 100.0 & 99.2 & 99.8 & 96.6 & 92.2 \\
\hline $\mathrm{p} / \mathrm{f}=16 / 2$ & 1200 & 41.6 & 63.6 & 87.9 & 99.9 & 86.2 & 99.8 & 76.3 & 82.3 \\
\hline $\mathrm{p} / \mathrm{f}=64 / 4$ & 1200 & 16.7 & 45.3 & 66.3 & 98.7 & 65.9 & 97.5 & 72.1 & 79.0 \\
\hline$N=75$ & 823 & 15.9 & 27.1 & 44.8 & 97.9 & 41.4 & 94.9 & 24.9 & 48.1 \\
\hline$N=150$ & 985 & 38.5 & 65.8 & 89.3 & 100.0 & 88.6 & 99.5 & 89.0 & 89.6 \\
\hline$N=300$ & 1138 & 64.8 & 95.1 & 100.0 & 100.0 & 100.0 & 99.8 & 99.0 & 95.2 \\
\hline$N=600$ & 1191 & 91.6 & 91.6 & 100.0 & 100.0 & 100.0 & 100.0 & 100.0 & 93.6 \\
\hline$K=-1.139$ & 1371 & 46.9 & 72.3 & 79.3 & 98.9 & 78.6 & 97.7 & 77.0 & 81.1 \\
\hline $\mathrm{K}=0.0$ & 1388 & 61.7 & 78.2 & 91.1 & 99.9 & 89.8 & 99.4 & 85.3 & 87.6 \\
\hline $\mathrm{K}=10.0$ & 1378 & 60.9 & 70.2 & 89.0 & 99.9 & 88.4 & 99.3 & 84.3 & 83.4 \\
\hline
\end{tabular}

Note: $\mathrm{p} / \mathrm{f}=$ Items/Factors, $\mathrm{N}=$ Sample Size, $\mathrm{K}=$ Specified Kurtosis 


\begin{tabular}{lccccc} 
& \multicolumn{2}{c}{ Saturation $=.40$} & & \multicolumn{2}{c}{ Saturation $=.70$} \\
Condition & $\begin{array}{c}\text { Item } \\
\text { Model }\end{array}$ & $\begin{array}{c}\text { Parcel } \\
\text { Model }\end{array}$ & & $\begin{array}{c}\text { Item } \\
\text { Model }\end{array}$ & $\begin{array}{c}\text { Parcel } \\
\text { Model }\end{array}$ \\
\hline & & & & & \\
All Models & .397 & .525 & .698 & .810 \\
$\mathrm{p} / \mathrm{f}=8 / 2$ & .402 & .540 & .699 & .812 \\
$\mathrm{p} / \mathrm{f}=16 / 4$ & .390 & .520 & .697 & .808 \\
$\mathrm{p} / \mathrm{f}=16 / 2$ & .397 & .521 & .699 & .812 \\
$\mathrm{p} / \mathrm{f}=64 / 4$ & .399 & .524 & .699 & .810 \\
& & & & \\
$\mathrm{~N}=75$ & .398 & .525 & .696 & .809 \\
$\mathrm{~N}=150$ & .398 & .526 & .699 & .811 \\
$\mathrm{~N}=300$ & .397 & .526 & .699 & .811 \\
$\mathrm{~N}=600$ & .396 & .525 & .699 & .811 \\
$\mathrm{~K}=-1.139$ & .396 & .523 & & .700 & .812 \\
$\mathrm{~K}=0.0$ & .400 & .530 & .698 & .809 \\
$\mathrm{~K}=10.0$ & .395 & .523 & .697 & .809 \\
\hline
\end{tabular}

Note: $\mathrm{p} / \mathrm{f}=$ Items/Factors, $\mathrm{N}=$ Sample Size, $\mathrm{K}=$ Specified Kurtosis 


\section{DISCUSSION}

Possibly the most important finding of Study 2 was the improvement in fit indices in parcel-level solutions. GFI was clearly affected the most by parceling. For almost all model conditions, GFI was greater in the parcel-level solutions. In many cases, the mean GFI improved drastically from approximately under .80 to over .90 . Consequently, in many cases models would meet the standard fit criterion of GFI $>.90$ for the parcel-level analysis, but would not meet the criterion if the data had been examined with an item-level analysis. CFI and NNFI were not as affected as GFI, but in most cases these fit indices were greater in the parcel-level solutions. RMSEA was the least affected by parceling. In most cases the RMSEA was approximately the same for each type of analysis.

Another consistent finding in Study 2 was that loadings were systematically increased when items were combined. Researchers should be aware of this when deciding to form parcels for the purpose of model fitting. With the possibility of correlated errors and residuals, it is not reasonable to assume that a parcel loading of .80 is better or worse than two item loadings of .70 . The item loadings and mean loadings are often of interest to researchers. Perhaps there should be a common notation to be used when indicators are parcels rather than items. When displaying model structures visually, it is most common to use circles to represent factors and rectangles for indicators. Parcels could be represented with their own shape, to add this important information for the reader. Another alternative could be to represent each 
parcel with the set of items that comprise each parcel. For example, instead of labeling a parcel $V_{1}$, it could instead be labeled $V_{1}+V_{2}+V_{3}$ if it is a parcel made up of three unique items. This would alert readers to the fact that it is a parcel indicator instead of an item indicator. One problem with this representation is that many parcels found in the literature are composites of over 20 variables. This notation would be difficult to display with such a large composite.

Another clear finding from Study 2 was that parceling generally does not improve the chances of obtaining a proper converging solution. In fact, the opposite effect was found. Many parcel-level models did not converge to proper solutions when the item-level models did. In the model structures examined here, this was probably due to the extremely small $\mathrm{p} / \mathrm{f}$ ratios $(2,3$, and 4$)$ in the parcel-level models. This finding is consistent with the Marsh et al. (1998) study, where differences were found when the $\mathrm{p} / \mathrm{f}$ ratio was 2 . It is clear, at least in the conditions examined here, that parceling will not enhance the chances of obtaining a proper solution.

Kurtosis seemed to have no effect on the dependent variables. Combining multiple items with extremely high or extremely low kurtosis will produce a more normal indicator. It was hypothesized that with more normal indicators, the fit and/or chance of obtaining a proper solution may be improved. This was not the case. Fit indices, loadings, and the number of proper converging solutions were not different by level of kurtosis.

With the number of conditions and replications of Study 2, the results show that parcels generally follow a predictable pattern of behavior. When using parcels, the 
number of indicators is reduced. This will most likely improve fit indices. The indicator saturations are improved, also likely to result in improved fit indices. There does not seem to be any factor that would contribute to a systematic decrease in fit indices. It seems clear that using a parcel-level analysis instead of an item-level analysis will produce higher loadings and better fit indices, although the parcel-level analysis may not be as strong of a test of the hypothesized model. 


\section{CHAPTER 4}

\section{Evaluating the Effects of Different Forms of Parceling. (Study 3)}

In Study 2, several interesting differences were observed between item-level solutions and 2-item parcel-level solutions. Indicator saturations and goodness-of-fit indices were greater in the parcel-level solutions. Parcel-level analyses were not advantageous in terms of the percent of properly converging models.

The purpose of Study 3 was to examine if the results of Study 2 also extend to models in which the number of items per parcel is greater. Increasing the number of items per parcel reduces the number of indicators per factor. With the decreased $\mathrm{p} / \mathrm{f}$ ratio, a further improvement in fit indices was expected. With additional items added to form parcels, it is also likely that item saturations would be greater. As for the percent of proper converging solutions, there was no strong prediction made in either direction. The improvement in saturation may help proper convergence and the reduced $\mathrm{p} / \mathrm{f}$ ratio may hinder it.

\section{METHOD}

Study 3 evaluated the effect of item parceling when different numbers of items were used to form parcels. Four different types of analyses were compared across similar conditions as those in Study 2. The four types of analyses consisted of models with no parcels (the raw simulated data as indicators), two-item parcels as indicators, four-item parcels as indicators, and eight-item parcels as indicators. 
Two different measurement models were tested. The first model included two latent factors measured by 16 items per factor. The second model had four latent factors measured by 16 items per factor. The raw simulated data for these models was used in Study 2. In Study 2, this data was examined with item-level analyses and twoitem parcel-level analyses. In Study 3, they will also be examined with 4-item parcellevel analyses and 8-item parcel-level analyses. The dependent variables under examination in Study 3 are the same as those from Study 2. The independent variables are the same, except for kurtosis, which was not examined in Study 3.

The independent variables for Study 3 were sample size and item saturation. Four levels of sample size were again used: $75,150,300$, and 600 . Two levels of specified saturation were used: .40 and .70 . With two types of model structures and two levels of saturation, four general model types are present and will be referred to as model structures 1-4. In model structure \#1, the item-level model has 16 items representing each of 2 factors, with specified loadings of .40. Model structure \#2 has 16 items representing each of 2 factors, with specified loadings of .70. Structure \#3 has 16 items representing each of 4 constructs, with specified loadings of .40. Finally, model structure \#4 had 16 items representing each of 4 constructs, with specified loadings of .70 .

The dependent variables in Study 3 will be the same as with Study 2: percent of properly converged models, four fit indices, and indicator saturations. The same fit indices used in Study 2 will again be examined: GFI, CFI, NNFI, and RMSEA. The 
mean saturations and fit indices were again examined with paired-sample t-tests, while the percent of proper converging solutions was examined with the chi-square test.

All models were simulated with $\mathrm{EQS}$ (Bentler, 1995) from specifications of univariate and multivariate normality (skewness and kurtosis equal to 0.0 ) and factor correlations of .30 . There were 100 replications of each model. Maximum likelihood was the estimation technique. All factor variances were fixed at unity while factor loadings, uniquenesses, and factor correlations were freely estimated. The maximum number of iterations was 500 and the admissibility check was turned off. Default starting values provided by EQS were used.

\section{RESULTS}

The results of Study 3 are divided into three sections which cover the hypotheses of the investigation. It was hypothesized that using a greater number of items to form parcels would increase the percent of proper converging models, goodness of fit indices, and item saturations. For each of these measures, the effect of two independent variables, saturation and sample size, are examined.

Convergence. It was hypothesized that models in which the number of items per parcel were greater would have higher rates of proper convergence. This hypothesis was not confirmed in this study. For the four model structures examined here, all itemlevel, two-item parcel, and four-item parcel models had proper convergence. However, analyses with eight-item parcels did not have a $100 \%$ proper convergence rate. For the eight-item parcel analyses, the percent of proper converging models increased with 
sample size for each model type, as should be expected. The $\mathrm{p} / \mathrm{f}$ ratio for the eight-item parcel analyses was 2.0 . Given the results of Study 2 and with previous research, it is not surprising that models with an extremely small p/f ratio would not properly converge. The percent of proper converging models by each condition can be found in Table 6.

Goodness of Fit. It was hypothesized that goodness of fit indices would improve as the number of items per parcel increased. This hypothesis was supported by the analyses. For all four model types, the mean of each fit index was greater (RMSEA was smaller) as the number of items per parcel increased and $p / f$ subsequently decreased. For example, in the 32 item, 2-factor model when specified saturation was .40 , the mean GFI for the item-level model was .855. When 2-item parcels were used, thus reducing the number of indicators from 32 to 16 , the mean GFI was .928. When 4item parcels were used, leaving 8 indicators, the mean GFI was .972 . Finally, when 8 item parcels were used, leaving only 4 indicators, the mean GFI was .998. This was the usual pattern with most conditions for this study. It is important to keep in mind that these analyses were performed with the same simulated data. The mean GFI, CFI, NNFI, and RMSEA for each condition by each type of analysis can be found in Tables $7-10$

With some models the mean fit index when 8-item parcels were used was not significantly greater than the mean fit index when 4-item parcels were used. This was due to the asymptotic behavior of the fit indices, as the mean GFI, CFI, and NNFI 
Table 6. Percent of Properly Converging Solutions Across Conditions - Study 3

Model \#1: 32 Items, 2 Factors, Saturation $=.40$

\begin{tabular}{lcccc} 
Condition & $\begin{array}{c}\text { Item } \\
\text { Model }\end{array}$ & $\begin{array}{c}\text { 2-Item } \\
\text { Parcels }\end{array}$ & $\begin{array}{c}\text { 4-Item } \\
\text { Parcels }\end{array}$ & $\begin{array}{c}8 \text {-Item } \\
\text { Parcels }\end{array}$ \\
\hline All Models & $100 \%$ & $100 \%$ & $100 \%$ & $69 \%$ \\
$\mathrm{~N}=75$ & $100 \%$ & $100 \%$ & $100 \%$ & $35 \%$ \\
$\mathrm{~N}=150$ & $100 \%$ & $100 \%$ & $100 \%$ & $61 \%$ \\
$\mathrm{~N}=300$ & $100 \%$ & $100 \%$ & $100 \%$ & $83 \%$ \\
$\mathrm{~N}=600$ & $100 \%$ & $100 \%$ & $100 \%$ & $97 \%$ \\
\hline
\end{tabular}

Model \#2: 32 Items, 2 Factors, Saturation $=.70$

\begin{tabular}{lcccc} 
Condition & $\begin{array}{c}\text { Item } \\
\text { Model }\end{array}$ & $\begin{array}{c}\text { 2-Item } \\
\text { Parcels }\end{array}$ & $\begin{array}{c}\text { 4-Item } \\
\text { Parcels }\end{array}$ & $\begin{array}{c}\text { 8-Item } \\
\text { Parcels }\end{array}$ \\
\hline All Models & $100 \%$ & $100 \%$ & $100 \%$ & $48 \%$ \\
$\mathrm{~N}=75$ & $100 \%$ & $100 \%$ & $100 \%$ & $16 \%$ \\
$\mathrm{~N}=150$ & $100 \%$ & $100 \%$ & $100 \%$ & $35 \%$ \\
$\mathrm{~N}=300$ & $100 \%$ & $100 \%$ & $100 \%$ & $58 \%$ \\
$\mathrm{~N}=600$ & $100 \%$ & $100 \%$ & $100 \%$ & $83 \%$ \\
\hline
\end{tabular}

Model \#3: 64 Items, 4 Factors, Saturation $=.40$

\begin{tabular}{lcccc} 
Condition & $\begin{array}{c}\text { Item } \\
\text { Model }\end{array}$ & $\begin{array}{c}2 \text {-Item } \\
\text { Parcels }\end{array}$ & $\begin{array}{c}\text { 4-Item } \\
\text { Parcels }\end{array}$ & $\begin{array}{c}8 \text {-Item } \\
\text { Parcels }\end{array}$ \\
\hline All Models & $100 \%$ & $100 \%$ & $100 \%$ & $73.8 \%$ \\
$\mathrm{~N}=75$ & $100 \%$ & $100 \%$ & $100 \%$ & $29 \%$ \\
$\mathrm{~N}=150$ & $100 \%$ & $100 \%$ & $100 \%$ & $72 \%$ \\
$\mathrm{~N}=300$ & $100 \%$ & $100 \%$ & $100 \%$ & $94 \%$ \\
$\mathrm{~N}=600$ & $100 \%$ & $100 \%$ & $100 \%$ & $100 \%$ \\
\hline
\end{tabular}

Model \#4: 64 Items, 4 Factors, Saturation $=.70$

\begin{tabular}{lcccc} 
Condition & $\begin{array}{c}\text { Item } \\
\text { Model }\end{array}$ & $\begin{array}{c}2 \text {-Item } \\
\text { Parcels }\end{array}$ & $\begin{array}{c}\text { 4-Item } \\
\text { Parcels }\end{array}$ & $\begin{array}{c}8 \text {-Item } \\
\text { Parcels }\end{array}$ \\
\hline All Models & $100 \%$ & $100 \%$ & $100 \%$ & $47 \%$ \\
$\mathrm{~N}=75$ & $100 \%$ & $100 \%$ & $100 \%$ & $8 \%$ \\
$\mathrm{~N}=150$ & $100 \%$ & $100 \%$ & $100 \%$ & $31 \%$ \\
$\mathrm{~N}=300$ & $100 \%$ & $100 \%$ & $100 \%$ & $60 \%$ \\
$\mathrm{~N}=600$ & $100 \%$ & $100 \%$ & $100 \%$ & $89 \%$ \\
\hline
\end{tabular}

Note: $N=$ Sample Size 
Table 7. Mean Fit Indices for Model Structure \#1 - Study 3

\begin{tabular}{|c|c|c|c|c|c|c|c|c|c|}
\hline \multirow[b]{2}{*}{ Condition } & \multirow[b]{2}{*}{$N$} & \multicolumn{4}{|c|}{ GFI } & \multicolumn{4}{|c|}{$\mathrm{CFI}$} \\
\hline & & $p / f=16$ & $\mathrm{p} / \mathrm{f}=8$ & $p / f=4$ & $p / f=2$ & $\mathrm{p} / \mathrm{f}=16$ & $\mathrm{p} / \mathrm{f}=8$ & $\mathrm{p} / \mathrm{f}=4$ & $\mathrm{p} / \mathrm{f}=2$ \\
\hline All Models & 276 & .855 & .928 & .972 & .998 & .885 & .975 & .990 & .998 \\
\hline$N=75$ & 35 & .717 & .851 & .941 & .996 & .674 & .934 & .977 & .998 \\
\hline$N=150$ & 61 & .838 & .922 & .969 & .997 & .908 & .980 & .991 & .998 \\
\hline$N=300$ & 83 & .911 & .959 & .984 & .999 & .969 & .991 & .995 & .998 \\
\hline$N=600$ & 97 & .954 & .979 & .992 & .999 & .989 & .996 & .998 & .999 \\
\hline
\end{tabular}

\begin{tabular}{|c|c|c|c|c|c|c|c|c|c|}
\hline \multirow[b]{2}{*}{ Condition } & \multirow[b]{2}{*}{$N$} & \multicolumn{4}{|c|}{ NNFI } & \multicolumn{4}{|c|}{ RMSEA } \\
\hline & & $p / f=16$ & $p / f=8$ & $\mathrm{p} / \mathrm{f}=4$ & $\mathrm{p} / \mathrm{f}=2$ & $\mathrm{p} / \mathrm{f}=16$ & $\mathrm{p} / \overline{\mathrm{f}}=8$ & $\mathrm{p} / \mathrm{f}=4$ & $\mathrm{p} / \mathrm{f}=2$ \\
\hline All Models & 276 & .881 & .982 & .998 & 1.007 & .024 & .017 & .019 & .019 \\
\hline$N=75$ & 35 & .651 & .939 & .996 & 1.042 & .056 & .036 & .032 & .017 \\
\hline $\mathrm{N}=150$ & 61 & .907 & .990 & .998 & 1.009 & .023 & .017 & .020 & .021 \\
\hline$N=300$ & 83 & .971 & .998 & .999 & 1.000 & .012 & .010 & .014 & .020 \\
\hline $\mathrm{N}=600$ & 97 & .994 & 1.000 & .999 & .999 & .006 & .006 & .010 & .016 \\
\hline
\end{tabular}

Note: $\mathrm{N}$ represents the number of simulations in which all types of analyses had proper convergence. 
Table 8. Mean Fit Indices for Model Structure \#2-Study 3

\begin{tabular}{|c|c|c|c|c|c|c|c|c|c|}
\hline \multirow[b]{2}{*}{ Condition } & \multirow[b]{2}{*}{$N$} & \multicolumn{4}{|c|}{ GFI } & \multicolumn{4}{|c|}{ CFI } \\
\hline & & $\mathrm{p} / \mathrm{f}=16$ & $\mathrm{p} / \mathrm{f}=8$ & $\mathrm{p} / \mathrm{f}=4$ & $\mathrm{p} / \mathrm{f}=2$ & $\mathrm{p} / \mathrm{f}=16$ & $\mathrm{p} / \mathrm{f}=8$ & $\mathrm{p} / \mathrm{f}=4$ & $\mathrm{p} / \mathrm{f}=2$ \\
\hline All Models & 192 & .855 & .928 & .972 & .998 & .974 & .995 & .998 & .999 \\
\hline$N=7$ & 16 & .717 & .852 & .941 & .995 & .921 & .985 & .994 & .999 \\
\hline$N=150$ & 35 & .838 & .922 & .969 & .99 & .98 & .996 & .998 & .999 \\
\hline$N=300$ & 58 & .911 & .959 & .984 & .998 & .994 & .998 & .999 & .999 \\
\hline $\mathrm{N}=600$ & 83 & .954 & .979 & .992 & .999 & .998 & .999 & .999 & .999 \\
\hline
\end{tabular}

\begin{tabular}{|c|c|c|c|c|c|c|c|c|c|}
\hline \multirow[b]{2}{*}{ Condition } & \multirow[b]{2}{*}{$N$} & \multicolumn{4}{|c|}{ NNFI } & \multicolumn{4}{|c|}{ RMSEA } \\
\hline & & $\mathrm{p} / \mathrm{f}=16$ & $\mathrm{p} / \mathrm{f}=8$ & $\mathrm{p} / \mathrm{f}=4$ & $\mathrm{p} / \mathrm{f}=2$ & $\mathrm{p} / \mathrm{f}=16$ & $\mathrm{p} / \mathrm{f}=8$ & $\mathrm{p} / \mathrm{f}=4$ & $\mathrm{p} / \mathrm{f}=2$ \\
\hline All Models & 192 & .973 & .996 & .999 & 1.000 & .024 & .017 & .019 & .020 \\
\hline$N=75$ & 16 & .915 & .986 & .998 & 1.005 & .055 & .036 & .031 & .023 \\
\hline$N=150$ & 35 & .982 & .998 & .999 & 1.001 & .023 & .016 & .020 & .021 \\
\hline$N=300$ & 58 & .995 & .999 & 1.000 & .999 & .012 & .011 & .014 & .025 \\
\hline$N=600$ & 83 & .999 & 1.000 & 1.000 & 1.000 & .006 & .007 & .010 & .015 \\
\hline
\end{tabular}

Note: $\mathrm{N}$ represents the number of simulations in which all types of analyses had proper convergence. 
Table 9. Mean Fit Indices for Model Structure \#3 - Study 3

\begin{tabular}{|c|c|c|c|c|c|c|c|c|c|}
\hline \multirow[b]{2}{*}{ Condition } & \multirow[b]{2}{*}{$N$} & \multicolumn{4}{|c|}{$\mathrm{GFI}$} & \multicolumn{4}{|c|}{ CFI } \\
\hline & & $\mathrm{p} / \mathrm{f}=16$ & $\mathrm{p} / \mathrm{f}=8$ & $\overline{\mathrm{p} / \mathrm{f}}=4$ & $p / f=2$ & $\mathrm{p} / \mathrm{f}=16$ & $\mathrm{p} / \mathrm{f}=8$ & $p / f=4$ & $\mathrm{p} / \mathrm{f}=2$ \\
\hline All Models & 295 & .749 & .856 & .930 & .986 & .712 & .942 & .983 & .997 \\
\hline$N=75$ & 29 & .548 & .720 & .856 & .964 & .265 & .789 & .956 & .996 \\
\hline$N=150$ & 72 & .711 & .839 & .924 & .979 & .695 & 1.000 & .984 & .994 \\
\hline$N=300$ & 94 & .831 & .913 & .961 & .989 & .912 & .984 & .996 & .997 \\
\hline $\mathrm{N}=600$ & 100 & .908 & .955 & .981 & .995 & .977 & .995 & .998 & .999 \\
\hline
\end{tabular}

\begin{tabular}{|c|c|c|c|c|c|c|c|c|c|}
\hline \multirow[b]{2}{*}{ Condition } & \multirow[b]{2}{*}{$\mathrm{N}$} & \multicolumn{4}{|c|}{ NNFI } & \multicolumn{4}{|c|}{ RMSEA } \\
\hline & & $\mathrm{p} / \mathrm{f}=16$ & $\mathrm{p} / \mathrm{f}=8$ & $\mathrm{p} / \mathrm{f}=4$ & $\mathrm{p} / \mathrm{f}=2$ & $\mathrm{p} / \mathrm{f}=16$ & $\mathrm{p} / \mathrm{f}=8$ & $\mathrm{p} / \mathrm{f}=4$ & $p / f=2$ \\
\hline All Models & 295 & .702 & .909 & .989 & 1.005 & .039 & .019 & .017 & .011 \\
\hline$N=75$ & 29 & .238 & .772 & .953 & 1.034 & .094 & .056 & .037 & .011 \\
\hline$N=150$ & 72 & .684 & .907 & .990 & 1.005 & .037 & .024 & .018 & .016 \\
\hline$N=300$ & 94 & .909 & .986 & .999 & 1.001 & .017 & .011 & .009 & .012 \\
\hline$N=600$ & 100 & .977 & .998 & 1.002 & 1.001 & .008 & .006 & .005 & .007 \\
\hline
\end{tabular}

Note: $N$ represents the number of simulations in which all types of analyses had proper convergence. 
Table 10. Mean Fit Indices for Model Structure \#4-Study 3

\begin{tabular}{|c|c|c|c|c|c|c|c|c|c|}
\hline \multirow[b]{2}{*}{ Condition } & \multirow[b]{2}{*}{$\mathrm{N}$} & \multicolumn{4}{|c|}{ GFI } & \multicolumn{4}{|c|}{ CFI } \\
\hline & & $p / f=16$ & $\mathrm{p} / \mathrm{f}=8$ & $p / f=4$ & $\mathrm{p} / \mathrm{f}=2$ & $p / f=16$ & $\mathrm{p} / \mathrm{f}=8$ & $\mathrm{p} / \mathrm{f}=4$ & $\mathrm{p} / \mathrm{f}=2$ \\
\hline All Models & 188 & .749 & .856 & .930 & .989 & .891 & .982 & .996 & .999 \\
\hline$N=75$ & 8 & .548 & .719 & .855 & .957 & .661 & .945 & .987 & .996 \\
\hline $\mathrm{N}=150$ & 31 & .710 & .839 & .923 & .978 & .926 & .987 & .996 & .998 \\
\hline$N=300$ & 60 & .831 & .913 & .961 & .989 & .983 & .997 & .999 & .999 \\
\hline$N=600$ & 89 & .908 & .955 & .981 & .995 & .996 & .999 & .999 & .999 \\
\hline
\end{tabular}

\begin{tabular}{|c|c|c|c|c|c|c|c|c|c|}
\hline \multirow[b]{2}{*}{ Condition } & \multirow[b]{2}{*}{$\mathrm{N}$} & \multicolumn{4}{|c|}{ NNFI } & \multicolumn{4}{|c|}{ RMSEA } \\
\hline & & $p / f=16$ & $\mathrm{p} / \mathrm{f}=8$ & $\mathrm{p} / \mathrm{f}=4$ & $\mathrm{p} / \mathrm{f}=2$ & $\mathrm{p} / \mathrm{f}=16$ & $\mathrm{p} / \mathrm{f}=8$ & $\mathrm{p} / \mathrm{f}=4$ & $\mathrm{p} / \mathrm{f}=2$ \\
\hline All Models & 188 & .888 & .981 & .996 & 1.001 & .039 & .024 & .017 & .011 \\
\hline$N=75$ & 8 & .649 & .940 & .986 & 1.003 & .094 & .056 & .038 & .026 \\
\hline & 31 & .923 & .987 & .997 & 1.0 & .03 & .024 & .018 & .020 \\
\hline$N=300$ & 60 & .982 & .997 & 1.000 & 1.001 & .017 & .011 & .009 & .010 \\
\hline $\mathrm{N}=600$ & 89 & .996 & 1.000 & 1.000 & 1.000 & .008 & .006 & .005 & .008 \\
\hline
\end{tabular}

Note: $\mathrm{N}$ represents the number of simulations in which all types of analyses had proper convergence. 
approached 1.0 for the 4-item parcels, especially when sample size was large. With RMSEA the 4-item parcels did not always have a significantly better mean than the 2item parcel analyses. This may have been due to greater variation with this fit index, or asymptotic behavior of this index as well.

In addition, the percent of models that met standard fit criteria was examined. Standard fit criteria was greater than .90 for GFI, CFI and NNFI, and less than .05 for RMSEA. The percent of models meeting the criteria generally increased as the number of items per parcel increased. When 4 and 8-item parcels were used, almost every model met the fit index standard, with the exception of RMSEA in the 32-item, 2-factor models. For this model, the percent of solutions having RMSEA less than .05 was greater in the 2-item parcel solutions compared to the item-level solutions. However, the percent of solutions with RMSEA less than .05 decreased with the 4 and 8 -item parcel solutions. This is a curious result that did not replicate in the 64 -item, 4 -factor models. The percent of models meeting fit criteria for each type of analysis across the study conditions can be observed in Table 11 .

Saturation. Not suprisingly, indicator saturation increased as the number of items per parcel increased. For $s=.40$ models, saturation increased from .40 in the item-level models to .52 in 2 -item parcel models, to .66 in 4-item parcel models, to .78 in 8-item parcel models. This pattern of means was consistent across all sample size conditions for the 32-item, 2-factor models and the 64-item, 4-factor models. For $\mathrm{s}=$ .70 models, mean indicator saturation increased from approximately .70 in the itemlevel models, to .81 in the 2 -item parcel models, to .89 in the 4 -item parcel models, to .94 in the 8 -item parcel models. This pattern of means was again consistent across all 
Table 11. Percent of Item and Parcel Solutions Meeting Standard Fit Criteria - Study 3

Model \#1: 32 Items, 2 Factors, Model \#2: 32 Items, 2 Factors,

\begin{tabular}{lccccccccc} 
& \multicolumn{3}{c}{ Saturation $=.40$} & & \multicolumn{3}{c}{ Saturation $=.70$} \\
\cline { 2 - 4 } Condition & $\mathrm{p} / \mathrm{f}=16$ & $\mathrm{p} / \mathrm{f}=8$ & $\mathrm{p} / \mathrm{f}=4$ & $\mathrm{p} / \mathrm{f}=2$ & & $\mathrm{p} / \mathrm{f}=16$ & $\mathrm{p} / \mathrm{f}=8$ & $\mathrm{p} / \mathrm{f}=4$ & $\mathrm{p} / \mathrm{f}=2$ \\
\hline GFI $>90$ & $50.0 \%$ & $75.0 \%$ & $99.3 \%$ & $100 \%$ & & $50.0 \%$ & $74.8 \%$ & $99.3 \%$ & $100 \%$ \\
CFI $>90$ & $64.3 \%$ & $93.5 \%$ & $99.5 \%$ & $100 \%$ & & $95.3 \%$ & $100 \%$ & $100 \%$ & $100 \%$ \\
NNFI $>.90$ & $62.5 \%$ & $91.8 \%$ & $96.8 \%$ & $98.6 \%$ & & $92.0 \%$ & $100 \%$ & $100 \%$ & $100 \%$ \\
RMSEA $<.05$ & $81.3 \%$ & $92.8 \%$ & $89.8 \%$ & $83.0 \%$ & & $81.0 \%$ & $92.0 \%$ & $88.5 \%$ & $82.3 \%$ \\
\hline
\end{tabular}

Model \#3: 64 Items, 4 Factors, $\quad$ Model \#4: 64 Items, 4 Factors, Saturation $=.40$

\begin{tabular}{|c|c|c|c|c|c|c|c|c|}
\hline \multirow[b]{2}{*}{ Condition } & \multicolumn{4}{|c|}{ Saturation $=.40$} & \multicolumn{4}{|c|}{ Saturation $=.70$} \\
\hline & $\mathrm{p} / \mathrm{f}=16$ & $\mathrm{p} / \mathrm{f}=8$ & $\mathrm{p} / \mathrm{f}=4$ & $\mathrm{p} / \mathrm{f}=2$ & $\mathrm{p} / \mathrm{f}=16$ & $\mathrm{p} / \mathrm{f}=8$ & $p / f=4$ & $\mathrm{p} / \mathrm{f}=2$ \\
\hline $\mathrm{GFI}>.90$ & $25.0 \%$ & $49.5 \%$ & $74.3 \%$ & $100 \%$ & $25.0 \%$ & $49.5 \%$ & $75.0 \%$ & $100 \%$ \\
\hline $\mathrm{CFI}>90$ & $41.0 \%$ & $76.5 \%$ & $97.3 \%$ & $100 \%$ & $74.0 \%$ & $99.8 \%$ & $100 \%$ & $100 \%$ \\
\hline $\mathrm{NNFI}>.90$ & $40.0 \%$ & $76.5 \%$ & $94.3 \%$ & $100 \%$ & $73.5 \%$ & $99.3 \%$ & $100 \%$ & $100 \%$ \\
\hline RMSEA $<.05$ & $75.0 \%$ & $82.5 \%$ & $90.0 \%$ & $95.3 \%$ & $75.0 \%$ & $82.5 \%$ & $91.0 \%$ & $96.3 \%$ \\
\hline
\end{tabular}


sample size conditions for the 32-item, 2-factor models and the 64-item, 4-factor models. The mean indicator saturation for each type of analysis across Study 3 conditions can be found in Table 12.

\section{DISCUSSION}

Given the results of Study 2, the results of Study 3 are not surprising. The same differences that were observed between item-level and two-item parcel-level solutions were also observed between the two-item parcel solutions and the four- and eight-item parcel solutions. The only surprising finding was the extent to which the dependent variables were different with the different analyses.

The results of this study were also consistent with the Marsh et al. (1998) study, at least in terms of the percent of proper converging solutions and fit indices. In the Marsh et al. study, the unstandardized item saturations did not increase in the parcellevel analyses, but it was noted that the standardized loadings would have increased.

The increase in fit indices across the different types of parcel-level solutions was dramatic, especially for GFI, CFI, and NNFI. This once again demonstrates the bias of the $\chi^{2}$ statistic in favor of models with a small number of indicators. Following the results of Study 2, it was noted that for parceled models stricter levels of acceptable fit indices may be appropriate. These results suggest that as the number of items per parcel increases, the level of acceptability for fit indices should be raised further.

A dramatic change in indicator saturations was also observed, as mean saturations for solutions with 8 -item parcels were consistently above .90 . Results such 
Table 12. Mean Indicator Saturation Across Conditions - Study 3

Model \#1: 32 Items, 2 Factors, $\quad$ Model \#2: 32 Items, 2 Factors,

\begin{tabular}{|c|c|c|c|c|c|c|c|c|}
\hline \multirow[b]{2}{*}{ Condition } & \multicolumn{4}{|c|}{ Saturation $=.40$} & \multicolumn{4}{|c|}{ Saturation $=.70$} \\
\hline & $\begin{array}{c}\text { Item } \\
\text { Model }\end{array}$ & $\begin{array}{l}\text { 2-Item } \\
\text { Parcels }\end{array}$ & $\begin{array}{l}\text { 4-Item } \\
\text { Parcels }\end{array}$ & $\begin{array}{l}\text { 8-Item } \\
\text { Parcels }\end{array}$ & $\begin{array}{c}\text { Item } \\
\text { Model }\end{array}$ & $\begin{array}{l}\text { 2-Item } \\
\text { Parcels }\end{array}$ & $\begin{array}{l}\text { 4-Item } \\
\text { Parcels }\end{array}$ & $\begin{array}{l}\text { 8-Item } \\
\text { Parcels }\end{array}$ \\
\hline All Models & .396 & .521 & .655 & .778 & .697 & .809 & .890 & .940 \\
\hline$N=75$ & .395 & .520 & .654 & .777 & .696 & .808 & .889 & .940 \\
\hline$N=150$ & .394 & .518 & .653 & .777 & .696 & .807 & .889 & .939 \\
\hline$N=300$ & .397 & .522 & .655 & .779 & .698 & .809 & .890 & .940 \\
\hline $\mathrm{N}=600$ & .399 & .524 & .657 & .778 & .699 & .810 & .890 & .941 \\
\hline
\end{tabular}

Model \#3: 64 Items, 4 Factors, $\quad$ Model \#4: 64 Items, 4 Factors, Saturation $=.40$ Saturation $=.70$

\begin{tabular}{lcccccccc} 
Condition & $\begin{array}{c}\text { Item } \\
\text { Model }\end{array}$ & $\begin{array}{c}\text { 2-Item } \\
\text { Parcels }\end{array}$ & $\begin{array}{c}\text { 4-Item } \\
\text { Parcels }\end{array}$ & $\begin{array}{c}\text { 8-Item } \\
\text { Parcels }\end{array}$ & $\begin{array}{c}\text { Item } \\
\text { Model }\end{array}$ & $\begin{array}{c}\text { 2-Item } \\
\text { Parcels }\end{array}$ & $\begin{array}{c}\text { 4-Item } \\
\text { Parcels }\end{array}$ & $\begin{array}{c}\text { 8-Item } \\
\text { Parcels }\end{array}$ \\
\hline All Models & .399 & .525 & .657 & .779 & .700 & .811 & .891 & .941 \\
$\mathrm{~N}=75$ & .400 & .526 & .659 & .777 & .700 & .812 & .891 & .940 \\
$\mathrm{~N}=150$ & .397 & .523 & .655 & .778 & .700 & .811 & .891 & .941 \\
$\mathrm{~N}=300$ & .400 & .525 & .658 & .780 & .700 & .811 & .891 & .941 \\
$\mathrm{~N}=600$ & .400 & .525 & .658 & .779 & .700 & .811 & .891 & .941 \\
\hline
\end{tabular}

Note: $\mathrm{N}=$ Sample Size 
as this may be misleading for researchers who are not aware of the systematic increase due to parceling. This was a clear demonstration that saturations are systematically increased when the number of items per parcel is increased. High parcel saturations my cover up poor individual items that would not have significant loadings on their own.

Overall, Study 3 showed how the same data analyzed in different ways can lead to very different results. As more items are added to each parcel, the parcel's saturation increases. This contributes to an improvement in fit indices. The number of indicators per factor is also decreased, again contributing to improved fit indices, although not as strong a test of theory. The results of Study 2 showed the differences between itemlevel and parcel-level analyses. Study 3 extended this and showed that the differences become greater as the number of items per parcel increases. 


\section{CHAPTER 5}

\section{Evaluating the Effects of Item Parceling}

\section{When The Parceling Assumption Is Violated. (Study 4)}

As the title suggests, the purpose of Study 4 was to examine the consequences of item parceling when the parceling assumption is violated. When the parceling assumption is violated, items that are not unidimensional are combined to form parcels. Within the description of Study 4, parceled indicators that are not unidimensional will be referred to as non-unidimensional parcels.

Unidimensionality is a critical assumption of parcels (see Chapter 1 ) that is rarely given attention in journal articles (see Chapter 2). Breaking this assumption should lead to decreased loadings, fit indices, and percent of proper converging solutions. However, Studies 2-3 showed that reducing the number of indicators and increasing saturations resulted in improved fit indices. This study may show which of these two forces has a greater effect on the fit indices. Because this could differ by model structure and the way in which non-unidimensional parcels are formed, eleven different model structures were examined.

\section{METHOD \& RESULTS}

As with Studies 2-3, only specific structures of measurement models were examined. Eleven different models were tested. All models were simulated from specifications of univariate and multivariate normality (skewness and kurtosis equal to 0.0 ), item saturations of .40 and .70 , factor correlations of .30 , and sample sizes of 75 , 150,300 , and 600 . There were 100 replications of each model. EQS was used to 
simulate the data and to analyze the item- and parcel-level models. All models were estimated with maximum likelihood. Factor variances were fixed at unity and factor loadings, uniquenesses, and factor correlations were freely estimated. The maximum number of iterations was fixed at 500 and the admissibility check was turned off. Default starting values provided by EQS were used.

The dependent variables examined were the same as with Studies 2-3: indicator saturations, four fit indices, and the percent of proper converging solutions. The four fit indices examined were GFI, CFI, NNFI, and RMSEA. Mean saturations and fit indices were compared with paired-sample t-tests while the percent of proper converging solutions were compared with chi-squared tests.

Within each model structure, the only independent variables manipulated were sample size and saturation. The sample sizes were $75,150,300$, and 600 . These were meant simply to add some variation to the data simulation and were not analyzed separately. The two levels of item saturation were .40 and .70 . Within each model structure $s=.40$ and $s=.70$ models were examined separately. All parcels were composites of two or three items, depending on the model structure.

For each level of sample size, 200 simulations were performed, including 100 when $\mathrm{s}=.40$ and 100 when $\mathrm{s}=.70$. Hence, there were 800 simulations for each model structure.

Of the eleven specified models, the first six were examined with a parcel-level analysis that included fewer factors than in the true model. Models 7 and 8 were examined with a parcel-level analysis that had the correct number of factors specified, but two parcels were incorrectly formed. Models 9 and 10 were examined with parcel- 
level analyses that had more factors specified than in the true model. Thus in all eleven models, the parcel-level analysis will be mis-specified. For each model, a description of the model will be followed by the results of the item- and parcel-level analyses.

Model \#1

Model \#1 Description. The first of these eleven models included eight items in the true model. Three correlated factors were specified, represented by two, four, and two items each. However, in the parcel-level analyses all parcels were indicators of a single factor. Each parcel included one item that was an indicator of the second factor of the true model. All parcels were therefore formed from items that were true indicators of different constructs, in terms of the true data set being generated, making each parcel non-unidimensional. This model is presented in Figure 7.

Model \#1 Results. The mean indicator saturation, percent of proper converging solutions, and mean fit indices for Model \#1 can be found in Table 13. For models in which $\mathrm{s}=.40$, parcel-level analyses produced proper converged solutions in $94.0 \%$ of the 400 simulations compared to only $49.5 \%$ for the item-level analyses. For models in which $s=.70$, parcel-level analyses again had a significantly higher rate of proper convergence, $100.0 \%$ to $78.0 \%$.

In $\mathrm{s}=.40$ models, the mean fit indices for the item-level models was already approaching asymptotic behavior. There was little room for improvement in the parcellevel analyses, and the mean GFI, CFI, and NNFI were approximately the same. Mean RMSEA increased from .010 in the item-level analyses to .034 in the parcel-level analyses. For the $s=.70$ models, the mean fit indices were worse in the parcel-level models. 
Figure 7. Visual representation of the true and mis-specified model \#1 of study \#4.

Correctly Specified Item Model

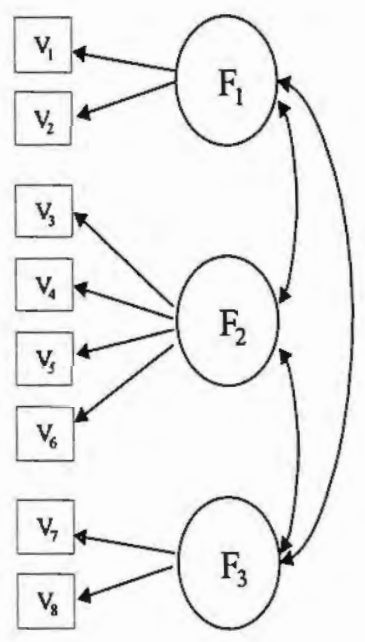

Mis-Specified Paroeled Model

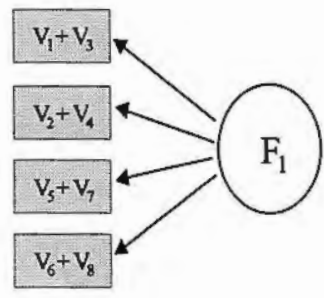

Note: Shaded boxes indicate non-unidimensional parcels 
Table 13. Model \#1 Comparisons - Study 4

\begin{tabular}{lcccc} 
& \multicolumn{4}{c}{ Saturation $=.40$} \\
\cline { 2 - 5 } Comparison & $\begin{array}{c}\text { Item } \\
\text { Model }\end{array}$ & $\begin{array}{c}\text { Parceled } \\
\text { Model }\end{array}$ & tor $\chi^{2}$ & $\mathrm{p}$ \\
\hline \% Proper Converging & $49.5 \%$ & $94.0 \%$ & 195.39 & $<.001$ \\
& & & & \\
Mean GFI & .985 & .995 & 11.17 & $<.001$ \\
Mean CFI & .971 & .966 & 0.76 & NS \\
Mean NNFI & 1.119 & .964 & 2.75 & $<.001$ \\
Mean RMSEA & .010 & .034 & 8.39 & $<.001$ \\
& & & & \\
\% GFI > .90 & $100 \%$ & $100 \%$ & 0.00 & NS \\
\% CFI > .90 & $81.5 \%$ & $82.0 \%$ & 0.03 & NS \\
\% NNFI $>.90$ & $75.0 \%$ & $61.5 \%$ & 16.82 & $<.001$ \\
\% RMSEA $<.05$ & $89.5 \%$ & $63.5 \%$ & 75.21 & $<.001$ \\
& & & & \\
Mean Saturation & .415 & .460 & 0.43 & NS \\
\hline
\end{tabular}

\begin{tabular}{lcccc} 
& \multicolumn{4}{c}{ Saturation $=.70$} \\
\cline { 2 - 5 } Comparison & $\begin{array}{c}\text { Item } \\
\text { Model }\end{array}$ & $\begin{array}{c}\text { Parceled } \\
\text { Model }\end{array}$ & t or $\chi^{2}$ & $\mathrm{p}$ \\
\hline \% Proper Converging & $78.0 \%$ & $100 \%$ & 98.88 & $<.001$ \\
& & & & \\
Mean GFI & .980 & .951 & 20.09 & $<.001$ \\
Mean CFI & .994 & .916 & 32.75 & $<.001$ \\
Mean NNFI & 1.000 & .749 & 35.59 & $<.001$ \\
Mean RMSEA & .015 & .020 & 53.87 & $<.001$ \\
& & & & \\
\% GFI $>.90$ & $100 \%$ & $96.8 \%$ & 13.21 & $<.001$ \\
\% CFI $>.90$ & $99.8 \%$ & $65.5 \%$ & 163.42 & $<.001$ \\
$\%$ NNFI $>.90$ & $96.5 \%$ & $10.3 \%$ & 597.85 & $<.001$ \\
$\%$ RMSEA $<.05$ & $85.8 \%$ & $3.3 \%$ & 551.17 & $<.001$ \\
& & & & \\
Mean Saturation & .703 & .676 & 22.11 & $<.001$ \\
\hline
\end{tabular}


Mean indicator saturation was not significantly different by type of analysis when $\mathrm{s}=.40$. However, when $\mathrm{s}=.70$, mean indicator saturation was significantly higher in the item-level analyses, .703 vs. .676 .

\section{Model \#2}

Model \#2 Description. In model structure \#2, three factors were indicated by five items each in the true model. Three of the five parcel indicators were formed by summing items from the same factor. The other two parcels were non-unidimensional, formed from two items from one factor and one item from another. This model is presented in Figure 8.

Model \#2 Results. The mean indicator saturation, percent of proper converging models, and mean fit indices for Model $\# 2$ can be found in Table 14. For models in which $\mathrm{s}=.40$, parcel-level analyses produced proper converged solutions in $95.8 \%$ of simulations compared to $92.8 \%$ of the item-level analyses. These percentages were not significantly different. For models in which $\mathrm{s}=.70$, item-level analyses had a significantly higher rate of convergence, $100.0 \%$ to $92.5 \%$.

In $\mathrm{s}=.40$ models, GFI and RMSEA improved slightly in the parcel-level analyses. However, CFI and NNFI were drastically reduced. In terms of the percent of solutions meeting standard fit criteria, parcel-level analyses had a significantly higher percentage only for GFI ( $99.8 \%$ vs. $75.5 \%$ ). The percent meeting standard criteria for CFI, NNFI, and RMSEA was much higher in the item-level analyses. When $\mathrm{s}=.70$, all fit indices were much better in item-level models. Also, the percent of models meeting fit criteria was significantly greater in item-level models for all fit indices. 
Figure 8. Visual representation of the true and mis-specified model \#2 of study \#4.

Correctly Specified Item Model

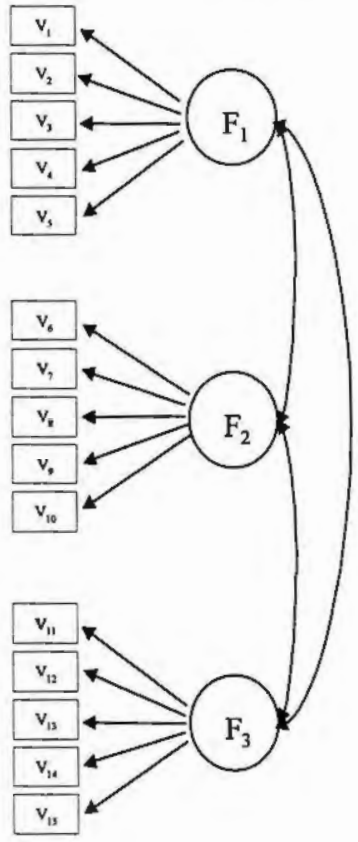

Mis-Specified Parceled Model

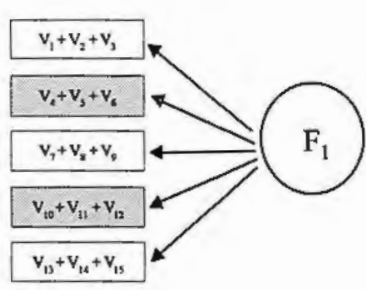

Note: Shaded boxes indicate non-unidimensional parcels 
Table 14. Model \#2 Comparisons-Study 4

\begin{tabular}{lcccc} 
& \multicolumn{4}{c}{ Saturation $=.40$} \\
\cline { 2 - 5 } Comparison & $\begin{array}{c}\text { Item } \\
\text { Model }\end{array}$ & $\begin{array}{c}\text { Parceled } \\
\text { Model }\end{array}$ & t or $\chi^{2}$ & $p$ \\
\hline \% Proper Converging & $92.8 \%$ & $95.8 \%$ & 3.32 & NS \\
& & & & \\
Mean GFI & .940 & .967 & 13.79 & $<.001$ \\
Mean CFI & .949 & .802 & 19.31 & $<.001$ \\
Mean NNFI & .998 & .614 & 20.37 & $<.001$ \\
Mean RMSEA & .015 & .010 & 38.29 & $<.001$ \\
& & & & \\
\% GFI $>.90$ & $75.5 \%$ & $99.8 \%$ & 108.46 & $<.001$ \\
\% CFI > .90 & $79.0 \%$ & $23.5 \%$ & 246.57 & $<.001$ \\
\% NNFI >.90 & $75.5 \%$ & $12.3 \%$ & 324.92 & $<.001$ \\
\% RMSEA $<.05$ & $89.5 \%$ & $10.5 \%$ & 499.28 & $<.001$ \\
Mean Saturation & .396 & .410 & 6.12 & $<.001$ \\
\hline
\end{tabular}

\begin{tabular}{lcccc} 
& \multicolumn{4}{c}{ Saturation $=.70$} \\
\cline { 2 - 5 } Comparison & $\begin{array}{c}\text { Item } \\
\text { Model }\end{array}$ & $\begin{array}{c}\text { Parceled } \\
\text { Model }\end{array}$ & tor $\chi^{2}$ & $\mathrm{p}$ \\
\hline \% Proper Converging & $100 \%$ & $92.5 \%$ & 31.17 & $<.001$ \\
& & & & \\
Mean GFI & .934 & .831 & 40.35 & $<.001$ \\
Mean CFI & .989 & .656 & 100.21 & $<.001$ \\
Mean NNFI & .991 & .312 & 105.24 & $<.001$ \\
Mean RMSEA & .017 & .331 & 155.72 & $<.001$ \\
& & & & \\
\% GFI $>.90$ & $75.5 \%$ & $1.5 \%$ & 462.55 & $<.001$ \\
\% CFI $>.90$ & $99.3 \%$ & $0.3 \%$ & 784.10 & $<.001$ \\
\% NNFI $>.90$ & $98.0 \%$ & $0.0 \%$ & 768.63 & $<.001$ \\
\% RMSEA $<.05$ & $91.0 \%$ & $0.0 \%$ & 667.89 & $<.001$ \\
& & & & \\
Mean Saturation & .696 & .586 & 52.24 & $<.001$ \\
\hline
\end{tabular}


Mean indicator saturation was greater in parcel-level analyses, .410 vs. .396 , when $\mathrm{s}=.40$. However, when $\mathrm{s}=.70$, mean indicator saturation was significantly higher in the item-level analyses, .696 vs. .586 .

\section{Model \#3}

Model \#3 Description. The third model structure was the same as model \#2, but all five parcels were non-unidimensional. Each parcel included two items from the same factor and one item from a different factor. This model is presented in Figure 9.

Model \#3 Results. The mean indicator saturation, percent of proper converging models, and mean fit indices for Model \#3 can be found in Table 15. When $\mathrm{s}=.40$, parcel-level analyses produced proper converged solutions in $98.8 \%$ of simulations compared to $94.4 \%$ of the item-level analyses. For s $=.70$ models, $100 \%$ of item- and parcel-level solutions were proper converging.

In $s=.40$ models, mean GFI was significantly better in parcel-level analyses (.980) compared to item-level analyses (.939). Mean CFI, NNFI, and RMSEA were significantly better in item-level analyses. In terms of the percent of solutions meeting standard fit criteria, parcel-level analyses had a significantly higher percentage only for GFI $(100 \%$ vs. $75.3 \%)$. The percent meeting standard criteria for CFI, NNFI, and RMSEA were significantly better in item-level than parcel-level analyses. When $\mathrm{s}=$ .70 , all fit indices were significantly better in item-level models. Also, the percent of models meeting fit criteria was significantly greater in item-level models for all fit indices.

Mean indicator saturation was greater in parcel-level analyses, .447 vs. .397 , when $\mathrm{s}=.40$. However, when $\mathrm{s}=.70$, mean indicator saturation was significantly 
Figure 9. Visual representation of the true and mis-specified model \#3 of study \#4.

Correctly Specified Item Model

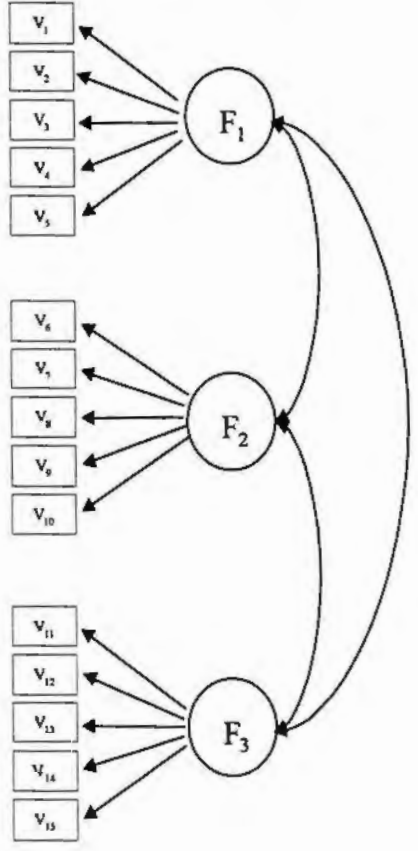

Mis-Specified Parceled Model

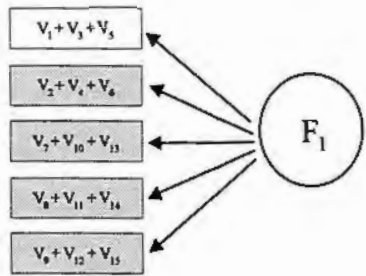

Note: Shaded boxes indicate non-unidimensional parcels 
Table 15. Model \#3 Comparisons - Study 4

\begin{tabular}{lcccc} 
& \multicolumn{4}{c}{ Saturation $=.40$} \\
\cline { 2 - 5 } Comparison & $\begin{array}{c}\text { Item } \\
\text { Model }\end{array}$ & $\begin{array}{c}\text { Parceled } \\
\text { Model }\end{array}$ & t or $\chi^{2}$ & $\mathrm{p}$ \\
\hline \% Proper Converging & $94.0 \%$ & $98.8 \%$ & 12.92 & $<.001$ \\
& & & & \\
Mean GFI & .939 & .980 & 21.45 & $<.001$ \\
Mean CFI & .945 & .921 & 4.13 & $<.001$ \\
Mean NNFI & .994 & .874 & 7.88 & $<.001$ \\
Mean RMSEA & .015 & .060 & 20.50 & $<.001$ \\
& & & & \\
\% GFI > 90 & $75.3 \%$ & $100 \%$ & 112.98 & $<.001$ \\
\% CFI $>.90$ & $77.8 \%$ & $69.5 \%$ & 7.10 & $<.01$ \\
\% NNFI $>.90$ & $74.5 \%$ & $41.3 \%$ & 90.44 & $<.001$ \\
\% RMSEA $<.05$ & $91.5 \%$ & $35.0 \%$ & 274.67 & $<.001$ \\
& & & & \\
Mean Saturation & .397 & .447 & 27.89 & $<.001$ \\
\hline
\end{tabular}

\begin{tabular}{lcccc} 
& \multicolumn{4}{c}{ Saturation $=.70$} \\
\cline { 2 - 5 } Comparison & $\begin{array}{c}\text { Item } \\
\text { Model }\end{array}$ & $\begin{array}{c}\text { Parceled } \\
\text { Model }\end{array}$ & $\mathrm{t}$ or $\chi^{2}$ & $\mathrm{p}$ \\
\hline \% Proper Converging & $100 \%$ & $100 \%$ & 0.00 & NS \\
& & & & \\
Mean GFI & .933 & .876 & 23.04 & $<.001$ \\
Mean CFI & .988 & .829 & 70.15 & $<.001$ \\
Mean NNFI & .990 & .657 & 75.80 & $<.001$ \\
Mean RMSEA & .018 & .249 & 121.96 & $<.001$ \\
& & & & \\
\% GFI $>.90$ & $75.0 \%$ & $16.0 \%$ & 280.75 & $<.001$ \\
\% CFI $>.90$ & $99.5 \%$ & $3.8 \%$ & 734.22 & $<.001$ \\
\% NNFI $>.90$ & $98.5 \%$ & $0.0 \%$ & 776.35 & $<.001$ \\
\% RMSEA $<.05$ & $89.5 \%$ & $0.0 \%$ & 647.96 & $<.001$ \\
& & & & \\
Mean Saturation & .700 & .687 & 10.96 & $<.001$ \\
\hline
\end{tabular}


higher in the item-level analyses, .700 vs. .687. The mean indicator saturation, percent of proper converging models, and mean fit indices for Model \#3 can be found in Table 15.

\section{$\underline{\text { Model \#4 }}$}

Model \#4 Description. The fourth model structure again included five nonunidimensional parcels. These 3-item parcels were formed from one item from each factor. This model is presented in Figure 10.

Model \#4 Results. . The mean indicator saturation, percent of proper converging models, and mean fit indices for Model $\# 4$ can be found in Table 16. When $s=.40$, parcel-level analyses produced proper converged solutions in $100 \%$ of simulations compared to $92.8 \%$ of the item-level analyses. For $\mathrm{s}=.70$ models, all item- and parcellevel solutions were proper converging.

For both $\mathrm{s}=.40$ and $\mathrm{s}=.70$ models, mean GFI, CFI, and NNFI improved with the parcel-level analyses. RMSEA stayed approximately the same for both types of analyses. In terms of the percent of solutions meeting standard fit criteria, similar patterns were present. The percent meeting criteria for GFI, CFI, and NNFI improved with the parcel-level analysis, while the percent for RMSEA decreased.

Mean indicator saturation was greater in parcel-level analyses, .485 vs. . 400 , when $\mathrm{s}=.40$. When $\mathrm{s}=.70$, mean indicator saturation was also significantly higher in the parcel-level analyses, .778 vs. 699 . 
Figure 10. Visual representation of the true and mis-specified model \#4 of study \#4.

Correctly Specified Item Model

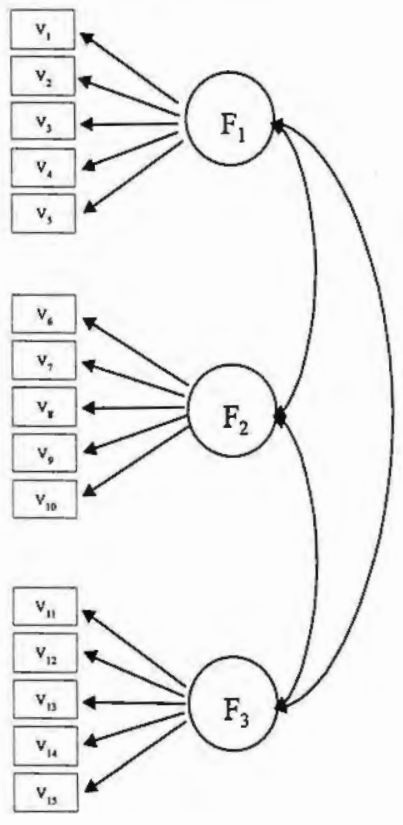

Mis-Specified Parceled Model

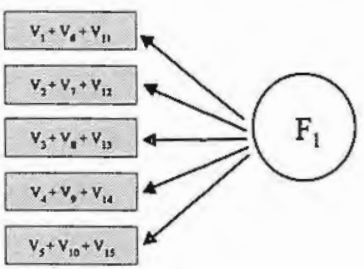

Note: Shaded boxes indicate non-unidimensional parcels 
Table 16. Model \#4 Comparisons - Study 4

\begin{tabular}{|c|c|c|c|c|}
\hline \multirow[b]{2}{*}{ Comparison } & \multicolumn{4}{|c|}{ Saturation $=.40$} \\
\hline & $\begin{array}{c}\text { Item } \\
\text { Model }\end{array}$ & $\begin{array}{c}\text { Parceled } \\
\text { Model }\end{array}$ & $\operatorname{tor} \chi^{2}$ & $\mathrm{p}$ \\
\hline$\%$ Proper Converging & $92,8 \%$ & $100 \%$ & 30.09 & $<.001$ \\
\hline Mean GFI & .939 & .989 & 27.39 & $<.001$ \\
\hline Mean CFI & .944 & .985 & 9.53 & $<.001$ \\
\hline Mean NNFI & .989 & 1.014 & 1.87 & NS \\
\hline Mean RMSEA & .016 & .018 & 1.25 & NS \\
\hline$\%$ GFI $>.90$ & $76.3 \%$ & $100 \%$ & 107.80 & $<.001$ \\
\hline$\%$ CFI $>.90$ & $77.8 \%$ & $94.0 \%$ & 43.54 & $<.001$ \\
\hline$\%$ NNFI > .90 & $73.5 \%$ & $88.8 \%$ & 30.38 & $<.001$ \\
\hline$\%$ RMSEA $<.05$ & $92.8 \%$ & $84.5 \%$ & 13.50 & $<.001$ \\
\hline Mean Saturation & .400 & .485 & 60.84 & $<.001$ \\
\hline & \multicolumn{4}{|c|}{ Saturation $=.70$} \\
\hline Comparison & $\begin{array}{c}\text { Item } \\
\text { Model }\end{array}$ & $\begin{array}{c}\text { Parceled } \\
\text { Model }\end{array}$ & $\operatorname{tor} x^{2}$ & $\mathrm{p}$ \\
\hline$\%$ Proper Converging & $100 \%$ & $100 \%$ & 0.00 & NS \\
\hline Mean GFI & .934 & .988 & 27.87 & $<.001$ \\
\hline Mean CFI & .989 & .997 & 8.68 & $<.001$ \\
\hline Mean NNFI & .993 & 1.002 & 5.65 & $<.001$ \\
\hline Mean RMSEA & .017 & .020 & 1.82 & NS \\
\hline$\%$ GFI $>.90$ & $75.3 \%$ & $100 \%$ & 112.98 & $<.001$ \\
\hline$\%$ CFI $>.90$ & $99.8 \%$ & $100 \%$ & 1.00 & NS \\
\hline$\%$ NNFI > .90 & $98.5 \%$ & $99.8 \%$ & 3.60 & NS \\
\hline$\%$ RMSEA $<.05$ & $92.8 \%$ & $82.0 \%$ & 20.95 & $<.001$ \\
\hline Mean Saturation & .699 & .778 & 115.52 & $<.001$ \\
\hline
\end{tabular}


Model \#5 Description. The fifth model structure was specified by three factors indicated by two, two and four items each. In the parceled model, the first pair of items were combined to form parcel indicators for a factor. The second pair of items were combined to form a parcel indicator for a second factor. Each of these two factors also had a second parcel indicator, formed from two items from the third factor in the specified model. This model is presented in Figure 11.

Model \#5 Results. The mean indicator saturation, percent of proper converging models, and mean fit indices for Model \#5 can be found in Table 17. When $\mathrm{s}=.40$, parcel-level analyses produced proper converged solutions in $72.3 \%$ of simulations compared to $48.5 \%$ of the item-level analyses. When $s=.70$, parcel-level analyses produced proper converged solutions in $98.0 \%$ of simulations compared to $83.0 \%$ of the item-level analyses.

For both $\mathrm{s}=.40$ and $\mathrm{s}=.70$ models, mean GFI, CFI, and NNFI were at extremely high levels in the item-level analysis. With little room for improvement, the mean GFI, CFI, and NNFI stayed approximately the same in the parcel-level analyses. The mean RMSEA was significantly better in the item-level analyses. The percent meeting standard criteria increased for GFI, CFI, and NNFI in the parcel-level models, while the percent meeting criteria for RMSEA decreased in the parcel-level models.

Mean indicator saturation was greater in parcel-level analyses, .466 vs. .413, when $s=.40$. When $\mathrm{s}=.70$, mean indicator saturation was also significantly higher in the parcel-level analyses, .746 vs. .702 . 
Figure 11. Visual representation of the true and mis-specified model \#5 of study \#4.

Correctly Specified Item Model

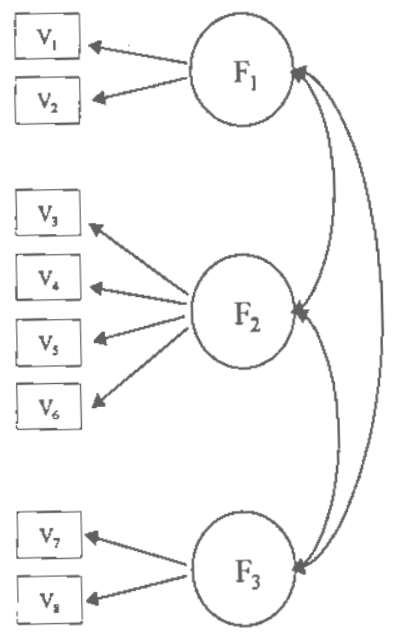

Mis-Specified Parceled Model
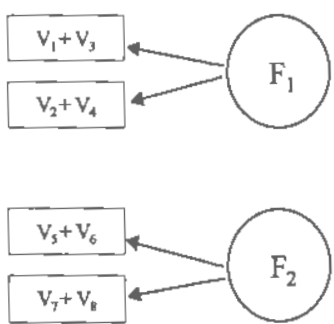
Table 17. Model \#5 Comparisons - Study 4

\begin{tabular}{lcccc} 
& \multicolumn{4}{c}{ Saturation $=.40$} \\
\cline { 2 - 4 } Comparison & $\begin{array}{c}\text { Item } \\
\text { Model }\end{array}$ & $\begin{array}{c}\text { Parceled } \\
\text { Model }\end{array}$ & t or $\chi^{2}$ & $\mathrm{p}$ \\
\hline \% Proper Converging & $48.5 \%$ & $72.3 \%$ & 47.16 & $<.001$ \\
Mean GFI & .985 & .998 & 15.44 & $<.001$ \\
Mean CFI & .973 & .987 & 2.69 & $<.001$ \\
Mean NNFI & 1.124 & 1.036 & 1.87 & $\mathrm{NS}$ \\
Mean RMSEA & .012 & .021 & 3.49 & $<.01$ \\
& & & & \\
\% GFI > 90 & $99.8 \%$ & $100 \%$ & 1.00 & $\mathrm{NS}$ \\
\% CFI $>.90$ & $80.5 \%$ & $90.8 \%$ & 17.07 & $<.001$ \\
\% NNFI > 90 & $72.5 \%$ & $75.8 \%$ & 1.10 & $\mathrm{NS}$ \\
\% RMSEA $<.05$ & $88.3 \%$ & $77.8 \%$ & 15.63 & $<.001$ \\
Mean Saturation & .413 & .466 & 19.96 & $<.001$ \\
\hline
\end{tabular}

\begin{tabular}{lcccc} 
& \multicolumn{4}{c}{ Saturation $=.70$} \\
\cline { 2 - 5 } Comparison & $\begin{array}{c}\text { Item } \\
\text { Model }\end{array}$ & $\begin{array}{c}\text { Parceled } \\
\text { Model }\end{array}$ & t or $\chi^{2}$ & $\mathrm{p}$ \\
\hline \% Proper Converging & $83.0 \%$ & $98.0 \%$ & 52.34 & $<.001$ \\
& & & & \\
Mean GFI & .979 & .997 & 21.29 & $<.001$ \\
Mean CFI & .994 & .997 & 4.02 & $<.001$ \\
Mean NNFI & 1.002 & .999 & 0.73 & $\mathrm{NS}$ \\
Mean RMSEA & .015 & .025 & 3.93 & $<.001$ \\
& & & & \\
\% GFI $>.90$ & $100 \%$ & $100 \%$ & 0.00 & $\mathrm{NS}$ \\
\% CFI > .90 & $99.0 \%$ & $100 \%$ & 4.02 & $\mathrm{NS}$ \\
\% NNFI $>.90$ & $97.5 \%$ & $92.8 \%$ & 9.73 & $\mathrm{NS}$ \\
\% RMSEA $<.05$ & $87.8 \%$ & $77.0 \%$ & 15.92 & $<.001$ \\
& & & & \\
Mean Saturation & .702 & .746 & 48.42 & $<.001$ \\
\hline
\end{tabular}




\section{Model \#6}

Model \#6 Description. In the sixth model structure, the true model will have four factors indicated by $4,8,4,8,12$ and 12 items, for a total of 48 items. The items from the first factor were combined to form two parcels. The items from the second factor were combined to form four parcels. These six parcels were indicators of the first factor in the parceled model. Similarly, the items from the third factor were combined to fom two parcels while the items from the fourth factor were combined to form four parcels. These six parcels were the indicators for the second factor in the parcel model. The 12 items from the fifth factor formed six parcels, which were the indicators for the third factor in the parcel model. Similarly, the 12 items from the sixth factor formed six parcels, which were the indicators for the fourth factor in the parcel model. This model is presented in Figure 12.

Model \#6 Results. The mean indicator saturation, percent of proper converging models, and mean fit indices for Model $\# 6$ can be found in Table 18 . When $s=.40$, parcel-level analyses produced proper converged solutions in $98.8 \%$ of simulations compared to $91.0 \%$ of the item-level analyses. When $s=.70,100 \%$ of item and parcellevel analyses converged to proper solutions.

In $s=.40$ models, mean GFI, CFI, and NNFI were significantly better in parcellevel analyses compared to item-level analyses. The mean RMSEA was significantly better in item-level analyses, .027 vs. .033 . In terms of the percent of solutions meeting standard fit criteria, parcel-level analyses had a significantly higher percentage for all fit indices. When $\mathrm{s}=.70$, the mean GFI was significantly better in parcel-level models, 
Figure 12. Visual representation of the true and mis-specified model \#6 of study \#4.

Conecty Specified Item Model
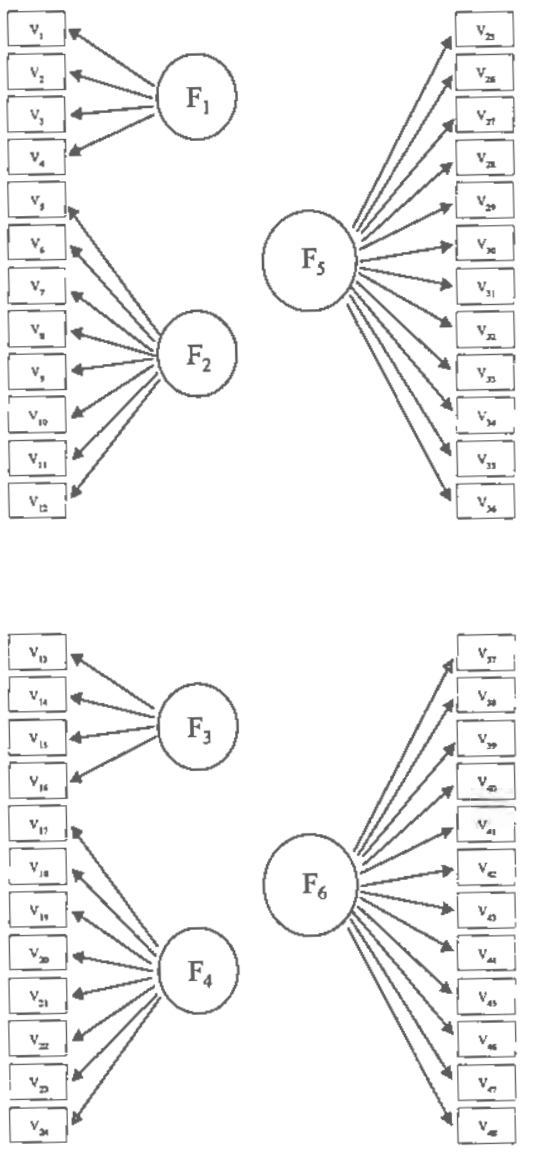

Mis-Specified Parceled Model
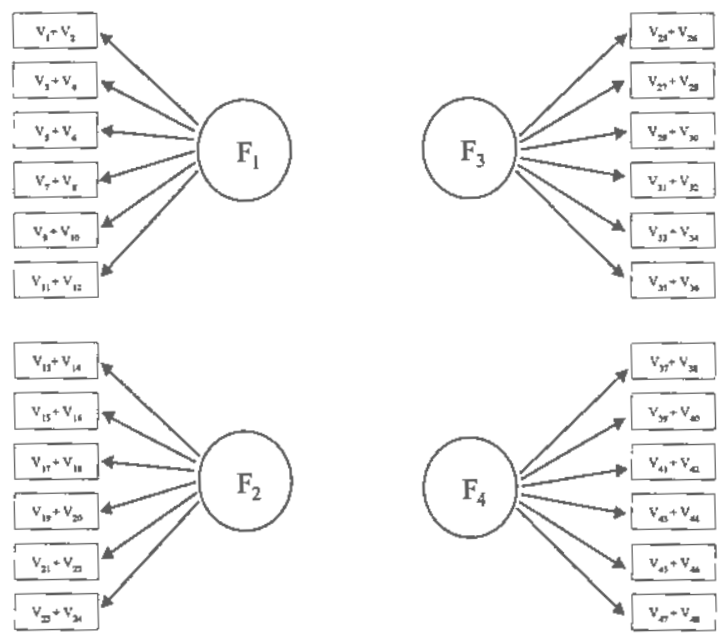

Notes: In the item model, all factors had specified correlations of .30 with every other factor.

In the parcel model, all factors had freely estimated correlations with all other factors. 
Table 18. Model \#6 Comparisons - Study 4

\begin{tabular}{lcccc} 
& \multicolumn{4}{c}{ Saturation $=.40$} \\
\cline { 2 - 5 } Comparison & $\begin{array}{c}\text { Item } \\
\text { Model }\end{array}$ & $\begin{array}{c}\text { Parceled } \\
\text { Model }\end{array}$ & tor $\chi^{2}$ & $\mathrm{P}$ \\
\hline \% Proper Converging & $91.0 \%$ & $98.8 \%$ & 24.71 & $<.001$ \\
& & & & \\
Mean GFI & .816 & .889 & 30.47 & $<.001$ \\
Mean CFI & .808 & .899 & 10.18 & $<.001$ \\
Mean NNFI & .798 & .888 & 9.49 & $<.001$ \\
Mean RMSEA & .027 & .033 & 7.04 & $<.001$ \\
& & & & \\
\% GFI > .90 & $25.0 \%$ & $50.0 \%$ & 53.33 & $<.001$ \\
\% CFI $>.90$ & $46.0 \%$ & $59.5 \%$ & 14.62 & $<.001$ \\
\% NNFI > .90 & $44.8 \%$ & $52.5 \%$ & 4.81 & NS \\
\% RMSEA $<.05$ & $75.0 \%$ & $84.8 \%$ & 11.83 & $<.001$ \\
& & & & \\
Mean Saturation & .399 & .471 & 113.92 & $<.001$ \\
\hline
\end{tabular}

\begin{tabular}{lcccc} 
& \multicolumn{4}{c}{ Saturation $=.70$} \\
\cline { 2 - 5 } Comparison & $\begin{array}{c}\text { Item } \\
\text { Model }\end{array}$ & $\begin{array}{c}\text { Parceled } \\
\text { Model }\end{array}$ & tor $\chi^{2}$ & $\mathrm{p}$ \\
\hline \% Proper Converging & $100 \%$ & $100 \%$ & 0.00 & $\mathrm{NS}$ \\
& & & & \\
Mean GFI & .799 & .826 & 9.09 & $<.001$ \\
Mean CFI & .931 & .905 & 6.99 & $<.001$ \\
Mean NNFI & .927 & .893 & 8.55 & $<.001$ \\
Mean RMSEA & .031 & .074 & 38.20 & $<.001$ \\
& & & & \\
\% GFI $>.90$ & $25.0 \%$ & $1.0 \%$ & 101.86 & $<.001$ \\
\% CFI > .90 & $75.0 \%$ & $70.5 \%$ & 2.04 & NS \\
\% NNFI $>.90$ & $75.0 \%$ & $45.5 \%$ & 72.67 & $<.001$ \\
\% RMSEA $<.05$ & $75.0 \%$ & $0.0 \%$ & 480.00 & $<.001$ \\
& & & & \\
Mean Saturation & .699 & .721 & 45.48 & $<.001$ \\
\hline
\end{tabular}


.826 vs. .799 . Mean CFI, NNFI, and RMSEA were significantly better in item-level models. The percent of models meeting fit criteria was significantly greater in itemlevel models for GFI, NNFI, and RMSEA. This percentage was approximately the same for mean CFI by analysis type.

Mean indicator saturation was greater in parcel-level analyses, .471 vs. .399 , when $\mathrm{s}=.40$. When $\mathrm{s}=.70$, mean indicator saturation was also significantly higher in the parcel-level analyses, .721 vs. .699 .

\section{Model \#7}

Model \#7 Description. The seventh model structure had the same true model as the sixth, but the formation of the parcels was different. In the parceled model, the first factor had four parcels that were non-unidimensional, formed from one item each from the first and second factor of the true model. Two of the parcel indicators were unidimensional, formed from the remaining four items of the second factor. Similarly, the second factor of the parcel model was indicated by four non-unidimensional and two unidimensional parcels. The unidimensional parcels were formed from the third and fourth factors of the true model in the same way as the indicators of the first factor were formed. The third and fourth factors in the parcel model were indicated by unidimensional parcels, formed from the items of factors five and six of the true model. This model is presented in Figure 13.

Model \#7 Results. The mean indicator saturation, percent of proper converging models, and mean fit indices for Model \#7 can be found in Table 19. When $s=.40$, parcel-level analyses produced proper converged solutions in $99.5 \%$ of simulations 
Figure 13. Visual representation of the true and mis-specified model \#7 of study \#4.

Correctly Specified Item Model
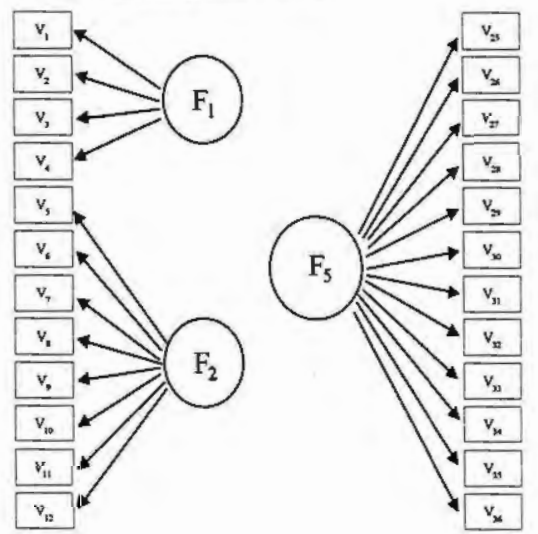

Mis-Specified Parceled Model
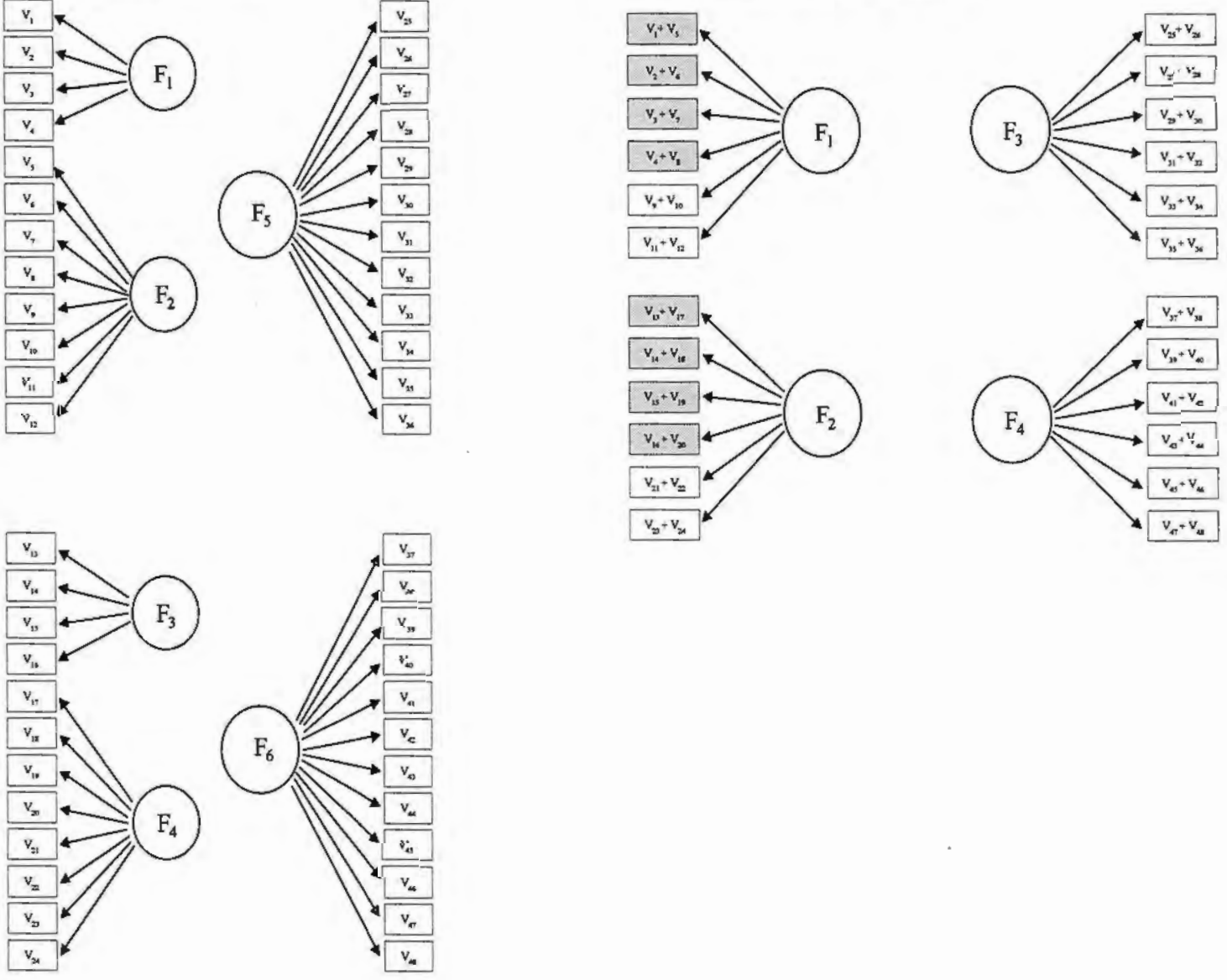

Notes: Shaded boxes represent non-unidimensional parcels.

In the item model, all factors had specified correlations of .30 with every other factor.

In the parcel model, all factors had freely estimated correlations with all other factors. 
Table 19. Model \#7 Comparisons - Study 4

\begin{tabular}{|c|c|c|c|c|}
\hline \multirow[b]{2}{*}{ Comparison } & \multicolumn{4}{|c|}{ Saturation $=.40$} \\
\hline & $\begin{array}{c}\text { Item } \\
\text { Model }\end{array}$ & $\begin{array}{c}\text { Parceled } \\
\text { Model }\end{array}$ & t or $\chi^{2}$ & $\mathrm{p}$ \\
\hline$\%$ Proper Converging & $90.8 \%$ & $99.5 \%$ & 33.02 & $<.001$ \\
\hline Mean GFI & .815 & .900 & 36.46 & $<.001$ \\
\hline Mean CFI & .806 & .950 & 16.30 & $<.001$ \\
\hline Mean NNFI & .796 & .949 & 16.36 & $<.001$ \\
\hline Mean RMSEA & .027 & .019 & 9.90 & $<.001$ \\
\hline$\% \mathrm{GFI}>.90$ & $25.0 \%$ & $50.0 \%$ & 53.33 & $<.001$ \\
\hline$\%$ CFI $>.90$ & $45.0 \%$ & $80.3 \%$ & 106.17 & $<.001$ \\
\hline$\%$ NNFI $>.90$ & $44.3 \%$ & $78.0 \%$ & 95.87 & $<.001$ \\
\hline$\%$ RMSEA $<.05$ & $75.0 \%$ & $90.3 \%$ & 32.40 & $<.001$ \\
\hline Mean Saturation & .399 & .485 & 167.64 & $<.001$ \\
\hline & \multicolumn{4}{|c|}{ Saturation $=.70$} \\
\hline Comparison & $\begin{array}{c}\text { Item } \\
\text { Model }\end{array}$ & $\begin{array}{c}\text { Parceled } \\
\text { Model }\end{array}$ & $\operatorname{tor} \chi^{2}$ & $\mathrm{P}$ \\
\hline$\%$ Proper Converging & $100 \%$ & $100 \%$ & 0.00 & NS \\
\hline Mean GFI & .800 & .873 & 28.79 & $<.001$ \\
\hline Mean CFI & .934 & .969 & 9.82 & $<.001$ \\
\hline Mean NNFI & .931 & .965 & 9.29 & $<.001$ \\
\hline Mean RMSEA & .031 & .040 & 9.68 & $<.001$ \\
\hline$\% \mathrm{GFI}>.90$ & $25,0 \%$ & $49.3 \%$ & 50.39 & $<.001$ \\
\hline$\%$ CFI $>.90$ & $75.0 \%$ & $99.3 \%$ & 104.85 & $<.001$ \\
\hline$\%$ NNFI $>.90$ & $75.0 \%$ & $98.5 \%$ & 96.09 & $<.001$ \\
\hline$\%$ RMSEA $<.05$ & $75.0 \%$ & $78.5 \%$ & 1.37 & NS \\
\hline Mean Saturation & .699 & .767 & 222.42 & $<.001$ \\
\hline
\end{tabular}


compared to $90.8 \%$ of the item-level analyses. When $\mathrm{s}=.70,100 \%$ of both the item and parcel-level analyses produced proper converged solutions.

In $s=.40$ models, all fit indices were significantly better in parcel-level analyses compared to item-level analyses. In terms of the percent of solutions meeting standard fit criteria, parcel-level analyses had a significantly higher percentage for all fit indices. When $\mathrm{s}=.70$, mean GFI, CFI, and NNFI were significantly better in parcel-level models while mean

RMSEA was significantly better in item-level models. The percent of models meeting fit criteria was significantly greater in parcel-level models for GFI, CFI, and NNFI but was not significantly different for RMSEA.

Mean indicator saturation was greater in parcel-level analyses, .485 vs. .399 , when $\mathrm{s}=.40$. When $\mathrm{s}=.70$, mean indicator saturation was also significantly higher in the parcel-level analyses, .767 vs. .699 .

\section{Model \#8}

Model \#8 Description. The eighth model structure of Study 4 had two factors indicated by six items each in the true model. The parceled model also had two factors, but one parcel indicator of each was non-unidimensional. The non-unidimensional parcel was formed by combining items from the first and second factors of the true model. Two of the parcel indicators for each factor were unidimensional. This model is presented in Figure 14.

Model \#8 Results. The mean indicator saturation, percent of proper converging models, and mean fit indices for Model $\# 8$ can be found in Table 20. When $\mathrm{s}=.40$, item-level analyses produced proper converged solutions in $97.3 \%$ of simulations 
Figure 14. Visual representation of the true and mis-specified model \#8 of study \#4.

\section{Contectly Specified Item Model}

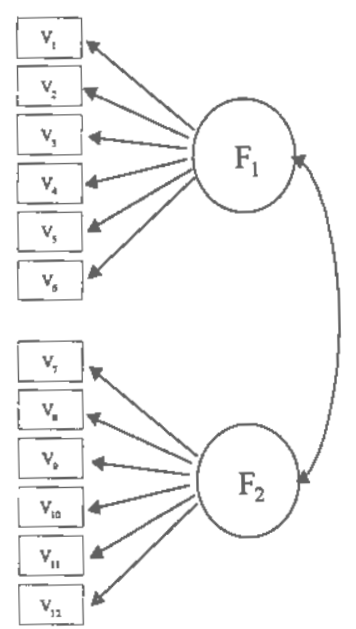

\section{Mis-Specified Parceled Model}

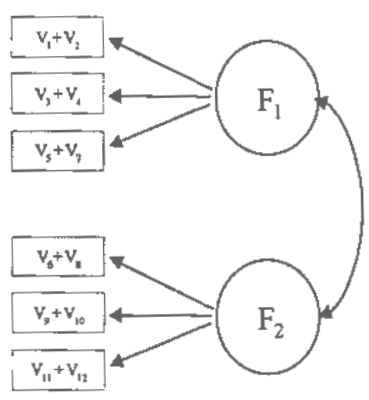

Note: Shaded boxes represent non-unidimensional parcels. 
Table 20. Model \#8 Comparisons - Study 4

\begin{tabular}{lcccc} 
& \multicolumn{4}{c}{ Saturation $=.40$} \\
\cline { 2 - 5 } Comparison & $\begin{array}{c}\text { Item } \\
\text { Model }\end{array}$ & $\begin{array}{c}\text { Parceled } \\
\text { Model }\end{array}$ & t or $\chi^{2}$ & $\mathrm{p}$ \\
\hline \% Proper Converging & $97.3 \%$ & $87.0 \%$ & 28.96 & $<.001$ \\
& & & & \\
Mean GFI & .950 & .972 & 14.57 & $<.001$ \\
Mean CFI & .953 & .898 & 9.89 & $<.001$ \\
Mean NNFI & 1.003 & .832 & 11.56 & $<.001$ \\
Mean RMSEA & .017 & .062 & 22.40 & $<.001$ \\
& & & & \\
\% GFI $>.90$ & $84.8 \%$ & $99.8 \%$ & 62.94 & $<.001$ \\
\% CFI $>.90$ & $80.5 \%$ & $55.5 \%$ & 57.44 & $<.001$ \\
$\%$ NNFI $>.90$ & $78.5 \%$ & $30.5 \%$ & 185.83 & $<.001$ \\
\% RMSEA $<.05$ & $91.8 \%$ & $30.3 \%$ & 317.97 & $<.001$ \\
& & & & \\
Mean Saturation & .398 & .466 & 37.89 & $<.001$ \\
\hline
\end{tabular}

\begin{tabular}{lcccc} 
& \multicolumn{4}{c}{ Saturation $=.70$} \\
\cline { 2 - 5 } Comparison & $\begin{array}{c}\text { Item } \\
\text { Model }\end{array}$ & $\begin{array}{c}\text { Parceled } \\
\text { Model }\end{array}$ & t or $\chi^{2}$ & $\mathrm{p}$ \\
\hline \% Proper Converging & $100 \%$ & $98.8 \%$ & 5.03 & NS \\
Mean GFI & .948 & .849 & 43.05 & $<.001$ \\
Mean CFI & .991 & .818 & 69.15 & $<.001$ \\
Mean NNFI & .994 & .659 & 73.09 & $<.001$ \\
Mean RMSEA & .018 & .233 & 109.63 & $<.001$ \\
& & & & \\
\% GFI > 90 & $82.8 \%$ & $4.3 \%$ & 501.45 & $<.001$ \\
\% CFI $>.90$ & $99.8 \%$ & $4.5 \%$ & 727.12 & $<.001$ \\
\% NNFI $>.90$ & $99.3 \%$ & $1.5 \%$ & 764.45 & $<.001$ \\
\% RMSEA $<.05$ & $90.8 \%$ & $0.0 \%$ & 664.53 & $<.001$ \\
& & & & \\
Mean Saturation & .696 & .734 & 35.42 & $<.001$ \\
\hline
\end{tabular}


compared to $87.0 \%$ of the parcel-level analyses, $\chi^{2}(1)=28.96, p<.001$. When $s=.70$, $100 \%$ of item-level and $98.8 \%$ of parcel-level analyses produced proper converged solutions, a non-significant difference.

In $\mathrm{s}=.40$ models, mean GFI was approximately the same for both types of analysis. Mean CFI, NNFI, and RMSEA were much better in item-level analyses. In terms of the percent of solutions meeting standard fit criteria, parcel-level analyses had a significantlyhigher percentage for only GFI, $99.8 \%$ vs. $84.8 \%$. The percent meeting standard criteria for CFI, NNFI, and RMSEA was significantly better in item-level than parcel-level analyses. When $\mathrm{s}=.70$, the mean of all fit indices was greatly improved in the item-level analyses compared to the parcel-level analyses. The percent of models meeting fit criteria was significantly greater in item-level models for all fit indices.

Mean indicator saturation was greater in parcel-level analyses, .466 vs. .398 , when $s=.40$. When $s=.70$, mean indicator saturation was also significantly higher in the parcel-level analyses, .734 vs. .696.

\section{Model \#9}

Model \#9 Description. The structure of the ninth model was similar to the eighth, but with additional items. In the true model, two factors were indicated by 12 items each. In the parceled model, each of the two factors again had one nonunidimensional parcel plus five unidimensional parcels. The non-unidimensional parcels were formed from one item from each the two factors of the true model. This model is presented in Figure 15. 
Figure 15. Visual representation of the true and mis-specified model \#9 of study \#4.

Correctly Spacified Itenn Model

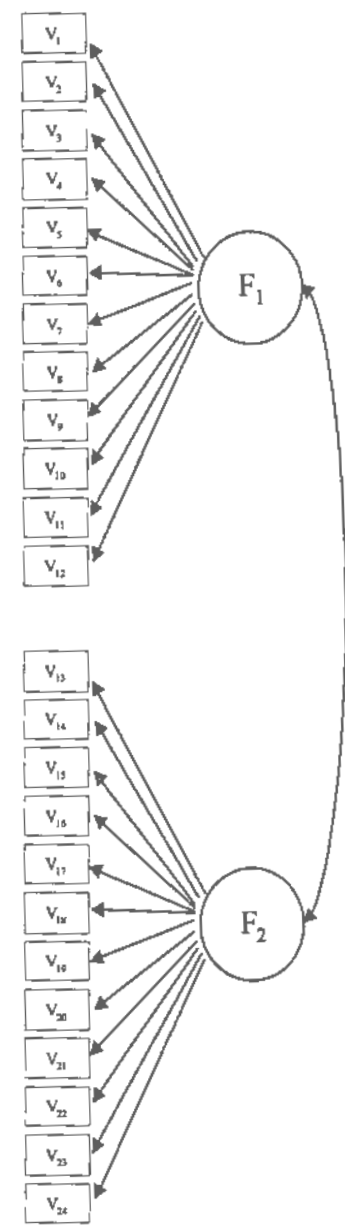

Mis-Specified Parceled Model

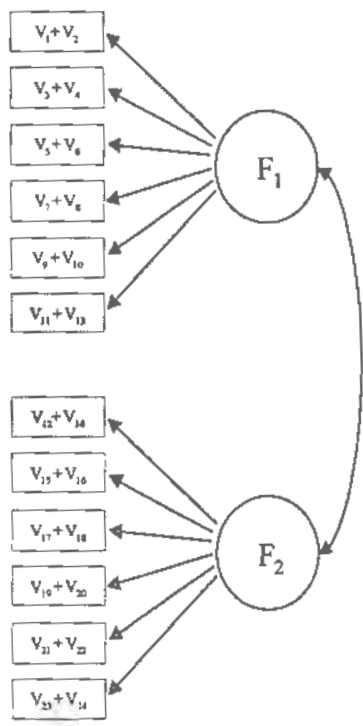

Note: Shaded boxes represent non-unidimensional parcels. 
Table 21. Model \#9 Comparisons - Study 4

\begin{tabular}{|c|c|c|c|c|}
\hline \multirow[b]{2}{*}{ Comparison } & \multicolumn{4}{|c|}{ Saturation $=.40$} \\
\hline & $\begin{array}{c}\text { Item } \\
\text { Model }\end{array}$ & $\begin{array}{c}\text { Parceled } \\
\text { Model }\end{array}$ & t or $\chi^{2}$ & $\mathrm{p}$ \\
\hline$\%$ Proper Converging & $100 \%$ & $100 \%$ & 0.00 & NS \\
\hline Mean GFI & .888 & .934 & 22.92 & $<.001$ \\
\hline Mean CFI & .918 & .920 & 0.35 & NS \\
\hline Mean NNFI & .919 & .903 & 2.69 & NS \\
\hline Mean RMSEA & .021 & .045 & 21.59 & $<.001$ \\
\hline$\%$ GFI $>.90$ & $50.0 \%$ & $78.3 \%$ & 69.38 & $<.001$ \\
\hline$\% \mathrm{CFI}>.90$ & $71.3 \%$ & $73.5 \%$ & 0.51 & NS \\
\hline$\%$ NNFI > .90 & $70.0 \%$ & $60.5 \%$ & 7.96 & $<.01$ \\
\hline$\%$ RMSEA $<.05$ & $89.8 \%$ & $67.8 \%$ & 57.85 & $<.001$ \\
\hline Mean Saturation & .400 & .499 & 172.77 & $<.001$ \\
\hline & \multicolumn{4}{|c|}{ Saturation $=.70$} \\
\hline Comparison & $\begin{array}{c}\text { Item } \\
\text { Model }\end{array}$ & $\begin{array}{c}\begin{array}{c}\text { Parceled } \\
\text { Model }\end{array} \\
\end{array}$ & $\operatorname{tor} \chi^{2}$ & $\mathrm{p}$ \\
\hline$\%$ Proper Converging & $100 \%$ & $100 \%$ & 0.00 & NS \\
\hline Mean GFI & .888 & .873 & 6.80 & $<.001$ \\
\hline Mean CFI & .983 & .915 & 53.77 & $<.001$ \\
\hline Mean NNFI & .982 & .894 & 60.14 & $<.001$ \\
\hline Mean RMSEA & .022 & .110 & 89.40 & $<.001$ \\
\hline$\%$ GFI $>90$ & $50.0 \%$ & $22.5 \%$ & 65.45 & $<.001$ \\
\hline$\% \mathrm{CFI}>.90$ & $99.0 \%$ & $84.3 \%$ & 56.70 & $<.001$ \\
\hline$\%$ NNFI $>.90$ & $97.3 \%$ & $39.8 \%$ & 306.45 & $<.001$ \\
\hline$\%$ RMSEA $<.05$ & $89.3 \%$ & $0.0 \%$ & 644.70 & $<.001$ \\
\hline Mean Saturation & .699 & .777 & 195.95 & $<.001$ \\
\hline
\end{tabular}


Model \#9 Results. The mean indicator saturation, percent of proper converging models, and mean fit indices for Model $\# 9$ can be found in Table 21. All item and parcel-level analyses converged to proper solutions when $\mathrm{s}=.40$ and $\mathrm{s}=.70$.

In $\mathrm{s}=.40$ models, mean GFI was significantly better in parcel-level analyses (.934) compared to item-level analyses (.888). Mean RMSEA were significantly better in item-level analyses. The mean CFI and NNFI was not significantly different. A similar pattern was present in terms of the percent of solutions meeting standard fit criteria. Parcel-level analyses had a significantly higher percentage for only GFI, $78.3 \%$ vs. $50.0 \%$. The percent meeting standard criteria for NNFI and RMSEA was significantly better in item-level analyses. When $s=.70$, the mean of all fit indices were significantly better in item-level analyses. The percent of models meeting fit criteria was also significantly greater in item-level models for all fit indices.

Mean indicator saturation was greater in parcel-level analyses, .499 vs. .400, when $\mathrm{s}=.40$. When $\mathrm{s}=.70$, mean indicator saturation was also significantly higher in the parcel-level analyses, .777 vs. .699 .

\section{Model \#10}

Model \#10 Description. In the tenth model structure of Study 4 , the true specified models had fewer factors than the parceled models. There were two factors indicated by six items each in the true model. The first four items of the first factor were combined to form two parcels, which were indicators of the first factor in the parceled model. The remaining two items of the first factor were combined with two items of the second factor to form two non-unidimensional parcels, which were indicators of the second factor in the parceled model. The remaining four items from 
the second factor formed two parcels which will be the indicators for the third factor of the parcel model. This model is presented in Figure 16.

Model \#10 Results. The mean indicator saturation, percent of proper converging models, and mean fit indices for Model \#10 can be found in Table 22. When $\mathrm{s}=.40$, item-level analyses produced proper converged solutions in $97.5 \%$ of simulations compared to $68.5 \%$ of the item-level analyses. When $\mathrm{s}=.70,100 \%$ of item-level solutions and $99.25 \%$ of parcel-level solutions were proper converging.

In $s=.40$ models, the mean of each fit index was excellent, leaving little room for improvement in the parcel-level solutions. The parcel-level solutions did have slightly better fit indices. In parcel-level analyses the percent of solutions meeting standard fit criteria was higher for GFI, CFI, and NNFI, while the percent meeting criteria for RMSEA was higher in item-level solutions. When $\mathrm{s}=.70$, the mean fit indices were again extremely high in both item- and parcel-level solutions. Overall, the parcel-level solutions had slightly better fit indices. The percent meeting criteria for GFI improved from $85.5 \%$ in item-level solutions and $100 \%$ in parcel-level solutions. For RMSEA, item-level solutions had a higher percent meeting criteria, $91.8 \%$ to $85.0 \%$. The percent meeting criteria for CFI and NNFI was near $100 \%$ for both types of analysis.

Mean indicator saturation was greater in parcel-level solutions, .514 vs. .402, when $s=.40$. When $s=.70$, mean indicator saturation again improved from .698 in item-level solutions to .788 in parcel-level solutions. 
Figure 16. Visual representation of the true and mis-specified model \#10 of study \#4.

\section{Correctly Specified Itom Model}

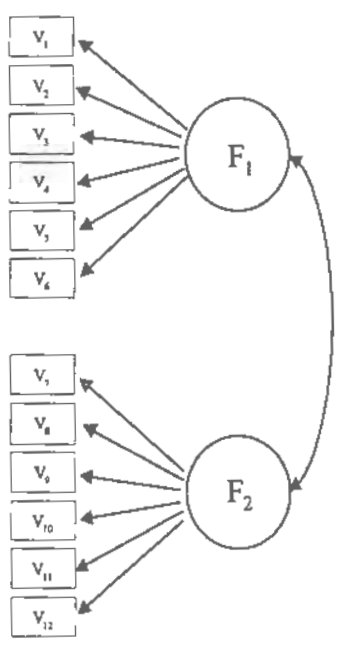

\section{Mis-Specified Parceled Madel}

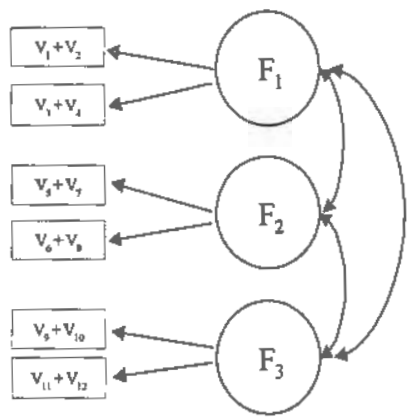

Note: Shaded boxes represent non-unidimensional parcels. 
Table 22. Model \#10 Comparisons - Study 4

\begin{tabular}{lcccc} 
& \multicolumn{4}{c}{ Saturation $=.40$} \\
\cline { 2 - 5 } Comparison & $\begin{array}{c}\text { Item } \\
\text { Model }\end{array}$ & $\begin{array}{c}\text { Parceled } \\
\text { Model }\end{array}$ & t or $\chi^{2}$ & $\mathrm{p}$ \\
\hline \% Proper Converging & $97.5 \%$ & $68.5 \%$ & 119.21 & $<.001$ \\
& & & & \\
Mean GFI & .950 & .988 & 26.61 & $<.001$ \\
Mean CFI & .955 & .981 & 6.69 & $<.001$ \\
Mean NNFI & 1.002 & 1.008 & 0.43 & $\mathrm{NS}$ \\
Mean RMSEA & .017 & .020 & 2.23 & $\mathrm{NS}$ \\
& & & & \\
$\%$ GFI $>.90$ & $84.8 \%$ & $100 \%$ & 66.04 & $<.001$ \\
$\%$ CFI $>.90$ & $82.8 \%$ & $94.8 \%$ & 28.85 & $<.001$ \\
$\%$ NNFI $>.90$ & $79.0 \%$ & $84.0 \%$ & 3.32 & NS \\
$\%$ RMSEA $<.05$ & $92.0 \%$ & $82.3 \%$ & 16.95 & $<.001$ \\
& & & & \\
Mean Saturation & .402 & .514 & 139.59 & $<.001$ \\
\hline
\end{tabular}

\begin{tabular}{lcccc} 
& \multicolumn{4}{c}{ Saturation =.70 } \\
\cline { 2 - 5 } Comparison & $\begin{array}{c}\text { Item } \\
\text { Model }\end{array}$ & $\begin{array}{c}\text { Parceled } \\
\text { Model }\end{array}$ & t or $\chi^{2}$ & $\mathrm{p}$ \\
\hline \% Proper Converging & $100 \%$ & $99.3 \%$ & 3.01 & NS \\
& & & & \\
Mean GFI & .949 & .988 & 26.86 & $<.001$ \\
Mean CFI & .992 & .997 & 5.94 & $<.001$ \\
Mean NNFI & .996 & 1.000 & 2.51 & NS \\
Mean RMSEA & .016 & .020 & 2.81 & NS \\
& & & & \\
$\%$ GFI $>.90$ & $85.5 \%$ & $100 \%$ & 62.53 & $<.001$ \\
$\%$ CFI $>.90$ & $99.5 \%$ & $100 \%$ & 2.01 & NS \\
$\%$ NNFI $>.90$ & $98.8 \%$ & $99.3 \%$ & 0.51 & NS \\
$\%$ RMSEA $<.05$ & $91.8 \%$ & $85.0 \%$ & 8.87 & NS \\
& & & & \\
Mean Saturation & .698 & .788 & 138.36 & $<.001$ \\
\hline
\end{tabular}




\section{Model \#11}

Model \#11 Description. The eleventh and final model structure of Study 4 had the same structure as the tenth model, except that the number of items in the true model was doubled. Consequently, the number of parcel indicators in the parcel model was doubled. The second factor of the parcel model was again indicated by nonunidimensional parcels only. This model is presented in Figure 17.

Model \#11 Results. The mean indicator saturation, percent of proper converging models, and mean fit indices for Model \#11 can be found in Table 23. When $\mathrm{s}=.40$, item-level analyses produced proper converged solutions in $100 \%$ of simulations compared to $90.3 \%$ of the item-level analyses, $\chi^{2}(1)=41.00, p<.001$. When $\mathrm{s}=.70$, all analyses produced proper converging solutions.

In both $\mathrm{s}=.40$ and $\mathrm{s}=.70$ models, the mean of each fit index was improved in the parcel-level analyses. The percent of models meeting standard criteria was also greater in the parcel-level analyses for each index.

Mean indicator saturation was greater in parcel-level analyses, .500 vs. .400, when $\mathrm{s}=.40$. When $\mathrm{s}=.70$, mean indicator saturation was also significantly higher in the parcel-level analyses, .788 vs. .698.

\section{OVERALL RESULTS}

Within Study 4, there were three basic types of misspecified models: A) the parcel-level model had fewer factors than the true item-level model, B) the parcel-level 
Figure 17. Visual representation of the true and mis-specified model \#11 of study \#4

Correctly Specified Item Model

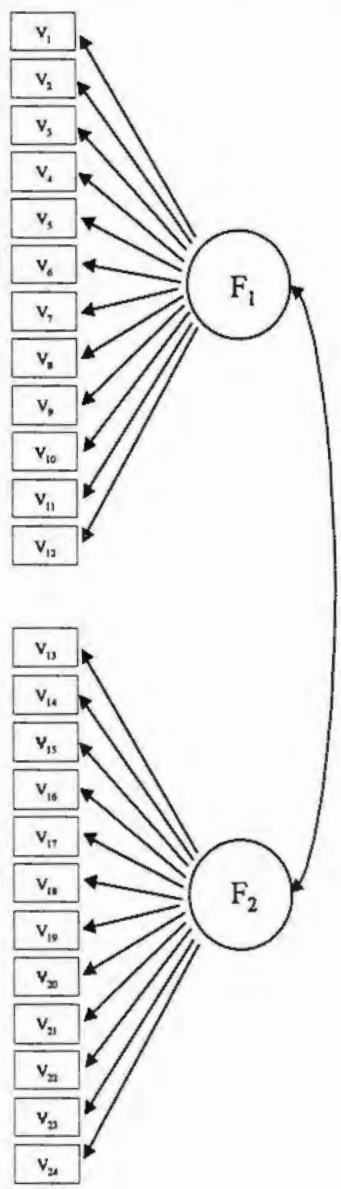

Mis-Specified Parceled Model

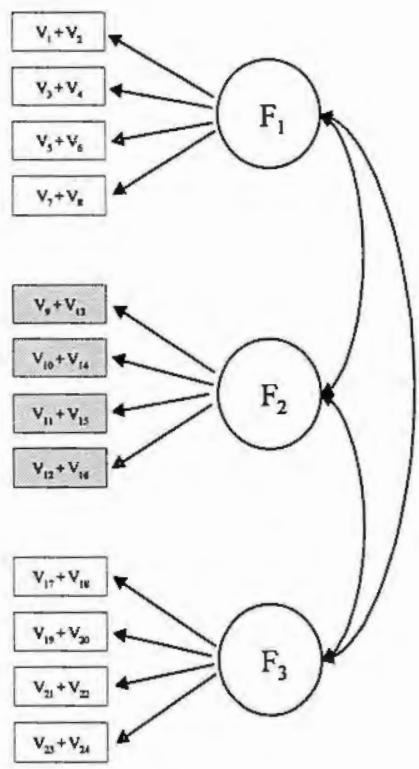

Note: Shaded boxes represent non-unidimensional parcels. 
Table 23. Model \#11 Comparisons - Study 4

\begin{tabular}{lcccc} 
& \multicolumn{4}{c}{ Saturation $=.40$} \\
\cline { 2 - 5 } Comparison & $\begin{array}{c}\text { Item } \\
\text { Model }\end{array}$ & $\begin{array}{c}\text { Parceled } \\
\text { Model }\end{array}$ & t or $\chi^{2}$ & $\mathrm{p}$ \\
\hline \% Proper Converging & $100 \%$ & $90.3 \%$ & 41.00 & $<.001$ \\
Mean GFI & .890 & .950 & 31.69 & $<.001$ \\
Mean CFI & .926 & .975 & 11.52 & $<.001$ \\
Mean NNFI & .928 & .989 & 9.32 & $<.001$ \\
Mean RMSEA & .020 & .018 & 1.65 & NS \\
\% GFI > .90 & $50.3 \%$ & $88.5 \%$ & 137.73 & $<.001$ \\
\% CFI $>.90$ & $72.5 \%$ & $92.3 \%$ & 53.73 & $<.001$ \\
\% NNFI > .90 & $71.0 \%$ & $90.5 \%$ & 48.92 & $<.001$ \\
\% RMSEA $<.05$ & $90.5 \%$ & $89.8 \%$ & 0.13 & NS \\
Mean Saturation & .400 & .500 & 139.59 & $<.001$ \\
\hline
\end{tabular}

\begin{tabular}{lcccc} 
& \multicolumn{4}{c}{ Saturation $=.70$} \\
\cline { 2 - 5 } Comparison & $\begin{array}{c}\text { Item } \\
\text { Model }\end{array}$ & $\begin{array}{c}\text { Parceled } \\
\text { Model }\end{array}$ & t or $\chi^{2}$ & $\mathrm{p}$ \\
\hline \% Proper Converging & $100 \%$ & $100 \%$ & 0.00 & $\mathrm{NS}$ \\
Mean GFI & .889 & .950 & 31.43 & $<.001$ \\
Mean CFI & .984 & .995 & 11.45 & $<.001$ \\
Mean NNFI & .984 & .997 & 10.55 & $<.001$ \\
Mean RMSEA & .021 & .017 & 3.34 & $<.01$ \\
& & & & \\
\% GFI > .90 & $50.0 \%$ & $86.0 \%$ & 119.12 & $<.001$ \\
$\%$ CFI $>.90$ & $99.0 \%$ & $100 \%$ & 4.02 & NS \\
\% NNFI $>.90$ & $99.0 \%$ & $100 \%$ & 4.02 & NS \\
\% RMSEA $<.05$ & $89.0 \%$ & $90.5 \%$ & 0.49 & NS \\
& & & & \\
Mean Saturation & .698 & .788 & 275.53 & $<.001$ \\
\hline
\end{tabular}


model had the same number of factors as the item-level model, and C) the parcel-level model had more factors specified than the item-level models. The first model type was represented by Model \#1-7, the second model type by Model \#8-9, and the third model type by Model $\# 10-11$. The differences between the correctly specified item-level solutions and the misspecified parcel-level solutions may be different across the three types of models. The results for each model are summarized in Table 24. The percent of proper solutions, mean fit indices, and mean loadings by each model type are explored below:

Model Type A. The percent of proper converging solutions was notably greater for the parcel-level models in three of the seven model structures. In the other four models, the percent of proper converging solutions was approximately the same. Of the three models that were different, two of them were within the small 8-item, 3-factor item-level models. However, the third model that differed was the large 48-item, 6factor model.

The four fit indices examined were differentially affected within model type A. GFI seemed to benefit most from parceling, as three of the seven models had a notable improvement in mean GFI in the parcel-level solutions and only one of the models had a notable improvement in the item-level solutions. The other three fit indices generally did not improve in the parceled models. CFI and NNFI were notably better in three item-level models and RMSEA was notably better in five item-level models. Overall, it was clear that RMSEA suffered most from the misspecified parcel models. Parceling 
Table 24. Summary of Study 4 Results

\begin{tabular}{cccccccccc}
$\begin{array}{c}\text { Model } \\
\#\end{array}$ & $\begin{array}{c}\text { Item } \\
\text { Model } \\
\mathrm{p} / \mathrm{f}\end{array}$ & $\begin{array}{c}\text { Parcel } \\
\text { Model } \\
\mathrm{p} / \mathrm{f}\end{array}$ & $\begin{array}{c}\text { Non- } \\
\text { Unidim- } \\
\text { ensional } \\
\text { Parcels }\end{array}$ & $\begin{array}{c}\text { Greater } \\
\text { \% Proper } \\
\text { Converging } \\
\text { Solutions }\end{array}$ & $\begin{array}{c}\text { Greater } \\
\text { Mean } \\
\text { GFI }\end{array}$ & $\begin{array}{c}\text { Greater } \\
\text { Mean } \\
\text { CFI }\end{array}$ & $\begin{array}{c}\text { Greater } \\
\text { Mean } \\
\text { NNFI }\end{array}$ & $\begin{array}{c}\text { Lesser } \\
\text { Mean } \\
\text { RMSEA }\end{array}$ & $\begin{array}{c}\text { Greater } \\
\text { Mean } \\
\text { Loadings }\end{array}$ \\
\hline 1 & $8 / 3$ & $4 / 1$ & 4 & $\mathrm{P}$ & - & $\mathrm{I}$ & $\mathrm{I}$ & $\mathrm{I}$ & - \\
2 & $15 / 3$ & $5 / 1$ & 2 & - & $\mathrm{I}$ & $\mathrm{I}$ & $\mathrm{I}$ & $\mathrm{I}$ & $\mathrm{I}$ \\
3 & $15 / 3$ & $5 / 1$ & 4 & - & - & $\mathrm{I}$ & $\mathrm{I}$ & $\mathrm{I}$ & - \\
4 & $15 / 3$ & $5 / 1$ & 5 & - & $\mathrm{P}$ & $\mathrm{P}$ & - & - & $\mathrm{P}$ \\
5 & $8 / 3$ & $4 / 2$ & 0 & $\mathrm{P}$ & - & - & - & $\mathrm{I}$ & $\mathrm{P}$ \\
6 & $48 / 6$ & $24 / 4$ & 0 & - & $\mathrm{P}$ & - & - & $\mathrm{I}$ & $\mathrm{P}$ \\
7 & $48 / 6$ & $24 / 4$ & 8 & $\mathrm{P}$ & $\mathrm{P}$ & $\mathrm{P}$ & $\mathrm{P}$ & - & $\mathrm{P}$ \\
8 & $12 / 2$ & $6 / 2$ & 2 & $\mathrm{I}$ & $\mathrm{I}$ & $\mathrm{I}$ & $\mathrm{I}$ & $\mathrm{I}$ & $\mathrm{P}$ \\
9 & $24 / 2$ & $12 / 2$ & 2 & - & $\mathrm{P}$ & $\mathrm{I}$ & $\mathrm{I}$ & $\mathrm{I}$ & $\mathrm{P}$ \\
10 & $12 / 2$ & $6 / 3$ & 2 & $\mathrm{I}$ & $\mathrm{P}$ & - & - & - & $\mathrm{P}$ \\
11 & $24 / 2$ & $12 / 3$ & 4 & $\mathrm{I}$ & $\mathrm{P}$ & $\mathrm{P}$ & $\mathrm{P}$ & - & $\mathrm{P}$ \\
\hline
\end{tabular}

I: Overall, the item-level solutions were better for this measure compared to the parcel-level analyses.

P: Overall, the parcel-level solutions were better for this measure compared to the item-level analyses.

(-): Overall, the item- and parcel-level solutions did not differ

Models 1-7: Fewer Factors in the parcel-level models

Models 8-9: Correct \# Factors in the parcel-level models

Models 10-11: More Factors in the parcel-level models 
reduced CFI and NNFI in some models, but raised them in others. Parceling generally improved GFI in these misspecified models.

Despite the misspecification, the mean loadings were notably higher in four parcel-level models and lower in only one. Generally, as was found in Study 2, parceling resulted in a systematic increase in the loadings, even in these misspecified models.

Model Type B. Of the two models in model type B, one had a higher rate of proper convergence in the item-level solutions, while the other did not differ. The difference in percent of proper solutions may have been due to the small $\mathrm{p} / \mathrm{f}$ ratio of the parcel-level Model $\# 8(\mathrm{p} / \mathrm{f}=6 / 2)$. With only two model structures tested and a difference in only one, it is difficult to generalize what would happen across other structures.

Generally, the fit indices were better in the item-level solutions than the parcellevel solutions. There was one exception, in which the mean GFI of the parcel-level solutions was higher in Model \#9. As with model type A, CFI, NNFI, and RMSEA were lowered in the misspecified parcel models while the results of GFI was mixed.

In both models, the mean loadings were higher in the parcel-level models. This was also consistent with model type A.

Model Type C. The percent of proper converging solutions was notably higher in the item-level solutions for both models (Model \#10-11). This may have again been due to the smaller $p / f$ ratios of the parcel-level analyses $(p / f=6 / 3,12 / 3)$. 
The means of the four fit indices were once again affected differentially. GFI improved in both models within the parcel-level solutions. CFI and NNFI improved in the parcel-level solutions only for Model \#11. RMSEA did not notably differ in either model.

The mean loadings were once again higher in the parcel-level solutions for both models.

Model Types A-C. Examining all eleven models of Study 4 is also worthwhile to see if there were consistent patterns. The percent of proper solutions was differentially affected by model structure. Mean GFI generally improved in the parcellevel solutions. Mean CFI and NNFI were generally better in the item-level solutions, but the results were not entirely consistent across all model structures. Mean RMSEA was better in the item-level solutions in seven of the eleven model structures. Loadings were greater with the parcel-level solutions across eight of the model structures.

\section{DISCUSSION}

Study 4 showed that with some model structures, mis-specified parcel-level models could fit just as well as or better than correctly specified item-level models. This may have been due to covering up correlated errors, the reduction of $\mathrm{p} / \mathrm{f}$ and/or the increase in indicator saturations. No matter the reason for this finding, the implication is that parceling can be dangerous. If the decision to form parcels is made, efforts should be made to verify the unidimensionality of the items. If this is not done and there are non-unidimensional parcels, the fit indices may not suffer, or they may not 
suffer enough to be noticable. Unfortunately as a result, the researcher's understanding of the phenomenon could be misguided. Again, this may be a bias of the fit indices. Consistent with Studies 2-3, RMSEA was the exception. RMSEA did not display the bias toward smaller numbers of indicators and therefore stayed approximately the same or increased (got worse) in the parcel-level solutions.

The percent of proper converging solutions was higher in the parcel-level analyses for some model structures, but higher for the item-level analyses for other model structures. In those models in which the item-level models had higher proper convergence rates, the $\mathrm{p} / \mathrm{f}$ ratio of the parcel-level models was two, three, and four. Consistent with Studies 2-3 and with previous research, this may simply be a demonstration of having too few indicators per factor. It is more difficult to explain the model structures that had higher rates of proper convergence in the parcel-level analyses. This may have been due to hidden correlated error terms or hidden items that had poor loadings in the item-level models. In each of these structures, the number of non-unidimensional parcels was four, four, and eight. This suggests that the number of non-umidimensional parcels may not generally hurt the chances of proper convergence.

It is interesting that the mean loadings were greater in the parcel-level solutions even with the presence of non-unidimensional items. This further illustrates how parceling non-unidimensional items can still lead to acceptable model characteristics and false conclusions about the data structures. 


\section{CHAPTER 6}

\section{CONCLUSIONS AND RECOMMENDATIONS FOR USING PARCELS}

With the results of a small literature review and three simulation studies on item parceling, it is appropriate to examine the original question of this investigation: to parcel or not to parcel?

Study 1 showed that parcels are utilized extensively in highly respected applied journals. In two of the three journals reviewed, confirmatory models that included parcels were more common than models that included only items. Clearly the "parcel or not to parcel" question is an important one that deserves attention in the form of simulation or mathematical studies.

Study 2 used data simulation to show the effects of parceling pairs of items. In general, parcel-level solutions had better fit indices and loadings. However, the percent of models converging to proper solutions was lower in the parcel-level analyses when the number of indicators per factor was reduced to two as a result of parceling. In this respect, using parcels did not benefit large models with 64 items (32 parcels), as all models converged to proper solutions. Although Study 2 did not examine the stability of parameter estimates, increasing model fit seemed to be an advantage of using parcels, as long as the number of indicators per factor was greater than two.

Study 3 extended the findings of Study 2 to models with four- and eight-item parcels. Loadings and fit indices improved further as the number of items per parcel increased. In fact, with the eight-item parcel models, loadings and fit indices approached asymptotic behavior. Consistent with Study 2, when the number of 
indicators per factor was reduced to only two (in the eight-item parcels), reaching proper convergence was problematic. Again the improvement in fit was an advantage of the parceled models while there seemed to be no disadvantages as long as the number of indicators per factor was greater than two.

Study 4 examined eleven mis-specified parcel models, most of which included non-unidimensional parcels. In most of these models, the fit of the mis-specified parcel model was just as good if not better than the correctly specified item-level model. Even with a large percentage of the parcels being non-unidimensional, the mean loadings generally increased when parcels were used. This demonstrated an extremely dangerous aspect of parceling. Mis-specified models should not fit as well as correctly specified models. Studies 2-3 showed that as $\mathrm{p} / \mathrm{f}$ decreased, model fit increased. This function was in conflict with the mis-specification, and resulted in the mis-specified parcel models still reaching the level of fit obtained in the item-level analyses.

The implications of this finding are extremely important. Very large item parcels have been used for years in the development of personality inventories such as the MMPI. This was done primarily to reduce the number of model indicators so that statistical analysis was possible. With advances in computer technology, this is no longer a barrier. Based on the results of Study 4, it is not unreasonable to think that many scales that have been developed through the analysis of parcels were incorrectly identified. In such cases, results may suggest that data and theory converge, but the fact that individual items were not modeled needs to be considered. 
Modeling parcels instead of individual items may introduce several problems that were discussed in Chapter 1. Parcels may cover up correlated error terms. Correlated errors usually suggest additional factors and/or a mis-specified model. Using parcels also sacrifices statistical power. Reducing the power to reject a model may lead to incorrect decisions regarding individual scales or entire theories.

Correct model identification is usually the primary goal of confirmatory factor analysis. Unfortunately this does not appear to be a strength of parceling. Instead, parcel-level analyses may identify incorrect models as correct.

To many researchers, parceling may be appealing because of the improvement in loadings and model fit. But if parceling increases the chance of incorrect model identification, it should not be utilized. Based on the results of this investigation, parceling cannot be recommended, but may still be useful in some cases. They may be useful with data that is dichotomous or is extremely non-normal. An examination of extreme levels of positive and negative kurtosis $(-1.139$ and +10.0$)$ in this investigation did not affect the solutions. Still, highly non-normal data will increase the chi-square statistic. As discussed previously, parcels in confirmatory analysis may be useful when model fitting is not the primary objective. Factorial invariance and growth curve modeling are two methods in which parcels may be useful.

It is recommended that if parcels are used, extensive preliminary work should be done to assure parcel unidimensionality. In conjuction with any parcel-level analysis, it is recommended that an item-level analysis also be conducted. The item- 
level analysis will provide a stronger test of theory and will result in a more realistic level of statistical power.

\section{Study Limitations}

As with any simulation study, there are limitations with the conditions that can be examined. In this study only two-, four- and eight-item parcels were tested. Researchers have used a much greater number of items to form parcels in published studies. It can be reasonably assumed that the differences between item-level and the eight-item parceled solutions can be extended to models with parcels of more than eight items, but this has not been demonstrated empirically.

Another condition of these studies which is unrealistic in applied settings is equal item saturations. Specifying variation in the saturations was possible, but would have complicated the decision of which items to add together to form the parcels. There are an unlimited number of combinations of item saturations that could be tested, and choosing a few of these might make the results only slightly more generalizable. Under the small sample size conditions of $\mathrm{N}=75$ and $\mathrm{N}=150$, the items had a good deal of variation in their saturations. Similarly, specifying item saturations to equal zero for non-specified factors is also unrealistic, but the actual simulated saturations were not exactly zero, especially in the small sample size conditions.

\section{Future Directions}

There are other conditions, not examined in this study, that might show important differences between the item- and parcel-level solutions. For example, using parceled models under conditions of high multicollinearity and singularity may be of 
benefit. Another situation that warrants investigation is when items have significant correlated errors. Extreme values of skewness could also be examined, as only kurtosis was varied in this investigation.

Although the conditions examined in this study were not comprehensive, it provided a large amount of information about the effects of item parceling and it can provide a basis for further research about when parceling may or may not be appropriate. 


\section{BIBLIOGRAPHY}

Akaike, H. (1987). Factor analysis and AIC. Psychometica, 52, 317-332.

Anderson, J. C. \& Gerbing, D. W. (1984). The effect of sampling error on convergence, improper solutions, and goodness-of-fit indices for maximum likelihood confirmatory factor analysis. Psychometrica, 49, 155-173.

Beardon, W. O., Sharma, S., \& Teel, J. E. (1982). Sample size effects on chi-square and other statistics used in evaluating causal models. Journal of Marketing Research, 19, 425-430.

Bentler, P. M. (1995). EQS Structural Equations Program Manual. Encino, CA: Multivariate Software, Inc.

Bollen, K. A. (1989). Structural equations with latent variables. New York: John Wiley \& Sons.

Boomsma, A. (1982). Robustness of LISREL against small sample sizes in factor analysis models. In K.G. Jöreskog \& H. Wold (Eds.), Systems under indirect observation: Causality, structure, prediction (Part I) (pp. 149-173). Amsterdam: North Holland.

Boomsma, A. (1985). Nonconvergence, improper solutions, and starting values in LISREL maximum likelihood estimation. Psychometrica, 50, 229-242.

Browne, M. W. (1974). Generalized least squares estimators in the analysis of covariance structures. South African Statistical Journal, 8, 1-24.

Browne, M. W. (1984). Asymptotically distribution-free methods for the analysis of covariance structures. British Journal of Mathematics and Statistical Psychology, $37,62-83$.

Catell, R.B. (1956a). A shortened "basic English" version (Form C) of the 16 PF Questionnaire. Journal of Social Psychology, 44, 257-278.

Catell, R. B. (1956b). Validation and intensification of the Sixteen Personality Factor Questionnaire. Journal of Clinical Psychology, 12, 205-214.

Catell, R. B. (1966). The scree test for the number of factors. Multivariate Behavioral Research, 1, 245-276.

Comrey, A. L. (1973). A First Course In Factor Analysis. New York: Academic Press. 
Comrey, A.L. (1988). Factor-analytic methods of scale development in personality and clinical psychology. Journal of Consulting and Clinical Psychology, 56, 754761 .

Curran, P. J., West, S. G, \& Finch, J. F. (1994). The robustness of test statistics and goodness-of-fit indices in confirmatory factor analysis. Manuscript submitted for publication.

Dillon, W. R., Kumar, A., \& Mulani, N. (1987). Offending estimates in covariance structure analysis: Comments on the causes of and solutions to Heywood cases. Psychological Bulletin, 101, 126-135.

Ding, L., Velicer, W. F., and Harlow, L. L. (1995). The effects of estimation methods, number of indicators per factor and improper solutions on structural equation modeling fit indices. Structural Equation Modeling, 2, 119-144.

Finch, J. F., Curran, P. J., \& West, S. G. (1994). The effects of model and data characteristics on the accuracy of parameter estimates and standard errors in confirmatory factor analysis. Unpublished manuscript.

Fleishman, A. I. (1978). A method for simulating non-normal distributions. Psychometrika, 43, 521-532.

Gerbing, D. W., and Anderson, J. C. (1987). Improper solutions in the analysis of covariance structures: Their interpretability and a comparison of alternative specifications. Psychometrica, 52, 99-111.

Gerbing, D. W., and Anderson, J. C. (1988). An updated paradigm for scale development incorporating unidimensionality and its assessment. Journal of Marketing Research, 26, 186-192.

Gerbing, D. W., and Anderson, J. C. (1992). Monte Carlo evaluations of goodness of fit indices for structural equation models. Sociological Methods \& Research, 21, $132-160$.

Guadagnoli, E. and W. F. Velicer (1988). "Relation of sample size to the stability of component patterns." Psychological Bulletin, 103(2): 265-275.

Hu, L. and Bentler, P. M. (1995). Evaluating model fit. In Hoyle, R. H. (Ed.) Structural Equation Modeling: Concepts, Issues, and Applications (pp. 76-99). Sage Publications. 
Hu, L. and Bentler, P. M. (1998a). Cutoff criteria for fit indexes in covariance structure analysis: Conventional criteria versus new alternatives. Structural Equation Modeling, 6(1), 1-55.

Hu, L, and Bentler, P. M. (1998b). Fit indices in covariance structure modeling: Sensitivity to underparameterized model misspecification. Psychological Methods, 3 (4), 424-453.

James, L. R., Mulaik, S. A., \& Brett, J. M. (1982). Causal analysis: Assumptions, models, and data. Beverly Hills, CA: Sage.

Joreskog, K. G. (1969). A general approach to confirmatory maximum likelihood factor analysis. Psychometrika, 34, 183-202.

Jöreskog, K. G., \& Sörbom, D. (1981). LISREL V-Analysis of linear structural equation relationships by the method of maximum likelihood. Chicago: National Educational Resources.

Jöreskog, K. G., \& Sörbom, D. (1988). LISREL 7 - A guide to the program and applications $\left(2^{\text {nd }}\right.$ ed.). Chicago, Illinois: SPSS.

Kishton, J. M., Widaman, K. F. (1994). Unidimensional versus domain representative parceling of questionnaire items: An emprical example. Educational and Psychological Measurement, 54, 757-765.

Marsh, H. W. \& Bailey, M. (1991). Confirmatory factor analyses of multitraitmiltimethod data: Many problems and a few solutions. Applied Psychological Measurement, 13, 335-361.

Marsh, H. W., Balla, J. R., \& McDonald, R. P. (1988). Goodness-of-fit indexes in confirmatory factor analysis: The effect of sample size. Psychological Bulletin, $103,391-410$.

Marsh, H. W., Gouvernet, P. J. (1989). Multidimensional self-concepts and perceptions of control: Construct validation of responses by children. Journal of Educational Psychology, 81, 57-69.

Marsh, H. W., Hau, K. T., Balla, J. R., Grayson, D. (1998). Is more ever too much? The number of indicators per factor in confirmatory factor analysis. Multivariate Behavioral Research, 33, 181-220.

McDonald, R. P. (1981). The dimensionality of tests and items. British Journal of Mathematical and Statistical Psychology, 24, 100-117. 
Mulaik, S. A. (1990, June). An analysis of the conditions under which the estimation of parameters inflates goodness-of-fit indices as measures of model validity. Paper presented at the annual meeting of the Psychometric Society, Princeton, NJ.

Satorra, A. (1989). Alternative test criteria in covariance structure analysis: A unified approach. Psychometrica, 54, 131-151.

Satorra, A. \& Bentler, P. M. (1994). Corrections to test statistic and standard errors in covariance structure analysis. In A. Von Eye \& C.C. Clogg (Eds.) Analysis of latent variables in developmental research (pp. 399-419). Newbury Park, CA: Sage.

Steiger, J. H., \& Lind, J. C. (1980, May). Statistically-based tests for the number of common factors. Paper presented at the Annual Meeting of the Psychometric Society, Iowa City, IO.

Turner, N. E. (Aug., 1996). The effect of the number of items on goodness of fit indicators. Paper presented at the 1996 Annual Meeint of the American Psychological Association, Toronto.

Vale, C. D., \& Maurelli, V. A. (1983). Simulating multivariate nonnormal distributions. Psychometrika, 48, 465-471.

van Driel, O. P. (1978) On the various causes of improper solutions in maximum likelihood factor analys. Psychometrica, 43(2), 225-243.

Velicer, W. F., Huckel, L. H., Hansen, C. E. (1989). "A measurement model for measuring attitudes towards violence." Personality and Social Psychology Bulletin 15(3): 349-364.

Velicer, W. F. and Jackson, D. N. (1990). "Component analysis versus common factor analysis: Some issues in selecting an appropriate procedure." Multivariate Behavioral Research 25(1): 1-28.

Velicer, W. F. and Fava, J. L. (1987). "An evaluation of the effects of variable sampling on component, image, and factor analysis." Multivariate Behavioral Research 22: 193-209.

Velicer, W. F. and Fava, J. L. (1988). Effects of variable and subject sampling on factor pattern recover. Psychological Methods 3, 231-251.

Velicer, W. F., LaForge, R. G., Levesque, D. A., Fava, J. L. (1994). "The development and initial validation of the smoking policy inventory." Tobacco Control 3: 347355 . 
West, S. G., Finch, J. F., \& Curran, P. J. (1995). Structural equation models with nonnormal variables. In Hoyle, R.H. (ed.) Structural Equation Modeling: Concepts, Issues, and Applications (pp. 56-75). Thousand Oaks, CA: Sage.

Widaman, K. F., Gibbs, K. W., \& Geary, D. C. (1987). Structure of adaptive behavior: I. Replication across fourteen samples of nonprofoundly mentally retarded people. American Journal of Mental Deficiency, 91, 348-360.

Wothke, W. (1993). Nonpositive definite matrices in structural equation modeling. In K.A. Bollen \& J.S. Long (Eds.), Testing structural equation models (pp. 256293). Newbury Park, CA: Sage. 